University of Tennessee Health Science Center UTHSC Digital Commons

\title{
Studies of Entry, Reverse Transcription, and Regulation of Splicing in Retroviruses
}

Timothy A. Sullivan

University of Tennessee Health Science Center

Follow this and additional works at: https://dc.uthsc.edu/dissertations

Part of the Viruses Commons

\section{Recommended Citation}

Sullivan, Timothy A. , "Studies of Entry, Reverse Transcription, and Regulation of Splicing in Retroviruses" (2008). Theses and Dissertations (ETD). Paper 352. http://dx.doi.org/10.21007/etd.cghs.2008.0305. 


\title{
Studies of Entry, Reverse Transcription, and Regulation of Splicing in Retroviruses
}

\begin{abstract}
The study of retroviruses and their lifecycle has contributed immensely to our knowledge of the world of biology and medicine. The central dogma of the basic flow of genetic information was shattered when the discovery that retroviruses copy their RNA genome into DNA was made. The same enzyme that performs this step, reverse transcriptase (RT), also revolutionized molecular biology when it was used as a tool to generate full length cDNA clones of expressed genes. The impact of retroviruses on the medical field has been extremely exciting as the ideas of using retroviral vectors to deliver genes providing long term expression is becoming a reality in the field of gene therapy.

The following study delves further into many aspects of the retroviral lifecycle including entry, reverse transcription, and alternative splicing. Recent evidence has shown that cathepsin B cleaves the Moloney Murine Leukemia Virus (MoMLV) surface unit (SU) and may be important for the membrane fusion step during viral entry. Here I present evidence that other host cell cathepsins including L, S, and D are able cleave MoMLV SU at specific sites. Many of the cathepsins tested appear to cleave in the very same region as cathepsin $B$, suggesting they may perform a similar function.
\end{abstract}

The second phase of this study focuses on the reverse transcription step of the retroviral lifecycle. Similar to other polymerases, retroviral RT requires a primer to initiate transcription. Retroviruses use host cell tRNAs which must first be deaminoacylated before the RT enzyme can begin reverse transcription. This work examines the crystal structure of human immunodeficiency virus type one (HIV-1) RT for a possible hydrolase site that is capable of deaminoacylating its primer tRNA. The hydrolase activity of HIV-1 RT was investigated when a charged tRNA was annealed to a genomic template. Furthermore recombinant HIV-1 virions were investigated for the presence of two cellular proteins histidine triad nucleotide-binding protein and human peptidyl-tRNA hydrolase 2 that may also play a role in deaminoacylation of the primer tRNA.

This study culminates by examining the cis-elements that control alternative splicing in MoMLV. The splice donor (SD) and splice acceptor (SA) sites within MoMLV poorly match the consensus sequence for optimal splicing. Mutagenesis was performed using a MoMLV envelope expression plasmid to alter the nucleotide sequence of the SD and SA to match the consensus sequence. This resulted in an increase in envelope expression and viral infectivity of recombinant MoMLV.

\section{Document Type}

Thesis

Degree Name

Master of Science (MS)

Program

Biomedical Sciences

Research Advisor

Lorraine M. Albritton Ph.D.

\section{Keywords}

Cathepsin, Deaminoacylation, MLV, Retrovirus, Splicing, tRNA 


\section{Subject Categories}

Medicine and Health Sciences | Organisms | Viruses 


\title{
Studies of Entry, Reverse Transcription, and Regulation of Splicing in Retroviruses
}

\author{
A Thesis \\ Presented for \\ The Graduate Studies Council \\ The University of Tennessee \\ Health Science Center \\ In Partial Fulfillment \\ Of the Requirements for the Degree \\ Master of Science \\ From The University of Tennessee
}

By

Timothy A. Sullivan

December 2008 
Copyright $(02008$ by Timothy A. Sullivan

All rights reserved 
This thesis is dedicated to my parents

Bob E. Sullivan and Christa K. Sullivan 


\begin{abstract}
The study of retroviruses and their lifecycle has contributed immensely to our knowledge of the world of biology and medicine. The central dogma of the basic flow of genetic information was shattered when the discovery that retroviruses copy their RNA genome into DNA was made. The same enzyme that performs this step, reverse transcriptase (RT), also revolutionized molecular biology when it was used as a tool to generate full length cDNA clones of expressed genes. The impact of retroviruses on the medical field has been extremely exciting as the ideas of using retroviral vectors to deliver genes providing long term expression is becoming a reality in the field of gene therapy.
\end{abstract}

The following study delves further into many aspects of the retroviral lifecycle including entry, reverse transcription, and alternative splicing. Recent evidence has shown that cathepsin B cleaves the Moloney Murine Leukemia Virus (MoMLV) surface unit (SU) and may be important for the membrane fusion step during viral entry. Here I present evidence that other host cell cathepsins including L, S, and D are able cleave MoMLV SU at specific sites. Many of the cathepsins tested appear to cleave in the very same region as cathepsin B, suggesting they may perform a similar function.

The second phase of this study focuses on the reverse transcription step of the retroviral lifecycle. Similar to other polymerases, retroviral RT requires a primer to initiate transcription. Retroviruses use host cell tRNAs which must first be deaminoacylated before the RT enzyme can begin reverse transcription. This work examines the crystal structure of human immunodeficiency virus type one (HIV-1) RT for a possible hydrolase site that is capable of deaminoacylating its primer tRNA. The hydrolase activity of HIV-1 RT was investigated when a charged tRNA was annealed to a genomic template. Furthermore recombinant HIV-1 virions were investigated for the presence of two cellular proteins histidine triad nucleotide-binding protein and human peptidyl-tRNA hydrolase 2 that may also play a role in deaminoacylation of the primer tRNA.

This study culminates by examining the cis-elements that control alternative splicing in MoMLV. The splice donor (SD) and splice acceptor (SA) sites within MoMLV poorly match the consensus sequence for optimal splicing. Mutagenesis was performed using a MoMLV envelope expression plasmid to alter the nucleotide sequence of the SD and SA to match the consensus sequence. This resulted in an increase in envelope expression and viral infectivity of recombinant MoMLV. 


\section{Table of Contents}

Chapter 1. Introduction................................................................................................. 1

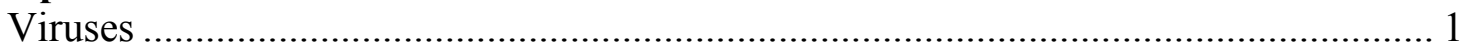

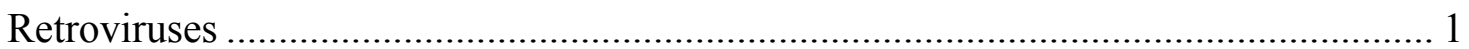

Retroviral genome

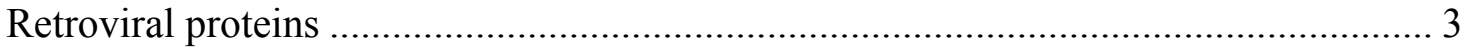

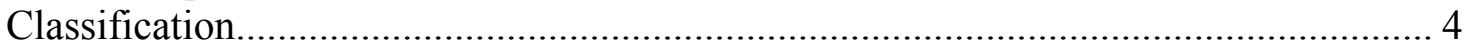

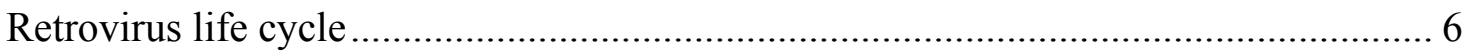

Chapter 2. Cathepsin Cleavage of MoMLV Envelope ....................................................... 7

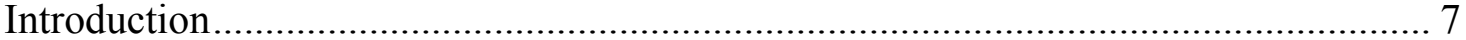

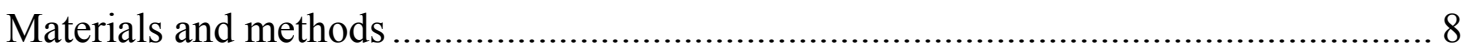

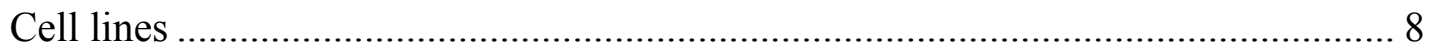

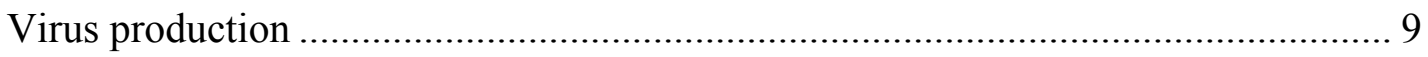

Cathepsin digestion and western blot analysis.................................................... 9

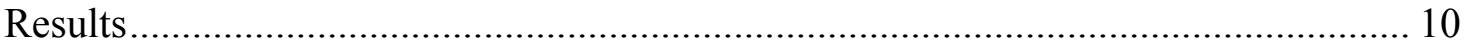

Cathepsin B, D, K, L, and S cleavage of MoMLV envelope protein ....................... 10

Controlling MoMLV Env digestion by temperature and inhibitors ......................... 16

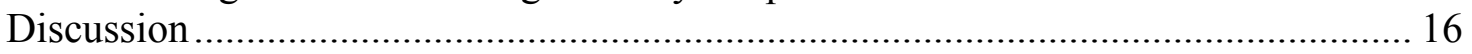

Chapter 3. Deaminoacylation of Primer tRNAs by Retroviruses ................................ 24

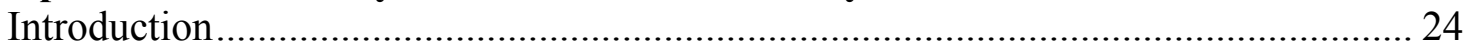



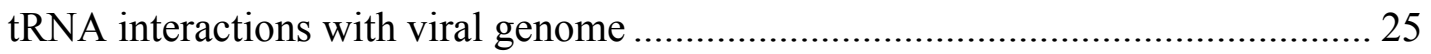

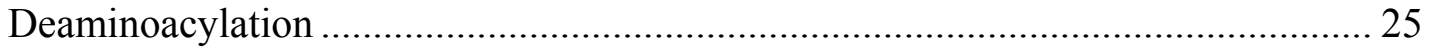

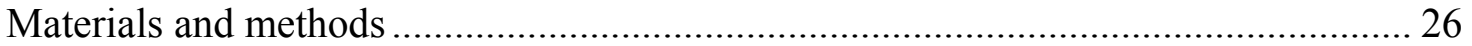

Construction and sub cloning of HIV-1 genomic segment....................................... 26

In vitro transcription of HIV-1 template................................................................ 27

Crude purification of murine aminoacyl tRNA synthetase....................................... 27

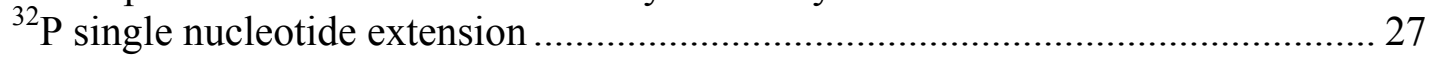

Aminoacylation assay and purification of tRNA................................................... 27

Annealing tRNA to HIV-1 genomic template ........................................................ 30

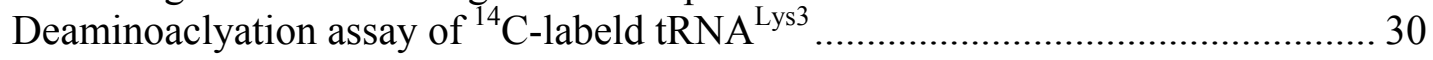

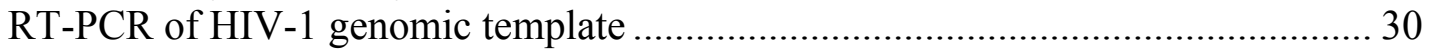

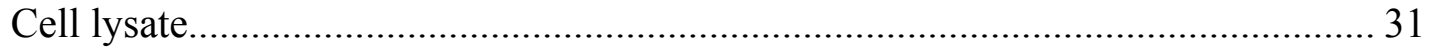

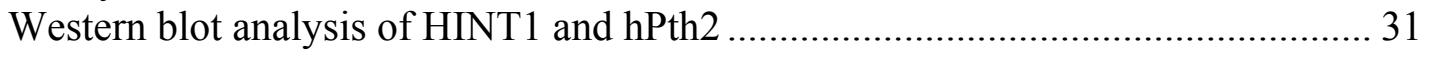

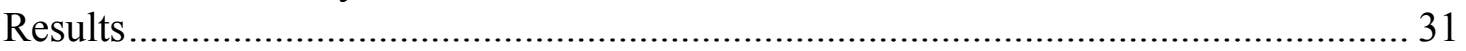

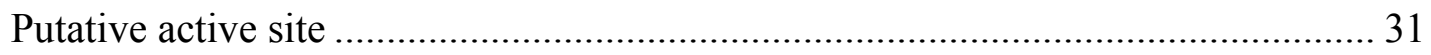

Sub cloning and in vitro transcription of HIV-1 genomic segment.......................... 32

Optimization of the heat-annealing method of primer tRNA association with a

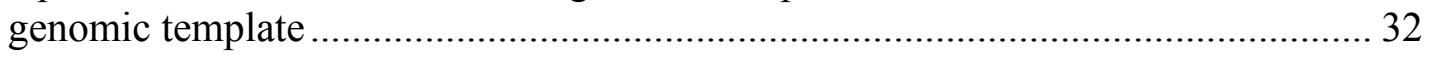

Crude purification of synthetases and aminoacylation of tRNA …………................. 38

Deaminoacylation of lys-tRNA ${ }^{\text {Lys }}$ by HIV-1 RT and AMV RT............................... 38

Detection of cellular proteins within recombinant HIV-1 ....................................... 43 


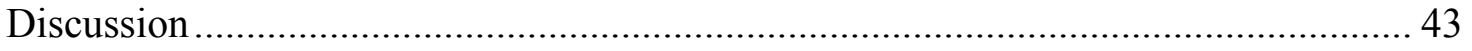

Retroviruses evolved different mechanisms to obtain deaminoacylated primer tRNAs

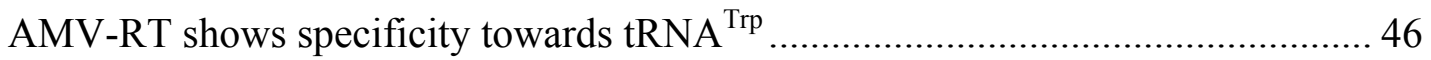

The presence and absence of cellular proteins from recombinant HIV-1 …............ 47

Chapter 4. Increasing MoMLV Envelope Gene Expression............................................ 48

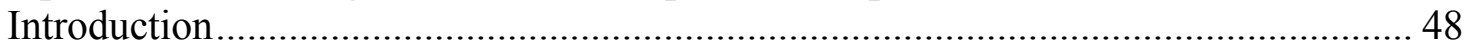

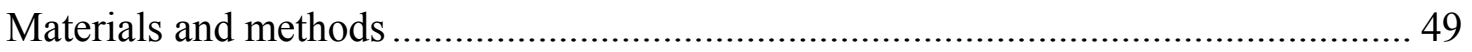

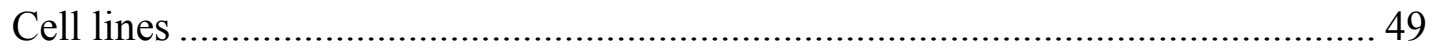

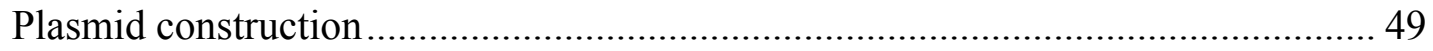

Virus production, titration, and western blot analysis ........................................... 51

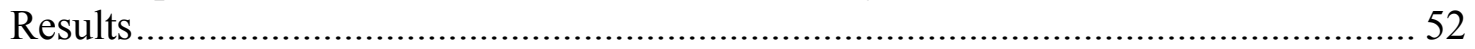

Increasing pcDNA-MoMLV Env positively affects Env expression and recombinant MoMLV infectivity......................................................................... 52

Mutations of the short open reading frames in the 5' untranslated region of the MoMLV envelope gene .................................................................................. 52 Mutational analysis of the splice donor and splice acceptor region of the MoMLV

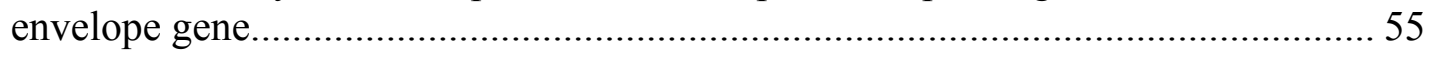

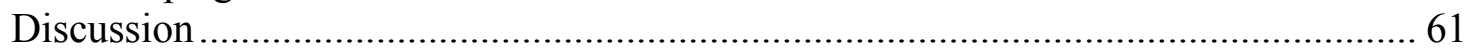

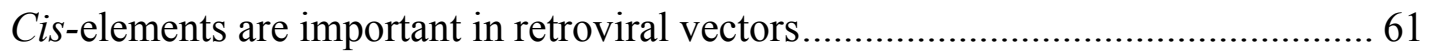

Splicing in MLV is regulated by multiple cis-elements including the splice

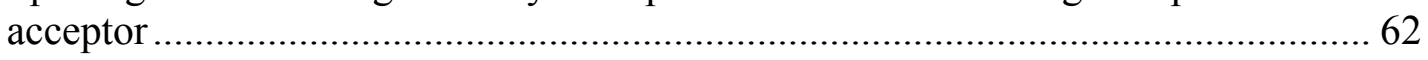

Chapter 5. Discussion .............................................................................................................. 64

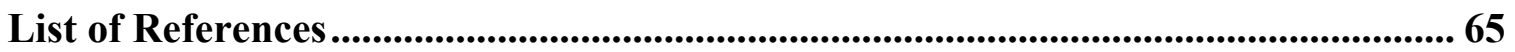

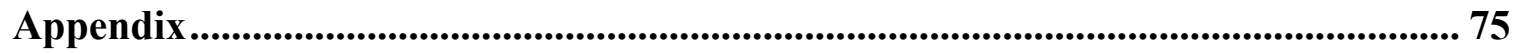

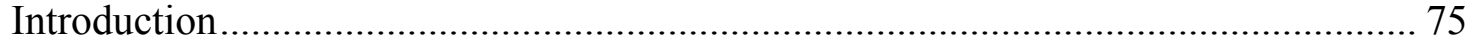

Aminoacyl-tRNA synthetases........................................................................ 75

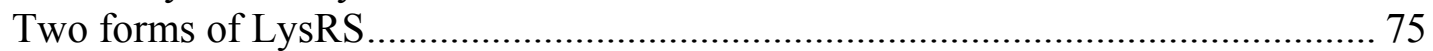

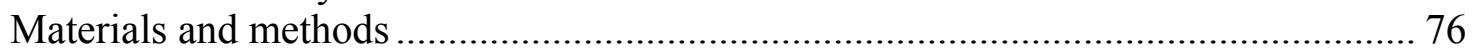

Previously described protocols ............................................................................. 76

MMTV production and western blot analysis ..................................................... 76

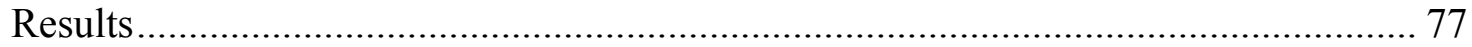

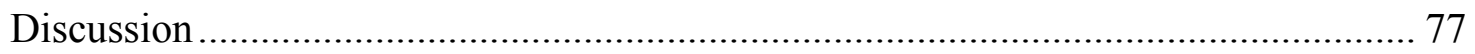

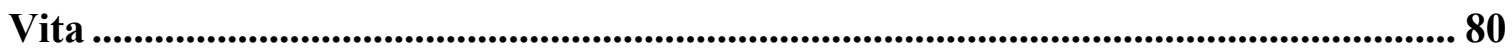




\section{List of Figures}

Figure 1-1. MLV particle and genome …................................................................ 2

Figure 1-2. Schematic representation of the MoMLV envelope protein........................ 5

Figure 2-1. Dose response of cathepsin B cleavage on MoMLV SU ........................... 11

Figure 2-2. Dose response of cathepsin S cleavage on MoMLV SU .......................... 12

Figure 2-3. Dose response of cathepsin L cleavage on MoMLV SU .......................... 13

Figure 2-4. Dose response of cathepsin K cleavage on MoMLV SU............................ 14

Figure 2-5. Dose response of cathepsin D cleavage on MoMLV SU........................... 15

Figure 2-6. Cathepsin digestion of MoMLV SU................................................... 17

Figure 2-7. Cathepsin S digestion of MoMLV SU over time..................................... 18

Figure 2-8. Time course of MoMLV SU cathepsin S digestion at $4{ }^{\circ} \mathrm{C}$......................... 19

Figure 2-9. Cathepsin B digestion of MoMLV SU in the presence of cathepsin inhibitor ......................................................................................... 20

Figure 2-10. Cathepsin S digestion of MoMLV SU in the presence of cathepsin

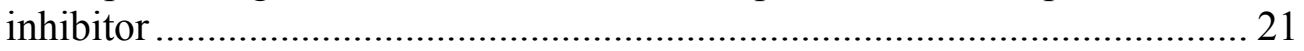

Figure 3-1. Potential hydrolase site in HIV-1 RT .............................................. 33

Figure 3-2. Sequence alignment of HIV-1 RT and AMV RT .................................. 35

Figure 3-3. Potential hydrolase site within model of AMV-RT ................................. 36

Figure 3-4. 652 nucleotide RNA transcript of HIV-1 genomic template. ...................... 37

Figure 3-5. Collection of crude murine aminoacyl-tRNA synthetase ........................... 39

Figure 3-6. Aminoacylation of rabbit tRNA lysine by crude murine aminoacyl-tRNA synthetase ............................................................................... 40

Figure 3-7. Deacylation of ${ }^{14} \mathrm{C}$-labeled Lys-tRNA ${ }^{\text {Lys }}$ by HIV-1 reverse transcriptase.... 41

Figure 3-8. Deacylation of ${ }^{14} \mathrm{C}$-labeled Lys-tRNA ${ }^{\text {Lys }}$ by HIV-1 reverse transcriptase.... 42

Figure 3-9. Absence of HINT1 from recombinant HIV-1 ........................................ 44

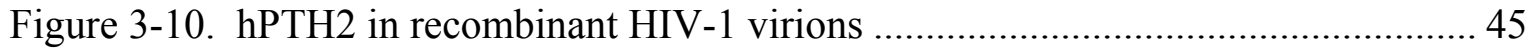

Figure 4-1. Western blot and titer analysis of virus produced with pcDNA MoMLV

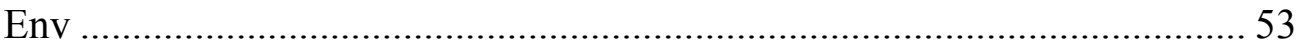

Figure 4-2. Schematic diagram of upstream ORFs found in pcDNA-MoMLV Env ...... 54

Figure 4-3. Western blot and titer analysis of virus produced using ORF envelope

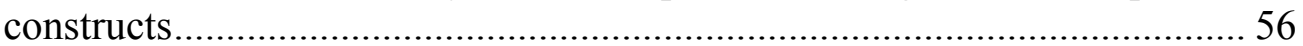

Figure 4-4. pcDNA-MoMLV Env and derived splicing mutants ............................... 58

Figure 4-5. Western blot and titer analysis of virus produced using splicing ....................

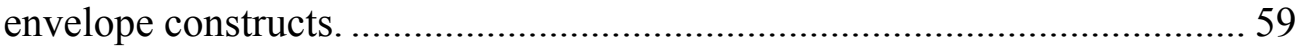

Figure A-1. Detection of lysyl synthetase in MMTV .............................................. 78

Figure A-2. Detection of the cytoplasmic and mitochondrial forms of lysine synthetase in MMTV 79 


\section{Chapter 1. Introduction}

\section{Viruses}

A virus is one of the smallest and simplest infectious agents. Viruses infect an extremely wide variety of organisms including plants, animals, and bacteria. Viruses are incapable of reproducing on their own and are obligate intracellular parasites. They rely on the machinery of the host cell to synthesize the viral proteins and in some cases even replicate the viral genome. They are extremely simplistic organisms and in their most basic form consist of a small RNA or DNA genome, which is encased by a protein shell or capsid. In addition to the capsid some viruses have an envelope that covers the outside of the virus. The envelope is a lipid membrane that is acquired from the host cell membrane. The simplest viruses encode for only four proteins while others encode a few hundred proteins [1].

Viruses can only infect cells to which they can bind. Attachment to a host cell requires a specific interaction between the viral surface proteins and a cellular receptor. The specificity of this interaction largely determines which cell types, tissues, and organisms a virus is capable of infecting. After binding, the virus must cross the plasma membrane. Enveloped and non-enveloped viruses utilize different mechanisms to accomplish this. Enveloped viruses undergo a fusion event between the cellular membrane and the viral membrane. This can occur at the plasma membrane or the virus can become internalized and fuse with the membrane of an internal organelle. The mechanisms used by non-enveloped viruses are not as well understood. Non-enveloped viruses can directly puncture or generate a pore in the cell membrane [2], this can also occur at the plasma membrane or after internalization of the virus. Once in the cytoplasm, a variety of pathways and mechanism are involved in the uncoating, replication, and assembly of progeny virus.

\section{Retroviruses}

The family Retroviridae is a large group of enveloped, positive strand RNA viruses. Retroviruses infect a wide range of animal and higher eukaryotic species causing a variety of diseases including tumors, leukemia, autoimmune disease, immunodeficiency, and neurological disorders. A typical retrovirus particle (Figure 1-1A) ranges from $80-120 \mathrm{~nm}$ in diameter. These particles are spherical in shape and consist of $1-2 \%$ RNA, about $35 \%$ lipids, and $65 \%$ protein [3]. The definitive characteristic of this family is the reverse transcription step during its life cycle. The replication of their genome is very different from other viruses; the flow of genetic information goes from RNA to DNA. Retroviruses reverse transcribe their RNA genome into double stranded DNA, which is then integrated into the genome of the host cell. 
A.

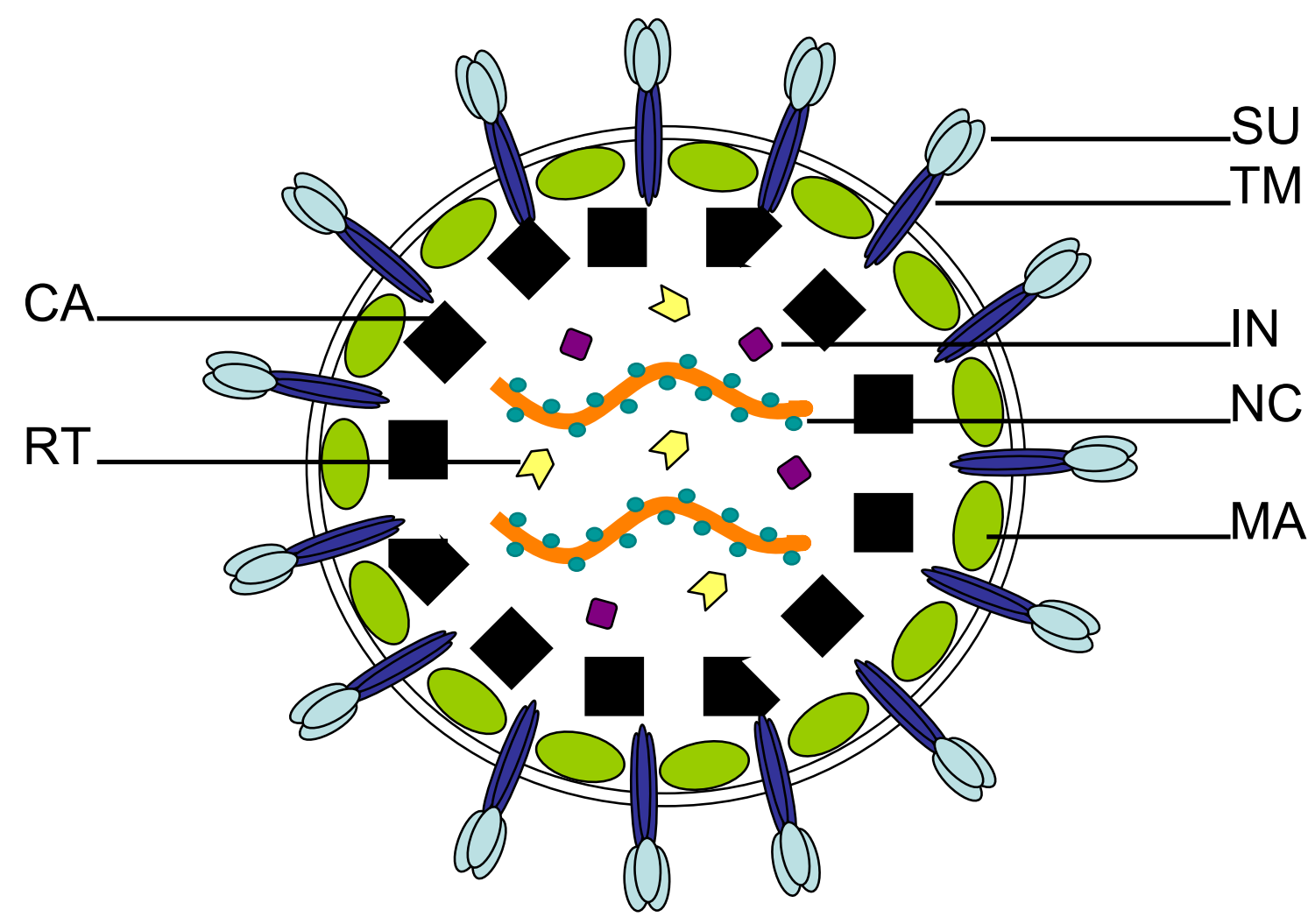

B.

\begin{tabular}{l|lllllll} 
5'cap & $R$ & U5 PBS $\Psi$ & gag & pol & env & PPT U3 $R$ & poly (A) 3.
\end{tabular}

Figure 1-1. MLV particle and genome. A) A schematic diagram of MLV particle. $\mathrm{TM}$, transmembrane components; SU, surface components; IN, integrase; CA, capsid protein; MA, matrix protein; NC, nucleocapsid protein; RT, reverse transcriptase. B) Schematic diagram representing the genomic organization of MLV. R, the repeat sequence; U5, unique 5' sequence; PBS, the primer binding site; $\psi$, the encapsidation sequence; gag, gene encoding the viral structural proteins; pol, gene encoding the viral enzymatic proteins; env, gene encoding the viral envelope protein; PPT, poly purine tract; U3, unique 3' sequence. 


\section{Retroviral genome}

Retroviral particles contain two single-stranded RNA copies of their genome that form a dimer through self-complementarity at their 5' ends [4]. Each monomer ranges from $7-13 \mathrm{~kb}$ in size. The genome is transcribed using host cell machinery and therefore has many similarities to mRNA. The genome has a 5' cap and a poly [A] tail [5-7].

The organization of most retroviral genomes is very similar (Figure 1-1B). Many sequences within the genome play important roles in the virus life cycle. The $\mathrm{R}$ or repeat region is a sequence that is repeated on both the 5' and the 3 ' termini of the genome and is required for reverse transcription of the entire viral genome [8]. The U5 and U3 regions stand for unique 5' and unique 3' sequences, respectively, and are critical for the provirus integration $[9,10]$. Located downstream of the U5 is the PBS or primer binding site. The PBS has specific interactions with host cell tRNA and is the site of initiation of reverse transcription $[11,12]$. The ppt or polypurine tract, found on the 3 ' end, is a run of nine or more $\mathrm{A}$ and $\mathrm{G}$ residues and is also a site of re-initiation of reverse transcription [13]. Downstream of the PBS is the $\psi$ (Psi) sequence, which is responsible for the preferential encapsidation of the genome into the viral particle.

The genomes of all retroviruses contain a minimum of three genes which are termed gag (group specific antigen), pol (polymerase), and env (envelope protein). The gag gene codes for capsid (Ca), nucelocapsid (NC), and matrix (MA) proteins, which are the structural proteins for the virus. The pol gene encodes the enzymatic proteins, reverse transcriptase (RT), integrase (IN) and protease (PR). The env gene codes for the viral envelope protein (Env) which covers the outside of the virus and is responsible for binding and membrane fusion with a host cell.

\section{Retroviral proteins}

The structural proteins of a retrovirus are derived from the Gag polypeptide which is cleaved by the viral protease to yield MA, CA, and NC [14]. The MA protein forms an outer shell around the virus. As the MA protein is translated it is modified by the addition of a myristic acid, a step which is key for proper retroviral assembly [15]. The modification targets the MA to the plasma membrane of the cell. If this site is mutated particles will still assemble within the cytoplasm but will fail to make it to the plasma membrane [16]. The CA protein is conserved among many retroviruses and has a highly conserved region termed the major homology region (MHR). The function the MHR region is not well understood, although mutations in this region seem to affect virion assembly in some viruses $[17,18]$. The capsid protein forms a shell around the condensed inner core of the virus which contains the genome and enzymes required for replication. This inner core can either be spherical, cylindrical, or conical in structure depending on the virus [2]. The NC protein is a small highly basic protein that has two copies of Cys-His motif. These sequences fold around $\mathrm{Zn}^{2+}$ molecules forming a structure known as zinc fingers or zinc knuckles. The NC protein binds tightly to the 
viral genome [19] and may have roles in genome encapsidation as well as annealing the primer tRNA $[2,20]$.

All retroviruses carry with them the three enzymatic proteins RT, IN, and PR [21]. RT has two enzymatic active sites, both are required for replication [3]. The first is an RNA-dependent DNA polymerase which reverse transcribes the viral genome into a DNA copy that can then be integrated into the host genome. RT is a low fidelity polymerase with no proofreading function and therefore leads to a high error rate during viral replication [22]. This error rate allows viral populations to evolve rapidly in the host cell environment, as well as acquire resistance to drugs designed to block their replication [23, 24]. The second enzymatic site within $\mathrm{RT}$ is termed ribonuclease $\mathrm{H}$ (RNase $\mathrm{H}$ ). Its nuclease activity is specific for the RNA strand in an RNA:DNA hybrid [25]. The function of RNase $\mathrm{H}$ is to degrade the viral RNA genome as the DNA copy is being generated, creating short RNA primers used by RT to complete the replication process. The IN and PR also play important roles in the replication process. IN catalyzes important steps in the integration reaction by integrating the double-stranded viral cDNA into host cell chromosomal DNA where it is then referred to as the provirus. The role of PR is to cleave the Gag polyprotein into the smaller protein products found in the mature virion [26]. Deletion of the sequences encoding PR from the pol gene result in noninfectious particles with unprocessed Gag [27].

The viral Env protein covers the outside of the virus. It is comprised of two virally encoded subunits termed surface protein (SU) and transmembrane protein (TM) that are anchored in the lipid bilayer derived from the host cell (Figure 1-2). These two subunits form an interaction through disulfide bonds or non-covalent bonds. Unlike Gag and Pol the Env protein contains a signal peptide that targets it for translation in the endoplasmic reticulum (ER). Within the ER the Env becomes glycosylated, folds, and assembles into oligomeric structures (mainly trimers) $[3,28]$. The amount of glycosylation Env differs greatly between different retroviruses. HIV-1 Env as approximately 30 glycosylation sites where as the MLV Env have less then 10 [3]. Env continues along the secretory pathway to the Golgi where it is cleaved to separate SU from TM and free the amino-terminus of the fusion peptide [29-31]. SU allows the virus to bind the host cell and the TM acts to anchor the protein to the virus and mediates the membrane fusion with the host cell membrane.

\section{Classification}

Initially retroviruses were classified by the morphology of the virion core as visualized by electron microscopy. These former classifications have now been expanded and new criteria have been added. The Retroviridae family now consists of seven different genera: Alpharetrovirus, Betaretrovirus, Gammaretrovirus, Deltaretrovirus, Epsilonretrovirus, Lentivirus, and Spumavirus. These seven genera are divided into two groups of retroviruses, simple and complex. Alpha, Beta, and Gammaretroviruses are considered simple retroviruses because they encode only the Gag, Pro, Pol, and Env gene products. Deltaretroviruses, Epsilonretroviruses, Lentiviruses, 


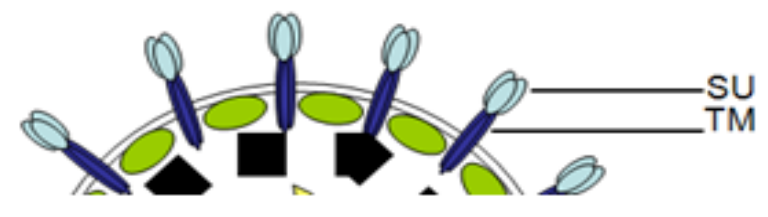

SU

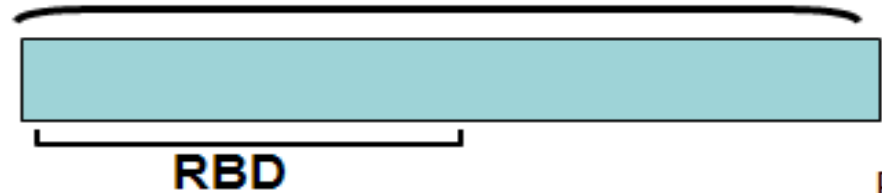

Receptor Binding Domain
TM

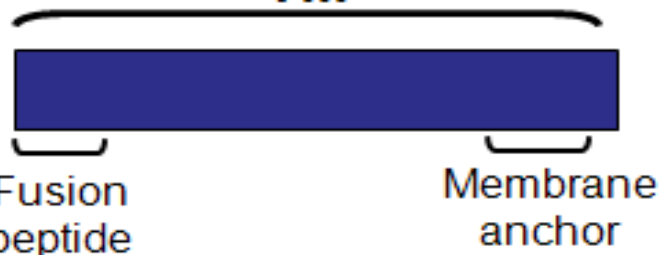

Figure 1-2. Schematic representation of the MoMLV envelope protein. The top represents a portion of the MoMLV particle that contains the surface protein (SU) and the transmembrane (TM) protein. The bottom is a schematic representation of the two subunits SU and TM. 
and Spumaviruses are considered complex retroviruses. They code for the gag, pol, pro, and $e n v$ genes as in simple retroviruses but they also encode many other additional proteins that have a range of different functions, particularly regulatory and virulence proteins.

\section{Retrovirus life cycle}

Receptor binding is the first step in a retroviral infection. The viral SU protein binds a protein on the cellular surface. Next, membrane fusion occurs; this is a mixing of the viral membrane with the cellular membrane. This step is catalyzed by the viral TM. Membrane fusion can occur at the cell surface or internally with an endocytic vesicle. After the viral core enters the cytoplasm, uncoating of the capsid protein takes place and reverse transcription of the viral genome begins.

There are approximately 50-100 molecules of RT per virion. RT has two domains. The first contains an RNA-dependent DNA polymerase activity which catalyzes reverse transcription of the RNA genome. The second domain contains RNaseH activity, which degrades the RNA genome as it is being reverse transcribed into DNA. Reverse transcription takes place in a complex made up of proteins including NC, $\mathrm{RT}$, IN, and the viral RNA [32]. Like other polymerases RT cannot initiate transcription de novo; it requires a primer. The RTs of all retroviruses use host cell tRNAs to prime the reverse transcription step.

The viral cDNA must gain entry to the nucleus. This occurs via two mechanisms depending on the virus. The first mechanism used by most simple retroviruses is to wait for nuclear envelope break down during mitosis [33,34]. The second mechanism which is used by lentiviruses and spumaviruses appears to be an active transport method across the nuclear membrane [33, 35]. After entry into the nucleus by one of these two methods the linear viral cDNA is integrated into the host cell chromosomal DNA.

The U3 region of the provirus contains a promoter recognized by the cellular RNA polymerase II system. Full-length viral transcripts generated by cellular RNA Polymerase II have several fates. Some are packaged into the progeny virus to serve as the viral genome for the next round of infection. Some are used for translation of Gag or Gag-Pol polyproteins. Others are spliced to yield a population of sub-genomic mRNAs. In simple retroviruses this alternatively spliced product codes for the viral Env. In complex retroviruses there can be multiple splicing events leading to the production of Env as well as other accessory proteins.

After transcription of the viral genome and translation of the viral proteins, the next step is assembly and budding of the virus particles. The site of particle assembly varies depending on the genus of retrovirus. The immature Gag proteins come together to form virus particles. Full length retroviral genome is recruited into the particle. These particles bud from the cellular membrane and their capsid becomes cleaved into a mature form by the viral protease. Upon this maturation the virus is ready to infect a new host cell. 


\section{Chapter 2. Cathepsin Cleavage of MoMLV Envelope}

\section{Introduction}

MLV are simple gammaretroviruses. They can be divided into five different subgroups based on host range: amphotropic, ecotropic, xenotropic, polytropic and dualtropic [36]. Moloney murine leukemia virus (MoMLV) is an ecotropic MLV that is used as a model in retroviral replication and as a vector for gene therapy. Despite extensive investigation there are still unanswered questions about early steps in this virus's life cycle, including the membrane fusion step.

Infection of enveloped viruses involves attachment to cell surface receptors followed by fusion with cellular membranes to release the viral nucleocapsids into the cytoplasm $[37,38]$. Receptor binding and low $\mathrm{pH}$ are known to be the two principal triggering mechanisms responsible for conformational changes in the retroviral Env which leads to the fusion event. For $\mathrm{pH}$-dependent viruses like mouse mammary tumor virus (MMTV) fusion occurs in an endocytic vesicle where these viruses encounter low $\mathrm{pH}$ (5.3-6.5) that induces rearrangement in the viral Env and drive viral-cell fusion [37, 39]. Entry into the endocytic pathway can be achieved by different routes including macropinocytosis, phagocytosis, clathrin- and caveolae-mediated pathways and some less-well defined routes called non-clathrin-, non-caveolae-dependent pathways [40]. Most retroviruses including HIV-1 and HTLV-1 are $\mathrm{pH}$-independent [41, 42]. Receptor binding in $\mathrm{pH}$-independent retroviruses causes structural changes in the Env and allows fusion at neutral $\mathrm{pH}$ with the plasma membrane.

In many cell types including SC-1 and NIH 3T3, receptor-bound MoMLV is endocytosed and infection is blocked by the weak base $\mathrm{NH}_{4} \mathrm{Cl}[42,43] . \mathrm{NH}_{4} \mathrm{Cl}$ raises the $\mathrm{pH}$ in cellular compartments and is a classic way to test for $\mathrm{pH}$-dependence. So initially it appeared that MoMLV was $\mathrm{pH}$-dependant. However, several pieces of evidence now point towards the idea that cellular proteases may have a key role in viral fusion. First, Klaus Andersen reported that MoMLV Env is cleaved upon virus entry [43] and that limited trypsin enhanced virus induced cell-cell fusion [44]. Second, although $\mathrm{NH}_{4} \mathrm{Cl}$ blocks infection in many cells types it does not do so in XC cells nor is it able to inhibit $\mathrm{XC}$ virus induced cell-cell fusion [42]. To explain this anomaly McClure and coworkers proposed that fusion was taking place at the cell surface aided by the secretion of a cellular protease that is normally found within the endosomal compartment [42]. This explanation turned out to be quite plausible. XC cells are derived from a rat sarcoma induced by Rous sarcoma virus; they are a highly transformed cell line due to the expression of the viral src gene [45-47]. Viral-src-transformed cells have been shown to secrete cellular proteases such as cathepsin L [48, 49].

Proteases belonging to the cathepsin family are best known for their role as lysosomal hydrolases. Cathepsins are named using letters of the alphabet and are divided into three subgroups depending on which amino acid is present in the active site, cysteine $(\mathrm{B}, \mathrm{C}, \mathrm{H}, \mathrm{F}, \mathrm{K}, \mathrm{L}, \mathrm{O}, \mathrm{S}, \mathrm{V}, \mathrm{W}$, and $\mathrm{X} / \mathrm{Z})$, aspartate (D and $\mathrm{E})$, and serine $(\mathrm{G})$ 
cathepsins [50]. Most cathepsins are endopeptidases while a few have exopeptidase activity as well. In general, cathepsins are active at a low $\mathrm{pH}$ (5.0-6.0.) Cathepsins are well known for their role in general protein turnover however recent works shows they also have roles outside the lysosomal compartment, i.e., degradation of extracellular matrix when secreted to the extracellular space and execution of programmed cell death when released to the cytosol $[51,52]$.

Kumar et al., (2007) examined the role of cathepsin B in the life cycle of MoMLV. They found that the cellular protease cathepsin B is important for MoMLV infection during membrane fusion and the best evidence suggested that it acts on the viral envelope protein [53]. Cathepsin B was able to cleave SU, but not TM or CA, into specific fragments. When mouse embryonic fibroblasts (MEFs) derived from a cathepsin $\mathrm{B}$ knockout $\left(\mathrm{B}^{-/}\right)$mouse were challenged with MoMLV they showed a decrease in infectivity when compared to $\mathrm{B}^{+/+}$MEFs. This suggested that cathepsin $\mathrm{B}$ plays a role during the infection. However, the fact that infectivity was lowered and not abolished indicated that cathepsin B was important for infection but not critical.

One explanation is other cathepsins perform a similar or redundant function for MoMLV in the absence of cathepsin B. Recent work on other viruses suggests that additional cathepsins could be involved during infection by cleavage of the viral glycoprotein. Hendra and Nipah virus fusion (F) proteins are activated by cathepsin L cleavage within the endosomal compartment [54-56]. During Ebola virus infection cathepsin B is essential and cathepsin L plays an accessory role [57]. It has also been shown that cathepsin L cleaves the Ebola glycoprotein [58]. In severe acute respiratory syndrome-coronavirus (SARS-CoV) inhibitors of cathepsin L inhibit infection [59] and SARS-CoV fusion protein is cleaved by cathepsin L [60]. Also feline enteric coronavirus (FECV) is highly dependent on cathepsin B and cathepsin L for entry into host cells [61]. The involvement of other cathepsins in MoMLV fusion had not previously been tested. The studies presented here investigate if other cysteinyl (cath B, K, L, S) and aspartyl (D) cathepsins cleave the MoMLV Env. This work also highlights optimal conditions for in vitro digestion of MoMLV Env, as well as compares and contrasts products of the cleavage events.

\section{Materials and methods}

\section{Cell lines}

Mouse Fibroblast NIH 3T3 cells chronically infected with MoMLV were cultured in Dulbecco's modified Eagle's medium (DMEM; Cellgro) which was supplemented with $8 \%$ fetal calf serum (FBS; Sigma). Cells were maintained at $37^{\circ} \mathrm{C}$ in $10 \% \mathrm{CO}_{2}$. 


\section{Virus production}

The virus used in these experiments was produced from NIH $3 \mathrm{~T} 3$ cells chronically infected with MoMLV. Viral supernatant was collected at 24, 48, and $72 \mathrm{hrs}$ after cells reached $100 \%$ confluence. Supernatant was then pooled and filtered through a $0.45-\mu \mathrm{m}$ filter. The viral filtrate was pelleted by ultracentrifugation using a Beckman $\mathrm{SW} 40$ rotor at $30,000 \mathrm{rpm}$ for $45 \mathrm{~min}$ at $4{ }^{\circ} \mathrm{C}$. Virus pellets were resuspended in $30 \mu 1$ of ice cold PBS and stored at $-80^{\circ} \mathrm{C}$.

\section{Cathepsin digestion and western blot analysis}

Reactions of $10 \mu \mathrm{l}$ volume were assembled on ice in an acetate buffer ( $\mathrm{pH}$ 5.5) and using MoMLV virus pellet and specified amounts of cathepsin B, D, K, L or S (Calbiochem). In all cases, cathepsin $\mathrm{K}$ was activated prior to us following the manufacturer's instructions. The amount of virus pellet used was equivalent to an envelope protein band of $2 \mathrm{~cm}$ height after a $15 \mathrm{sec}$ exposure of a western blot incubated with anti-gp70 antiserum. The reaction was then incubated for $20 \mathrm{~min}$ at $37^{\circ} \mathrm{C}$. In some cases the reaction parameters for the cathepsin digestions varied. The temperature was either $37^{\circ} \mathrm{C}$ or $4{ }^{\circ} \mathrm{C}$. The amount of a cathepsin used varied from $0.185 \mathrm{mU}$ to $1000 \mathrm{mU}$. The reaction time varied from 2 min to $100 \mathrm{~min}$. In order to limit the amount of digestion during a cathepsin $\mathrm{B}$ or cathepsin $\mathrm{S}$ digestion cathepsin $\mathrm{S}$ inhibitor (Calbiochem) was used at a concentration ranging from $0.1 \mu \mathrm{M}$ to $100 \mu \mathrm{M}$. Reactions were stopped by adding an equal volume of $2 \mathrm{X}$ gel loading buffer (1) and immediately heated to above 90 ${ }^{\circ} \mathrm{C}$ for $10 \mathrm{~min}$.

After heating, samples were separated by SDS-PAGE through a 10-20\% Trisglycine gel (Invitrogen) and transferred to a nitrocellulose membrane (Protran, Schleicher and Schuell). The membrane was blocked for two hrs in 6\% dry milk, 2\% Tween 20 then incubated with goat anti-gp70 antiserum (Quality Biotech no. 80S000018; 1:100) for one $\mathrm{hr}$. The primary antibody was detected by incubation with mouse anti-goat antibody conjugated to horseradish peroxidase $(1: 5,000)$ for $45 \mathrm{~min}$ followed by incubation with SuperSignal West Pico Chemiluminescent Substrate (Pierce). After exposure membranes were stripped by incubation with Restore Western Blot Stripping Buffer (Pierce) according to the manufacturer's protocol, with two exceptions. First, the incubation temperature was increased to $37{ }^{\circ} \mathrm{C}$. Second, the time of incubation was increased to 25 min and including an additional $10 \mathrm{~min}$ at room temperature with constant rocking. Membranes were then reprobed for the capsid protein (CA) goat anti-p30 antiserum (Quality Biotech no. 80S000018; 1:100) for one hr and detected using the same secondary antibody as above. 


\section{Results}

\section{Cathepsin B, D, K, L, and S cleavage of MoMLV envelope protein}

In the following experiments purified cysteinyl cathepsin $\mathrm{B}, \mathrm{K} \mathrm{L}, \mathrm{S}$, or aspartyl cathepsin D were incubated with replication competent MoMLV under various conditions to investigate their cleavage ability on the SU and CA proteins. Viral supernatant from NIH-3T3 cells was harvested and ultracentrifuged to purify replication competent MoMLV virions. In vitro digestion by purified cathepsin was carried out using aliquots of pelleted MoMLV. In a dose response to Cathepsin B the MoMLV SU was specifically cleaved but the CA remained intact (Figure 2-1). These results agree with published data from Kumar et al, [53]. At $9.25 \mathrm{mU}$ of cathepsin B, the SU was specifically cleaved yielding fragments that were 47,35 , and $28 \mathrm{kDa}$. Increasing the amount of cathepsin B did not yield any new fragments but diminished the signal of the remaining protein.

In a dose response to cathepsin $\mathrm{S}, \mathrm{SU}$ was specifically cleaved and CA was intact (Figure 2-2). Low amounts of cathepsin S (lanes 3 and 4) specifically cleaved SU yielding fragments of 47 and $33 \mathrm{kDa}$. At higher amounts of cathepsin S (lanes 5 and 6), these fragments became diminished and a $28 \mathrm{kDa}$ fragment appeared. The $28 \mathrm{kDa}$ fragment remained resistant to cathepsin S cleavage until high amounts of cathepsin $\mathrm{S}$ were used (lane7). At $50 \mathrm{mU}$ of cathepsin S, the only signal detected was a small amount of intact SU.

In a dose response using cathepsin $L$ the MoMLV SU was specifically cleaved and at high levels the CA signal was slightly diminished (Figure 2-3). At $1.85 \mathrm{mU}$ of cathepsin L (lane 4), the MoMLV SU was cleaved yielding fragments of 47 and $35 \mathrm{kDa}$. As the level of cathepsin L was increased to $9.25 \mathrm{mU}$ the signal from the 47 and $35 \mathrm{kDa}$ fragments became diminished and a $28 \mathrm{kDa}$ fragment appeared. At the highest dose of cathepsin L (lane 7), no protein could be detected. Among all the cathepsins tested in this study, MoMLV SU showed the greatest sensitivity to cathepsin L. Throughout the dose response the level of CA remains constant with the exception of the highest dose in which over half of the CA signal is gone (lane 7).

MoMLV was subjected to a dose response to cathepsin K ranging from 0.185 to $50 \mathrm{mU}$ and appeared no different than a no cathepsin control (data not shown). However, using cathepsin $\mathrm{K}$ at levels 10-100 times that of the other cathepsins tested resulted in cleavage of SU (Figure 2-4). When used at $100-500 \mathrm{mU}$ cathepsin $\mathrm{K}$ was able to specifically cleave SU generating a $47 \mathrm{kDa}$ band. Using $1000 \mathrm{mU}$ resulted in complete digestion of the $70 \mathrm{kDa} \mathrm{SU}$ and its products, leaving only a slightly detectable $28 \mathrm{kDa}$ fragment. The CA signal was reduced by over half when using this same dose. Cathepsin $\mathrm{K}$ does not appear to digest the $\mathrm{SU}$ at any biologically relevant level.

In a dose response to the aspartyl protease cathepsin $\mathrm{D}$, the $\mathrm{SU}$ was specifically cleaved (Figure 2-5). Unlike cathepsin B, S, and L, cathepsin D digestion led to only one 


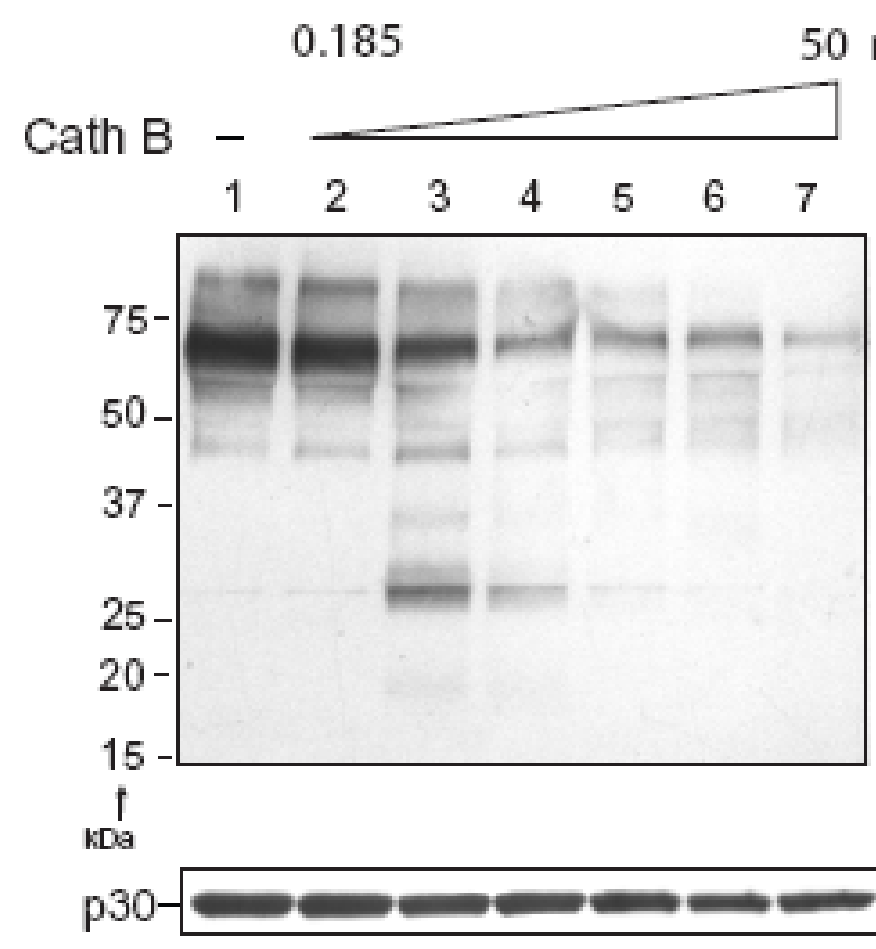

Figure 2-1. Dose response of cathepsin B cleavage on MoMLV SU. Aliquots of MoMLV were incubated in acetate buffer ( $\mathrm{pH}$ 5.5) with increasing amounts of cathepsin $\mathrm{B}$ for $1 \mathrm{hr}$ at $37^{\circ} \mathrm{C}$. Doses of cathepsin B from left to right were 0, 0.185, 9.25, 18.5, 25, 37, $50 \mathrm{mU}$. Reaction products were separated via 10-20\% SDS-PAGE and transferred to nitrocellulose membranes. Membranes were incubated with anti-SU antiserum (top) then stripped and reprobed with anti-CA antiserum. 


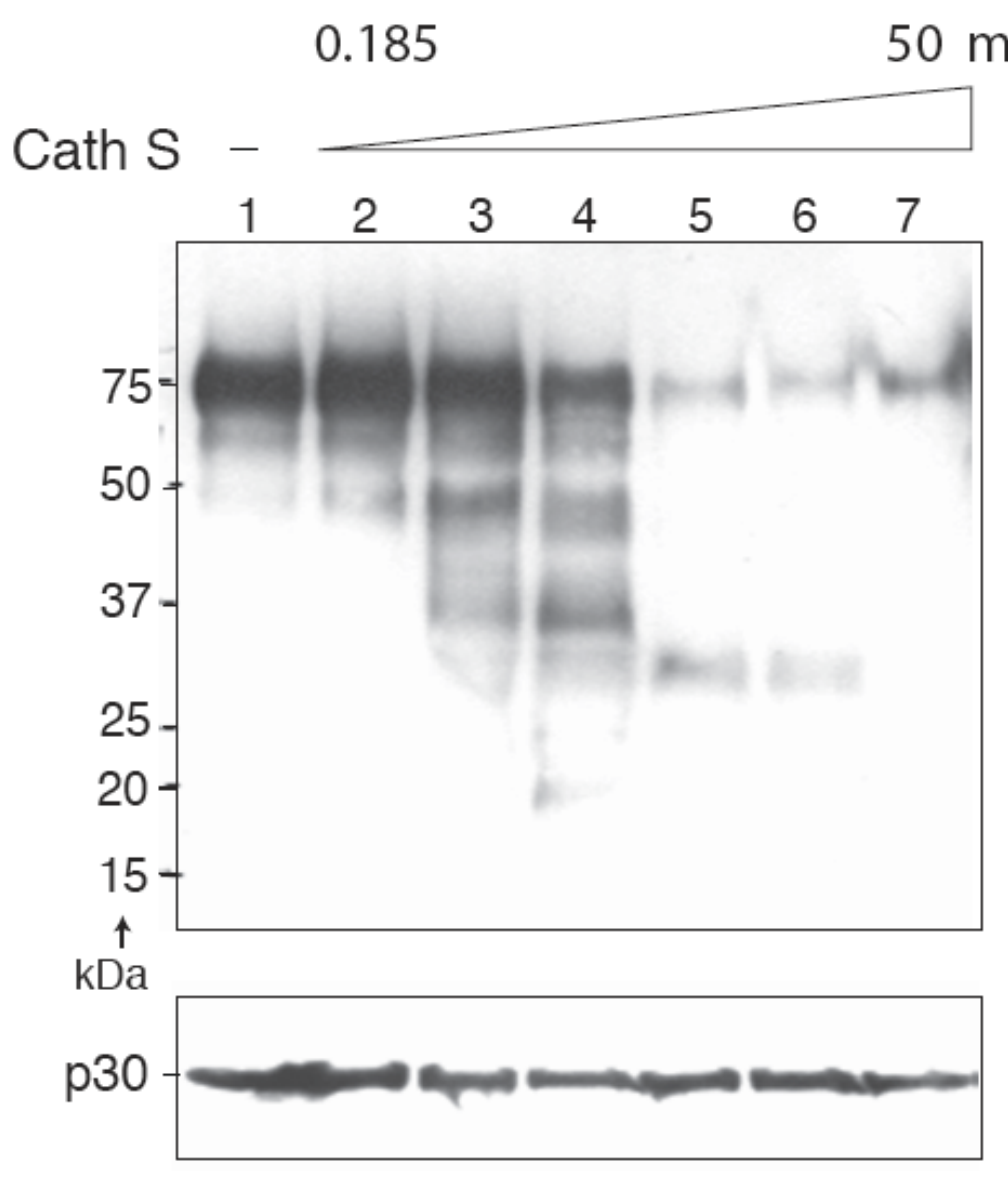

Figure 2-2. Dose response of cathepsin S cleavage on MoMLV SU. Aliquots of MoMLV were incubated in a $\mathrm{pH} 5.5$ buffer with increasing amounts of cathepsin B for $20 \mathrm{~min}$ at $37^{\circ} \mathrm{C}$. Doses from left to right were $0,0.185,0.925,1.85,9.25,18.5,50 \mathrm{mU}$. Reaction products were separated via 10-20\% SDS-PAGE and transferred to nitrocellulose membranes. Membranes were incubated with anti-SU antiserum (top) then stripped and reprobed with anti-CA antiserum. 


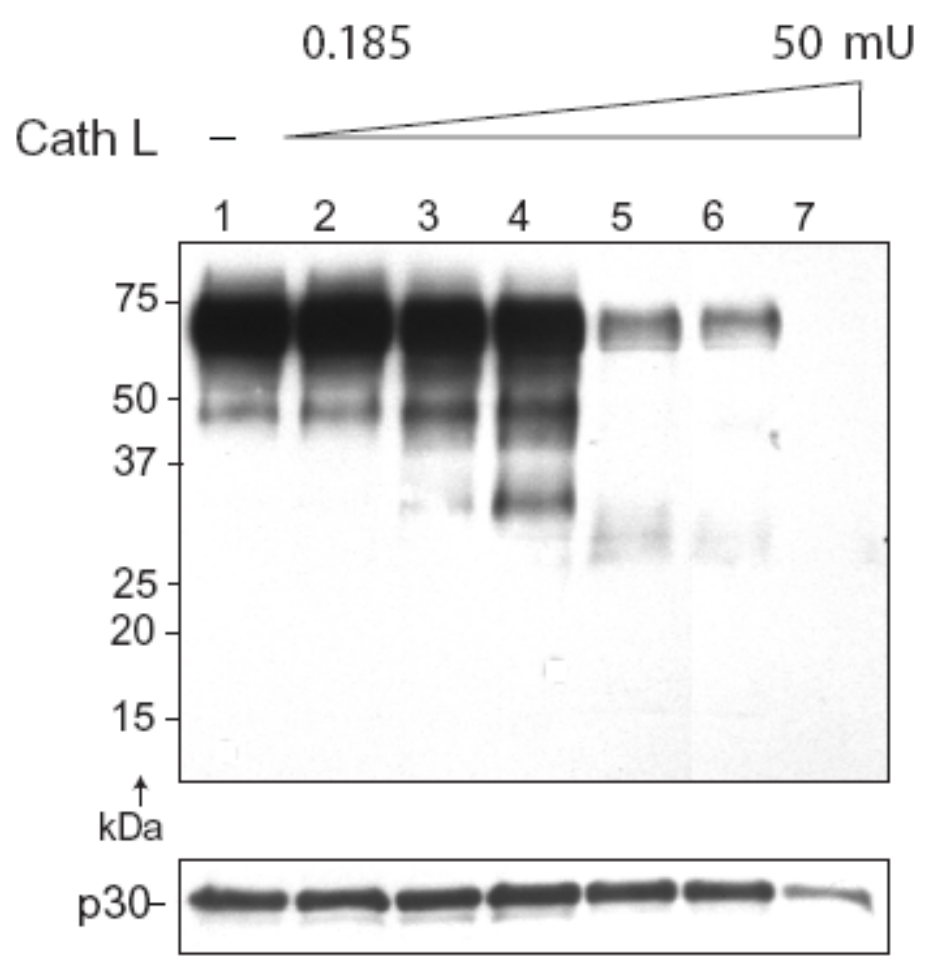

Figure 2-3. Dose response of cathepsin L cleavage on MoMLV SU. Aliquots of MoMLV were incubated in a pH 5.5 buffer with increasing amounts of cathepsin $\mathrm{L}$ for 20 min at $37{ }^{\circ} \mathrm{C}$. Doses from left to right were $0,0.185,0.925,1.85,9.25,18.5,50 \mathrm{mU}$. Reaction products were separated via 10-20\% SDS-PAGE and transferred to nitrocellulose membranes. Membranes were incubated with anti-SU antiserum (top) then stripped and reprobed with anti-CA antiserum. 


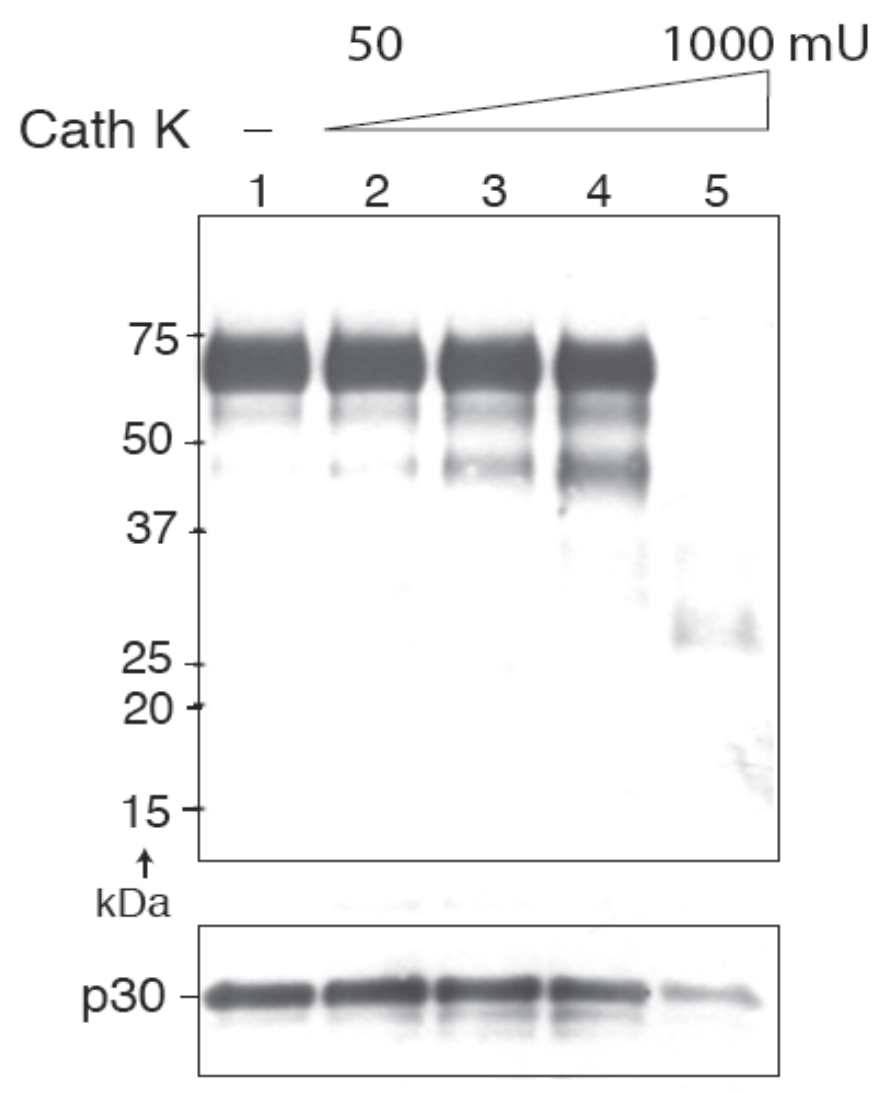

Figure 2-4. Dose response of cathepsin K cleavage on MoMLV SU. Aliquots of MoMLV were incubated in a $\mathrm{pH} 5.5$ buffer with increasing amounts of cathepsin $\mathrm{K}$ for $20 \mathrm{~min}$ at $37^{\circ} \mathrm{C}$. Doses from left to right were $0,50,100,500,1000 \mathrm{mU}$. Reaction products were separated via $10-20 \%$ SDS-PAGE and transferred to nitrocellulose membranes. Membranes were incubated with anti-SU antiserum (top) then stripped and reprobed with anti-CA antiserum. 


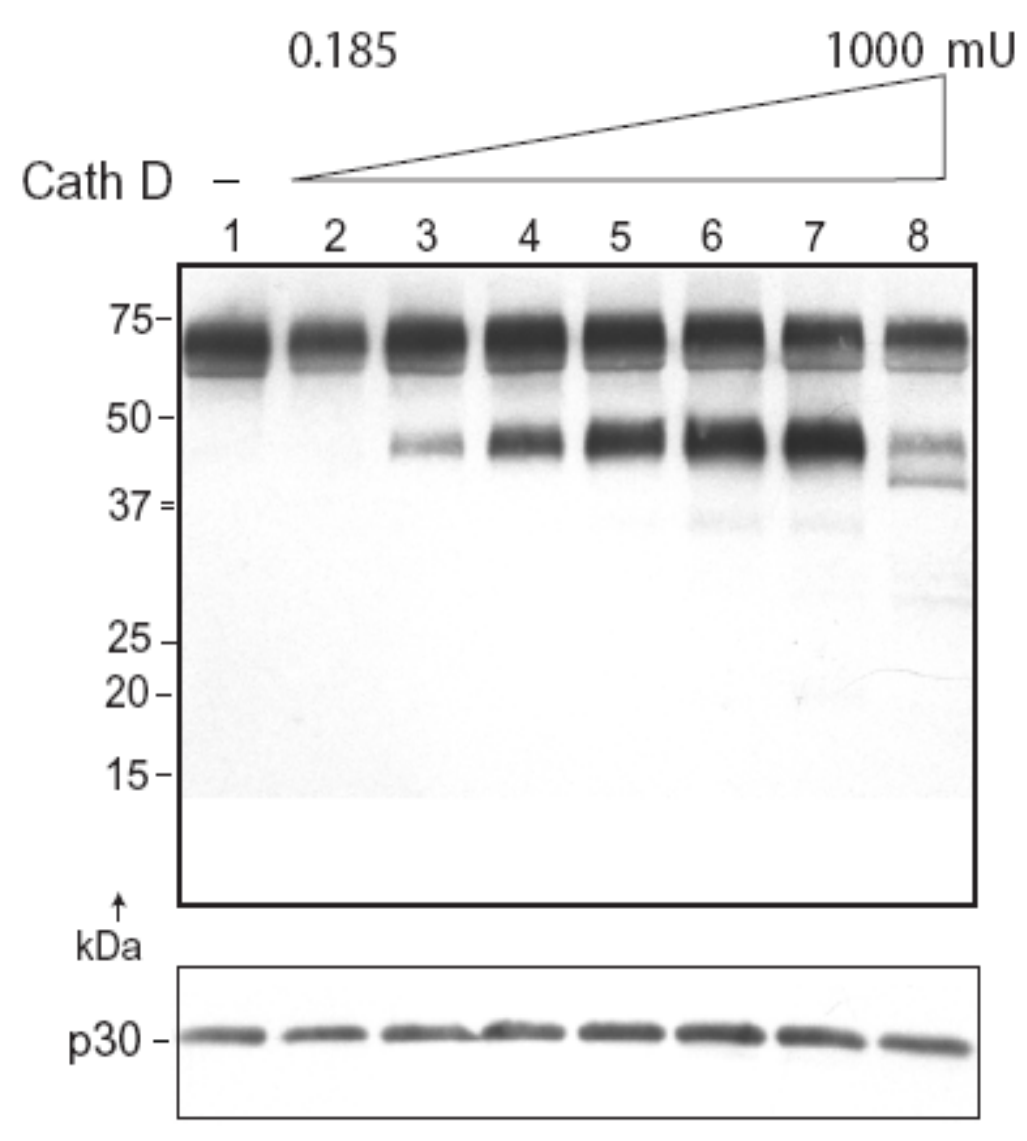

Figure 2-5. Dose response of cathepsin D cleavage on MoMLV SU. Aliquots of MoMLV were incubated in a $\mathrm{pH} 5.5$ buffer with increasing amounts of cathepsin D for $20 \mathrm{~min}$ at $37^{\circ} \mathrm{C}$. Doses from left to right were $0,0.185,0.925,1.85,9.25,18.5,50$, and $1000 \mathrm{mU}$. Reaction products were separated via $10-20 \%$ SDS-PAGE and transferred to nitrocellulose membranes. Membranes were incubated with anti-SU antiserum (top) then stripped and reprobed with anti-CA antiserum. 
major fragment at $47 \mathrm{kDa}$. The other cathepsins displayed several major cleavage products. Cathepsin D displayed a very low level of exopeptidase activity. It was unable to cleave a significant amount of SU unless used at high levels. To determine if the entire SU could be cleaved into the $47 \mathrm{kDa}$ fragment, $1000 \mathrm{mU}$ of cathepsin $\mathrm{D}$ was used (Figure 2-5, lane 8). This did not result in a significantly higher amount of cleaved SU but instead diminished the signal of the $47 \mathrm{kDa}$ product.

Cathepsins B, S, L, and D were able to cleave the MoMLV SU to some extent when used at low levels. Direct comparison of digestion products from each cathepsin reaction were separated on the same gel (Figure 2-6). Reactions were carried out at two different doses $(1.85 \mathrm{mU}$ and $9.25 \mathrm{mU})$. All four cathepsins cleaved $\mathrm{SU}$ and generated a $47 \mathrm{kDa}$ band. Cathepsin S and L shared identical cleavage patterns (47, 33, and $28 \mathrm{kDa})$. Digestion with cathepsin B yields only a slightly different banding pattern. Instead of a $33 \mathrm{kDa}$ fragment a $37 \mathrm{kDa}$ fragment. MoMLV SU was more resistant to cathepsin D cleavage when compared to cathepsin B, S, and L. It yielded only one product at $47 \mathrm{kDa}$ and did so only at the higher dose.

\section{Controlling MoMLV Env digestion by temperature and inhibitors}

It was possible that time could affect the digestion pattern. To address this issue, a time course using $9.25 \mathrm{mU}$ of cathepsin $\mathrm{S}$ at $37{ }^{\circ} \mathrm{C}$ was carried out (Figure 2-7). Two observations came from this study. First, the reaction was occurring very rapidly. By the first time point, all the cleavage products were already formed. Second, extended incubation time led to a decrease in signal from all fragments including SU. Two approaches were used to limit the rate of the reaction so that the chronological appearance of the fragments could be investigated. The first approach was to slow the enzyme's activity by lowering the reaction temperature. A time course at $4{ }^{\circ} \mathrm{C}$ using 9.25 $\mathrm{mU}$ of cathepsin B resulted in the stepwise formation of the cleavage products seen in earlier digestions (Figure 2-8A). This approach was useful for determining the order in which the cleavage products occurred and gave increased signal of these products. Even after 100 min of incubation a large amount of protein remained (Figure 2-8B). The second approach used Z-FL-COCHO, a reversible inhibitor of cathepsin B and S, to limit the enzymes activity. Using a constant amount of cathepsin $\mathrm{B}$ or $\mathrm{S}(9.25 \mathrm{mU})$ and varying the amount of Z-FL-COCHO inhibitor allowed the sequential order of the fragments to be determined while maintaining larger amounts of the fragments (Figure 2-9 and Figure 2-10).

\section{Discussion}

Cathepsins are emerging as key players in the entry mechanism of many different viruses including SARS-CoV, murine hepatitis virus, Ebola, Hendra, and Nipah [62]. Cathepsins proteolytically cleave the viral glycoprotein which affects viral fusion [53-56, $58,60,63]$. Recent work in MoMLV indicated that cathepsin B is important for MoMLV 


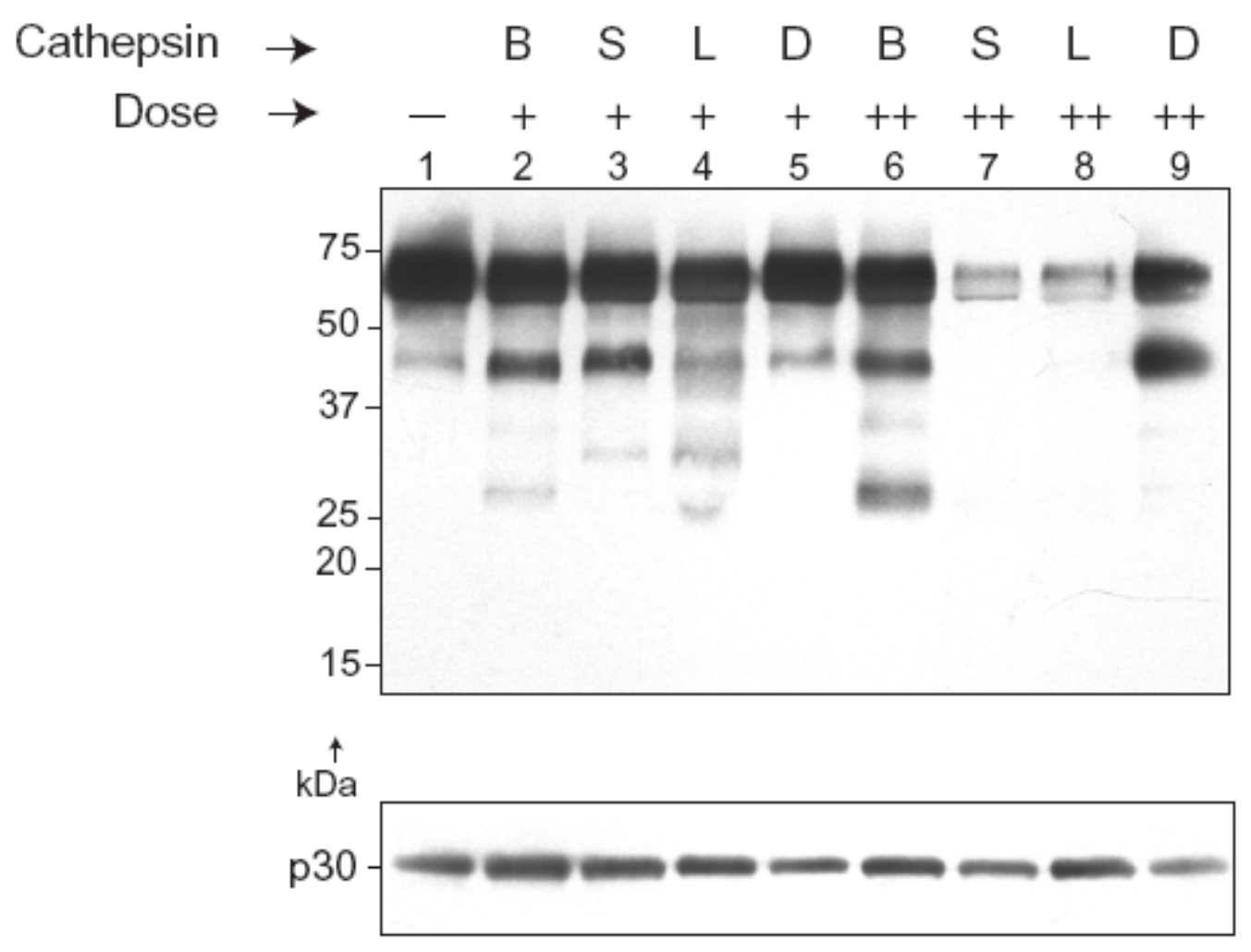

Figure 2-6. Cathepsin digestion of MoMLV SU. Aliquots of MoMLV were incubated in a pH 5.5 buffer with two doses of either cathepsin B, S, L, or D for 20 min at $37^{\circ} \mathrm{C}$. Doses are $1.85 \mathrm{mU}$ indicated by $(+)$ or $9.25 \mathrm{mU}$ indicated by $(++)$. Reaction products were separated via 10-20\% SDS-PAGE and transferred to nitrocellulose membranes. Membranes were incubated with anti-SU antiserum (top) then stripped and reprobed with anti-CA antiserum. 


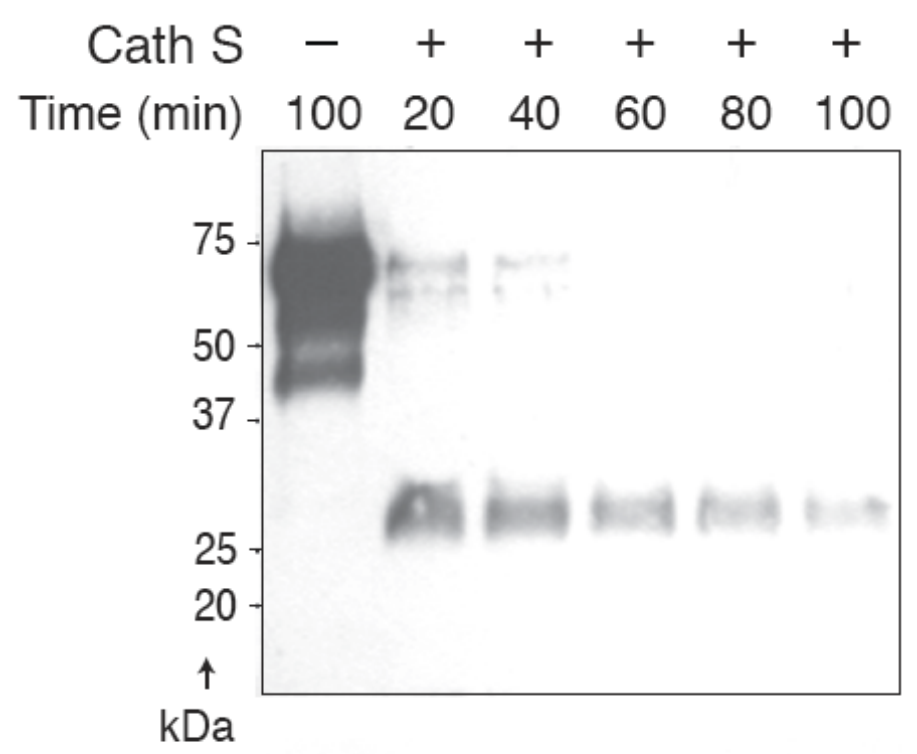

Figure 2-7. Cathepsin S digestion of MoMLV SU over time. Aliquots of MoMLV were incubated in a $\mathrm{pH} 5.5$ buffer with or without $9.25 \mathrm{mU}$ of cathepsin $\mathrm{S}$ for 20,40, or $60,80,100 \mathrm{~min}$ at $4^{\circ} \mathrm{C}$. Reaction products were separated via 10-20\% SDS-PAGE and transferred to nitrocellulose membranes. Membranes were incubated with anti-SU antiserum (top) then stripped and reprobed with anti-CA antiserum. 


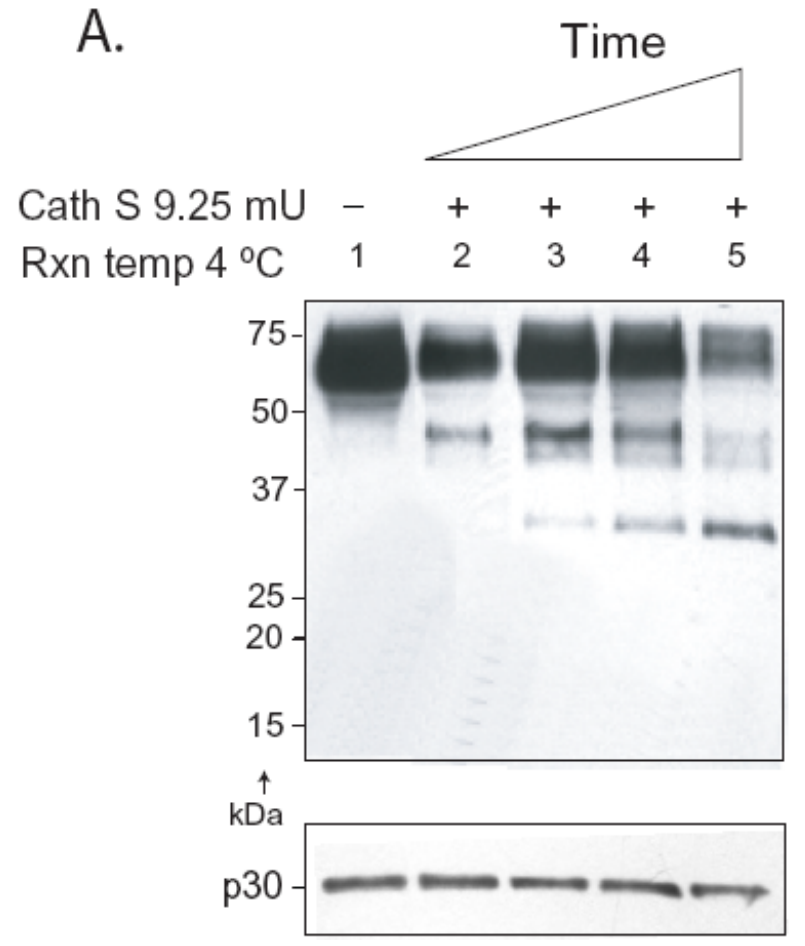

B.
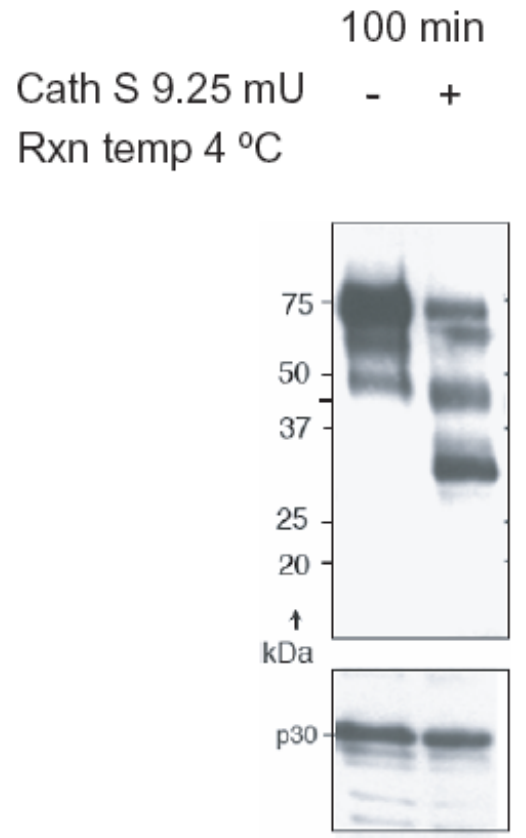

Figure 2-8. Time course of MoMLV SU cathepsin S digestion at $4^{\circ} \mathrm{C}$. A) Aliquots of MoMLV were incubated in a pH 5.5 buffer with or without $9.25 \mathrm{mU}$ of cathepsin $\mathrm{S}$ for 20,40 , or $60 \mathrm{~min}$ at $4{ }^{\circ} \mathrm{C}$. Reaction products were separated via 10-20\% SDS-PAGE and transferred to nitrocellulose membranes. Membranes were incubated with anti-SU antiserum (top) then stripped and reprobed with anti-CA antiserum. B) Aliquots of MoMLV were incubated in a $\mathrm{pH} 5.5$ buffer with $9.25 \mathrm{mU}$ of cathepsin $\mathrm{S}$ for $100 \mathrm{~min}$ at 4 ${ }^{\circ} \mathrm{C}$. Products were then separated and probed using the same method as figure 3-8A. 


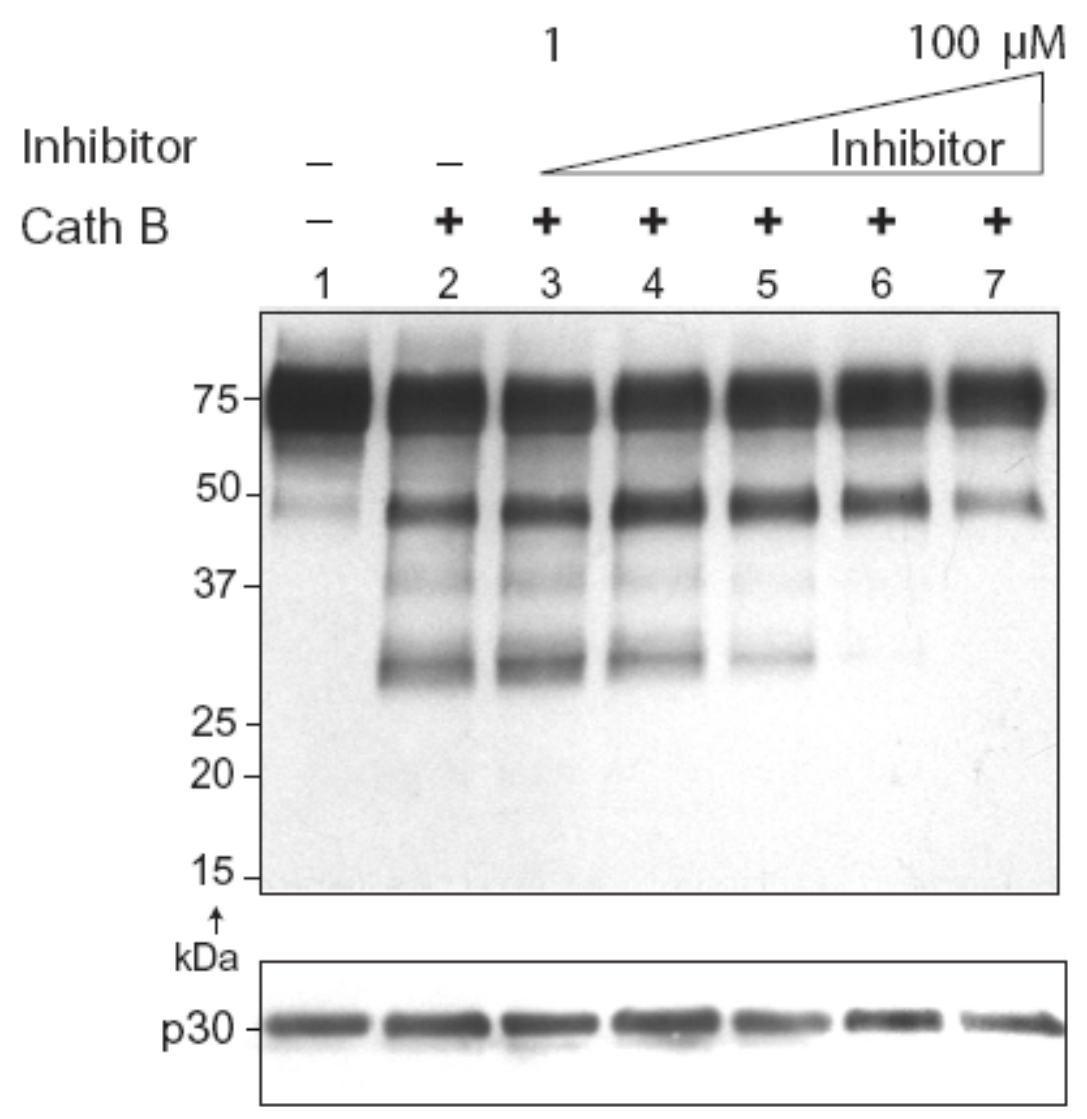

Figure 2-9. Cathepsin B digestion of MoMLV SU in the presence of cathepsin inhibitor. Aliquots of MoMLV were incubated in a $\mathrm{pH} 5.5$ buffer with or without 9.25 $\mathrm{mU}$ of cathepsin S. The cathepsin inhibitor, Z-FL-COCHO, was included in lanes 2-7 at levels of $1,5,1025$, and $100 \mu \mathrm{M}$ respectively. Reaction products were separated via 10$20 \%$ SDS-PAGE and transferred to nitrocellulose membranes. Membranes were incubated with anti-SU antiserum (top) then stripped and reprobed with anti-CA antiserum. 


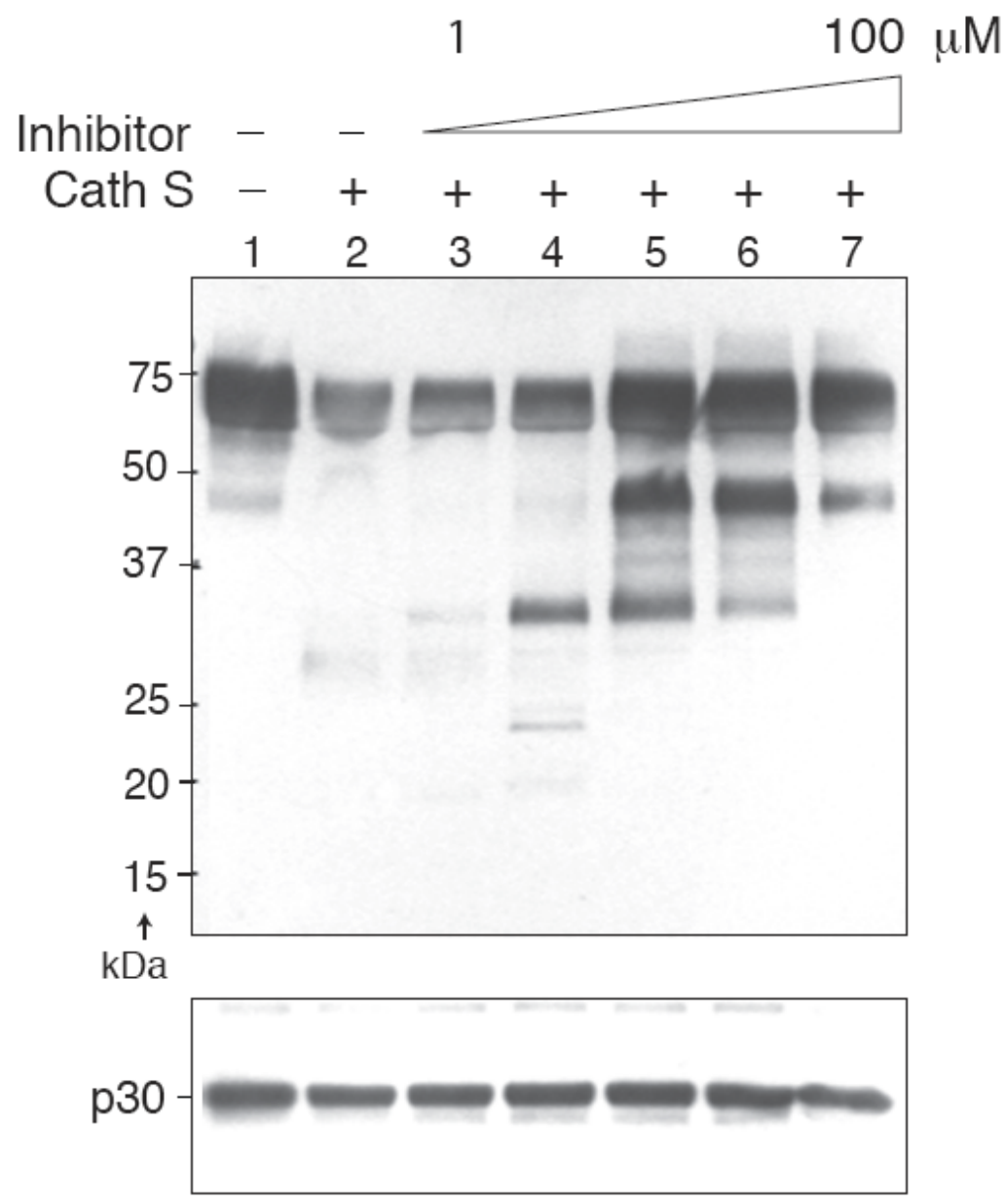

Figure 2-10. Cathepsin S digestion of MoMLV SU in the presence of cathepsin

inhibitor. Aliquots of MoMLV were incubated in a $\mathrm{pH} 5.5$ buffer with or without 9.25 $\mathrm{mU}$ of cathepsin S. The cathepsin inhibitor, Z-FL-COCHO, was included in lanes 2-7 at levels of $1,5,1025$, and $100 \mu \mathrm{M}$ respectively. Reaction products were separated via 10$20 \%$ SDS-PAGE and transferred to nitrocellulose membranes. Membranes were incubated with anti-SU antiserum (top) then stripped and reprobed with anti-CA antiserum. 
infection during membrane fusion and that it cleaves the viral glycoprotein [53]. However, in the absence of cathepsin B in KO cells, MoMLV infection is decreased and not blocked. This lead to the hypothesis that other cathepsins may be involved by performing a redundant function in the absence of cathepsin B. This is a likely scenario because the virus enters most cell types through the endosomal pathway, where it would encounter a variety of different cathepsins. Being able to rely on more than one cathepsin could be a tremendous evolutionary advantage.

Together these results have shown that cysteinyl cathepsin B, S, L, and aspartyl cathepsin D are capable of cleaving MoMLV SU, while cleavage by cysteinyl cathepsin $\mathrm{K}$ required greater amounts of protease. This means that the active site, which determines the class of the cathepsin, does not determine if cleavage of $\mathrm{SU}$ is possible. Cathepsins B, L, and D are ubiquitously expressed and located in the lysosomal compartment $[64,65]$. Cathepsin $\mathrm{S}$ is also found in the lysosomal compartment of cells in many different tissues including kidney, lymph nodes, lung, and spleen [66]. Cathepsin K which has collagenolytic activity, plays a key role in bone resorption [67] and is expressed highly and preferentially in osteoclasts [65]. MoMLV enters through the lysosomal pathway, therefore it is likely to encounter cathepsins B, L, S, and D but not cathepsin K. It is interesting that the cathepsins it probably encounters during infection are also the cathepsins most capable of cleaving SU.

Could the cleavage by cathepsins S, L, and D perform the same function as cathepsin B? The digestion patterns of cathepsin $\mathrm{S}$ and $\mathrm{L}$ are nearly identical to that of $\mathrm{B}$ and the levels of enzyme at which this activity took place were similar. Cathepsin B, L and $\mathrm{S}$ yield a cleavage product of $47 \mathrm{kDa}$, which is subsequently cleaved into a $28 \mathrm{kDa}$ product. They differ slightly in that cathepsin $\mathrm{B}$ has an intermediate product at $35 \mathrm{kDa}$ and cathepsin $\mathrm{S}$ and $\mathrm{L}$ have an intermediate product at $33 \mathrm{kDa}$. Given the similarities in the digestion patterns and activity it seems likely cathepsin $\mathrm{S}$ and $\mathrm{L}$ could function in the same manner as cathepsin B in MoMLV infection.

Cathepsin D generates an initial $47 \mathrm{kDa}$ product but only at slightly higher concentrations then cathepsin B, L, and S. At extremely high levels of cathepsin D the $47 \mathrm{kDa}$ band remains intact and is digested further. Also a large population of the SU remains intact. One explanation for the intact SU may be the heterogeneity of the population with respect to the level of glycosylation. Given this heterogeneity, it is possible that the cleavage site of cathepsin D in SU could be masked on some molecules but not others.

Since the key cleavage site has not been identified, it cannot yet be determined if cathepsin D might provide a similar function in the absence of cathepsin B. If the first cleavage product at $47 \mathrm{kDa}$ is important to fusion, than cathepsin $\mathrm{D}$ could perform the same function as cathepsin B. Cathepsin D appears to have a lower activity for SU cleavage than cathepsin B but the levels of cathepsin D that give the $47 \mathrm{kDa}$ fragment are still within the physiological range observed in lysosomes. 
The cathepsins examined in this study should also be investigated for their role in fusion to provide evidence for their relevance of the observed digestion of SU. When using the drug CA-074 Me during a MoMLV infection of NIH 3 T3 cells, the amount of virus induced cell-cell fusion that occurs is reduced [53]. At low levels, CA-074 Me is an inhibitor of cathepsin B, at high levels it inhibits other cathepsins as well. NIH 3T3 cells could be incubated with CA-074 Me to inactivate the amount of endogenous cathepsin present and then the inhibitor removed immediately prior to infection. MoMLV could then be added to the cells in the presence or absence of the different cathepsins. The affect of the cathepsins on cell-cell fusion could then be observed. Cathepsins that restore cell-cell fusion would be inferred to have a role in the membrane fusion step of MoMLV infection.

Recent work indicates that cathepsin B may play a role in the membrane fusion step of MoMLV infection by cleaving the SU protein [53]. The current work shows that other lysosomal cathepsins are also able to cleave MoMLV SU. Is the cleavage of SU important for the membrane fusion step? If so, which sites are important? The cleavage sites could be identified by digesting purified virus, removing the cathepsin digested fragments from an SDS-PAGE gel, and subjecting them to mass spectrometry and Edman degradation. Using site directed mutagenesis these sites could be mutated, making them resistant to cleavage. The importance of each site for membrane fusion could then be tested by infecting NIH 3T3 cells with the different cleavage mutants. Mutants that display reduced or no fusion during infection would identify sites are important during membrane fusion and provide valuable information about the rearrangements of SU during the membrane fusion step of MoMLV infection.

Recently several enveloped viruses from different families were shown to be activated for fusion by cathepsin cleavage of their envelope glycoprotein, however the cleavage sites have not been determined. Identification of the cathepsin cleavage sites within MoMLV SU could be helpful in determining the mechanism of protease triggered fusion for the other enveloped viruses. The location of the cleavage sites within the MoMLV SU structure should define new functional domains and give new insights into the mechanism triggering the envelope glycoprotein rearrangements that drive membrane fusion. If analogous domains exist in the other protease triggered viral glycoproteins then the mechanism revealed by MoMLV studies might be broadly applicable to understanding the protease trigger and structural rearrangements in the other enveloped viruses. 


\section{Chapter 3. Deaminoacylation of Primer tRNAs by Retroviruses}

\section{Introduction}

Upon infection of a host cell the RNA genome is reverse transcribed into double stranded DNA, which then becomes integrated into the host cell genome [68,69]. This process is mediated by the virally encoded enzyme reverse transcriptase (RT), which has RNA and DNA dependant DNA polymerase activity [68]. RT is found either in a monomer or in a dimer depending on the virus [4]. Similar to other polymerases, RT cannot initiate synthesis de novo, therefore a primer is required for reverse transcription to occur. The RT of all retroviruses use host cell tRNA isoacceptors as primers to initiate transcription of the viral genome $[11,12]$. Different retroviruses utilize different species of tRNA's; Human immunodeficiency virus type 1 (HIV-1) and MMTV use tRNA ${ }^{\text {Lys3 }}$, avian myeloblastosis virus (AMV) uses tRNA ${ }^{\text {Trp }}$, and MLV uses tRNA ${ }^{\text {pro }}$ [70-75].

\section{Recruitment of tRNA to retroviral virions}

Packaging of host cell tRNA takes place during the viral assembly process. The amount and species of tRNA packaged varies greatly between viruses. HIV, AMV, avian leukosis virus (ALV), Rous Sarcoma virus (RSV), and MMTV all selectively package their cognate primer tRNA [70, 76-80], while MLV does not show comparable levels of selectivity [78]. Despite all the interactions between the viral genome and primer tRNA, the viral genome does not appear to be involved in tRNA recruitment to the virion.

Studies in MLV, HIV, and ASV have shown that in the production of viral particles that do not contain genomic RNA, tRNA profiles are the same as WT [74, 81]. A very interesting study was done in which three viruses were compared, HIV-1, RSV, (which both specifically recruit primer tRNA) and MLV. Western blot analysis was performed on viral lysates to identify the presence of the three cognate synthetases, lysine (LysRS), tryptophan (TrpRS), and proline (ProRS). HIV and RSV contained only LysRS and TrpRS respectively while MLV was negative for all three [82]. It appears that recruiting host cell aminoacyl-tRNA synthetase is a mechanism for specific tRNA recruitment. Using siRNA against LysRS leads to reduced packaging of tRNA ${ }^{\text {Lys3 }}$, reduced annealing of primer to viral genome, and reduced viral infectivity of HIV-1 [83].

The viral RT also seems to play a role in specific recruitment of primer tRNAs in certain retroviruses. It has been shown through enzymatic digestion, chemical probes and

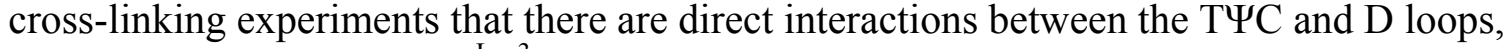
and the 3 'terminus of tRNA ${ }^{\text {Lys3 }}$ and HIV-1 RT [84-87]. In HIV-1, RSV and AMV, selective packaging is not observed in RT negative viruses [74, 88, 89]. Interestingly HIV-1 that is RT negative still contains LysRS but cannot specifically recruit tRNA ${ }^{\text {Lys } 3}$ or place it on the viral genome [90]. This same involvement of RT does not seem to exist in MLV, a virus in which the primer tRNA is not heavily recruited. A MLV mutant that was deleted for $40 \%$ of its C-terminus showed only small differences in the amount of 
tRNA $^{\text {Pro }}$ present in the virion and had WT amounts of tRNA ${ }^{\text {Pro }}$ bound to the viral genome [91]. MLV mutants deleted completely for RT did show a reduction in the amount of free tRNA ${ }^{\text {Pro }}$ but still had WT amounts of the primer bound to the genome [91]. From these studies it seems that retroviruses that significantly recruit their primer tRNA do so through an interaction involving both their RT and the host cell aaRS. MLV, a virus that does not share this same specific recruitment, does not require RT or the host cell aaRS to obtain and anneal its primer tRNA.

\section{tRNA interactions with viral genome}

The tRNA binds the eighteen nucleotides of its 3' termini to a complementary sequence, the primer binding site (PBS), located in the 5' untranslated leader region of the viral RNA genome [92]. The PBS is present in all retroviruses and is critical for replication. Viruses that contain mutations in which the eighteen nucleotide PBS is deleted, are non infectious [93]. Recently other sites having complimentarity between the tRNA and viral genome have been discovered. These sites include the A-loop in HIV-1 and the primer activation site (PAS) in HIV-1 and RSV [94, 95]. The A-loop region in HIV-1 is located just upstream of the PBS and is made up of four consecutive adenosine nucleotides that interact with the anticodon arm of tRNA ${ }^{\text {Lys } 3}$ [87]. Deletion of the Aloop results in reduced replication kinetics and after many passages the sequence reverts back to WT [96]. The PAS, which has been characterized in HIV as well as RSV, is a small section of the viral genome upstream of the PBS which interacts with the TYC loop of the primer tRNA [94, 95]. Deletion of the PAS does not decrease the amount of primer bound to the genome but reduces initiation, therefore lowering the amount of viral replication [95]. Phylogenetic analysis suggests that the PAS/tRNA interaction is possible in all retroviruses and may act as an underlying mechanism to regulate reverse transcription in retroviruses [97]. To summarize, the PBS binds the primer tRNA and is necessary for replication to occur, while the A-loop and PAS act once the primer is bound to regulate initiation of transcription.

\section{Deaminoacylation}

One problem that all retroviruses must overcome in order to replicate is hydrolyzing the ester bond that is formed at the 3' terminus when a tRNA isoacceptor is charged with an amino acid. One way to overcome this is to bring tRNAs into the virion that are already deaminoacylated. This would be very difficult to do because steady state cellular levels of tRNAs are almost always in the aminoacylated form [98]. There is also evidence to support the idea that the tRNAs going into the virion are in the aminoacylated state. By making tRNA ${ }^{\text {Lys3 }}$ anticodon mutants that differed in their ability to be aminoacylated, Kleiman's lab was able to show a positive correlation between aminoacylation and incorporation into the virion [99].

Deaminoacylation by RT has only been studied in two retroviruses, AMV and HIV-1. The AMV RT enzyme was able to deaminoacylate tRNA ${ }^{\text {Trp }}$, but only when the 
tRNA was annealed to the genome [100]. This suggests that the complex formed between the AMV RT, genome, and primer places the RT in the correct position to perform the deaminoacylation step. HIV-1 and AMV are very similar in their recruitment mechanism of tRNAs to the virion, and the RT's of these viruses have very specific interactions with their cognate primer tRNA [85, 101, 102]. It is likely that HIV-1 RT uses the same mechanism to deaminoacylate its primer tRNA. Currently there has been only one study on the RT of HIV-1 to look for deaminoacylation activity in vitro. The conclusion of this study was that RT did not substantially increase the rate of deaminoacylation [103]. However, this study was done using a very short segment of the HIV-1 genome, which failed to include the PAS site and therefore may not have been capable of forming the WT conformation best recognized by HIV-1 RT. The experiments in the following study investigate the structure of HIV-1 RT for a logically placed hydrolase site. Then the deaminoacylation activity of HIV-1 RT is tested using a template that includes all the known interaction sites with the primer tRNA ${ }^{\text {Lys3 }}$. In addition, HIV-1 virions were examined for the presence of two proteins, histidine triad nucleotide-binding protein (HINT1) and human peptidyl-tRNA hydrolase 2 (Pth2), which could also attribute to deaminoacylation of tRNA ${ }^{\text {Lys3 }}$.

\section{Materials and methods}

\section{Construction and sub cloning of HIV-1 genomic segment}

Polymerase chain reaction (PCR) was used to amplify nucleotides 1-652 of the HIV-1 genome from pLL3.7, a lentiviral expression plasmid (Invitrogen). $100 \mathrm{ng}$ of the sense primer(5'ATAGGAATTCTACAATTAATACATAACCTTATGTATCATACAC ATAC GATTTAGGTGACACTATAGGTCTCTCTGGTTAGACCAG) and the antisense primer ( $5^{\prime}$ TGATCCCGGGCCTCTATCTTGTCTAAAGCTTC) were used in the reaction. The sense primer contained a SP6 promoter site that would later be used for in vitro transcription. Also within the primer sequence were EcoR I and Xma I restriction sites allowing for downstream subcloning. Pfu DNA polymerase (Invitrogen) was used for high fidelity amplification. PCR parameters were as follows; anneal at $68{ }^{\circ} \mathrm{C}$, extend at $72{ }^{\circ} \mathrm{C}$ for 30 cycles. The PCR product was purified using the QIAquick PCR purification kit (Qiagen) according to the protocol supplied by the manufacturer. Utilizing EcoR I and Xma I restriction sites contained in the primers, the 720 base pair fragment containing the HIV-1 genomic segment was subcloned into the E.coli expression vector pUC18 and then transformed into Top 10F' E. coli. Plasmid DNA was harvested from E. coli cultures grown under ampicillin selection using the Wizard plus Maxi prep kit (Promega) according to the protocol supplied by the manufacturer. Plasmid DNA was linearized using Xma I, treated with RNase A, to eliminate any residual RNA, then proteinase $\mathrm{K}$ digested and phenol/chloroform extracted. This purified linear DNA was used as a template for in vitro transcription. 


\section{In vitro transcription of $\mathrm{HIV}-1$ template}

The linear DNA was in vitro transcribed and 5' capped using MAXIscript (Ambion) and Cap Analog (Ambion) according to the protocol supplied by the manufacturer. The product was then treated with DNase (Qiagen) to remove plasmid DNA. The 652 nucleotide RNA product was verified by gel electrophoresis in a formaldehyde based running buffer [104] through a $0.8 \%$ agarose gel containing ethidium bromide.

\section{Crude purification of murine aminoacyl tRNA synthetase}

Six livers from 14 week old B6 mice weighing 7.46 grams were mixed with 1.5 volumes of cold cell lysis solution containing $10 \mathrm{mM}$ Tris- $\mathrm{HCl}, 10 \mathrm{mM} \mathrm{KCl}, 2 \mathrm{mM}$ $\mathrm{MgCl}_{2}, 250 \mathrm{mM}$ sucrose and $20 \mathrm{mM}$ beta-mercaptoethanol. The livers were then homogenized on ice and the solution was ultra-centrifuged in a SW40 rotor at $100,000 \times$ $g$ for $90 \mathrm{~min}$. The supernatant was loaded onto a DEAE cellulose column $(30 \mathrm{ml}$ bed volume) equilibrated with $0.05 \mathrm{M} \mathrm{NaCl}, 1 \mathrm{mM} \mathrm{Na} 2$ EDTA, $10 \mathrm{mM} \mathrm{MgCl}$. The column was washed with 3 bed volumes of $0.25 \mathrm{M} \mathrm{NaCl}, 1 \mathrm{mM} \mathrm{Na}_{2}$ EDTA, $10 \mathrm{mM} \mathrm{MgCl}_{2}$ and eluted with $0.75 \mathrm{M} \mathrm{NaCl}, 1 \mathrm{mM} \mathrm{Na} 2$ EDTA, and $10 \mathrm{mM} \mathrm{MgCl}_{2}$. Four $\mathrm{ml}$ fractions were collected and protein concentrations were determined by spectrophotometry. Fractions with a protein concentration above $6 \mathrm{mg} / \mathrm{ml}$ were pooled. The final protein concentration of the pooled fractions was $11.75 \mathrm{mg} / \mathrm{ml}$ and frozen at $-80^{\circ} \mathrm{C}$.

\section{${ }^{32} \mathbf{P}$ single nucleotide extension}

HIV-1 genomic template (130 ng) was heat annealed to either $100 \mathrm{ng}$ of a oligonucleotide complimentary to the PBS or $250 \mathrm{ng}$ of purified tRNA using one of the three methods listed in Table 3-1. Each of the reactions was then incubated with $0.5 \mu 1$ of ${ }^{32} \mathrm{P}$ labeled dCTP [3000 Ci/mmol, $10 \mathrm{mCi} / \mathrm{ml}$ (PerkinElmer)], 3 units of HIV-1 RT (Ambion) in a buffer containing $50 \mathrm{mM}$ Tris- $\mathrm{HCl}$ (pH 8.3), $75 \mathrm{mM} \mathrm{KCL}, 3 \mathrm{mM} \mathrm{MgCl} 2$ and $5 \mathrm{mM}$ DTT. Reaction was carried out at $37{ }^{\circ} \mathrm{C}$ for $45 \mathrm{~min}$. Aliquots $(5 \mu \mathrm{l})$ of each sample were spotted on DE81 filter paper (Whatmann) and air dried. Filters were washed five times for 5 min each in $\mathrm{Na}_{2} \mathrm{HPO}_{4}$ then twice in ethyl alcohol for $2 \mathrm{~min}$ and allowed to air dry. Samples were placed in glass vials and mixed with $2 \mathrm{ml} \mathrm{of} \mathrm{H}_{2} 0$. The Cherenkov radiation was measured in a liquid scintillation counter.

\section{Aminoacylation assay and purification of tRNA}

The crude murine synthetase preparation was used to aminoacylate tRNA with ${ }^{14}$ $\mathrm{C}$ lysine. The reaction mixture contained $50 \mathrm{mM}$ Tris- $\mathrm{HCl}(\mathrm{pH} 7.5), 25 \mathrm{mM} \mathrm{KCl}, 10 \mathrm{mM}$ $\mathrm{MgCl}_{2}, 5 \mathrm{mM}$ ATP (pH 7.0), $20 \mathrm{mM} \mathrm{BME}, 0.4 \mathrm{mg}$ crude murine synthetase preparation, $1 \mathrm{mg}$ of rabbit liver tRNA (gift from Dr. Katz), and $750 \mu \mathrm{M}$ C-14 L-Lysine 322

$\mathrm{mCi} / \mathrm{mMol}$ (Perkin Elmer). As a control, a duplicate reaction was set up but did not 
Table 3-1. Optimization of primer annealment to HIV-1 genomic template. A) Heat annealing. Each of the annealing protocols was tested by heat annealing the HIV1 genomic template to either a short DNA primer matching the PBS or purified tRNA. B) ${ }^{32}$ P-labeled single nucleotide extensions by HIV-1 RT. Annealing reactions (3-1 A) were extended using ${ }^{32} \mathrm{P}$-labeled dCTP by incubation with HIV-1 RT at $37{ }^{\circ} \mathrm{C}$ for 30 min. Aliquots of each reaction were spotted on DE81 filter paper and washed five times with $\mathrm{Na}_{2} \mathrm{HPO}_{4}(\mathrm{pH} 7.5)$ then washed twice with ethyl alcohol. Radioactivity was measured using a liquid scintillation counter in counts per minute (CPM). 


\begin{tabular}{|c|c|c|}
\hline Annealing protocol A & Annealing protocol B & Annealing protocol $\mathrm{C}$ \\
\hline $\begin{array}{c}30 \mathrm{mM} \text { Tris-HCl pH } 7.5 \\
20 \mathrm{mM} \mathrm{EDTA} \\
600 \mathrm{mM} \mathrm{NaCl}\end{array}$ & $\begin{array}{c}30 \mathrm{mM} \text { Tris-HCl pH } 7.5 \\
20 \mathrm{mM} \text { EDTA } \\
600 \mathrm{mM} \mathrm{NaCl}\end{array}$ & $\begin{array}{c}83 \text { mM Tris-HCl pH } 7.5 \\
125 \mathrm{mM} \mathrm{KCl}\end{array}$ \\
\hline $\begin{array}{l}95^{\circ} \mathrm{C} \quad 3 \mathrm{~min} \\
75^{\circ} \mathrm{C} \quad 30 \mathrm{~min}\end{array}$ & $95^{\circ} \mathrm{C} \quad 3 \mathrm{~min}$ & $\begin{array}{l}85^{\circ} \mathrm{C} 3 \mathrm{~min} \\
65^{\circ} \mathrm{C} 10 \mathrm{~min}\end{array}$ \\
\hline $\begin{array}{l}\text { Return to room temp over } \\
\qquad 45 \mathrm{~min}\end{array}$ & $\begin{array}{l}\text { Return to room temp over } \\
45 \mathrm{~min}\end{array}$ & $\begin{array}{l}\text { Return to room temp over } \\
\qquad 45 \mathrm{~min}\end{array}$ \\
\hline $\begin{array}{l}\text { Ethyl alcohol precipitate / } \\
\text { resuspend in } \mathrm{H}_{2} 0\end{array}$ & $\begin{array}{l}\text { Ethyl alcohol precipitate / } \\
\text { resuspend in } \mathrm{H}_{2} 0\end{array}$ & \\
\hline
\end{tabular}

B.

Annealing method (A, B, or $\mathrm{C})$ and primer used

CPM

(A) No RT control

1936

RNA primer

2207

DNA primer

14327

(B) No RT control

3810

RNA primer

2600

DNA primer

21576

(C) No RT control

2721

RNA primer

3930

DNA primer

70100 
contain protein from the synthetase preperation. Both reactions were incubated at $30{ }^{\circ} \mathrm{C}$ for one hr. To detect aminoacylation, $2 \mu \mathrm{l}$ aliquots were spotted on $\mathrm{GF} / \mathrm{C}$ filter paper (Whatmann) and immediately soaked in cold 10\% TCA for ten min. Filters were washed three times in cold 10\% TCA and a final wash in cold absolute ethanol, all washes were 10 min. Filters were then dried and placed in Ecoscint XR scintillation solution (national diagnostics) and radioactivity was determined using a liquid scintillation counter. Radio labeled aminoacyl-tRNA was purified by applying to a DEAE-cellulose column ( $3 \mathrm{ml}$ bed volume). Column and sample were equilibrated, washed, and eluted with the same buffers used in crude purification of murine Aminoacyl tRNA synthetase protocol described above. The eluate $(\sim 8 \mathrm{ml})$ was mixed with 2.5 volumes ethyl alcohol, incubated $1 \mathrm{hr}$ at $-20^{\circ} \mathrm{C}$ and centrifuged at $3000 \times g$ for $25 \mathrm{~min}$. Pellet was resuspended in $100 \mu \mathrm{l}$ of Diethyl pyrocarbonate treated $\mathrm{dH}_{2} \mathrm{O}$. This radiolabeled tRNA could then be heat annealed to the HIV-1 genomic template.

\section{Annealing tRNA to HIV-1 genomic template}

$200 \mu \mathrm{g}$ of C-14 aa-tRNA was incubated with $8 \mu \mathrm{g}$ of HIV-1 genomic RNA template at $95^{\circ} \mathrm{C}$ for $2 \mathrm{~min}$ then placed on ice for $2 \mathrm{~min}$. The reaction was then incubated at $75^{\circ} \mathrm{C}$ for $20 \mathrm{~min}$ in a buffer containing $20 \mathrm{mM} \mathrm{KAc}$ (pH 5.6). Next $5 \mathrm{mM} \mathrm{MgCl}_{2}$ was added and the reaction was allowed to return to room temperature.

\section{Deaminoaclyation assay of ${ }^{14} \mathrm{C}$-labeld tRNA ${ }^{\text {Lys3 }}$}

The annealed primer/template was mixed with a buffer to bring the final concentration of the reaction to $50 \mathrm{mM}$ Tris- $\mathrm{HCl}$ ( $\mathrm{pH} 8.3$ ), $75 \mathrm{mM} \mathrm{KCl}, 3 \mathrm{mM} \mathrm{MgCl}_{2}$, and 5 mM DTT. Either 25 units HIV-1 RT (Ambion) or AMV RT (NEB) was added and the mixture incubated at $37^{\circ} \mathrm{C}$. As a control, RT that had been heat inactivated for 30 min at $95{ }^{\circ} \mathrm{C}$ was added to a separate reaction. Over time aliquots were removed and spotted on GF/C filter paper (Whatmann) and immediately soaked in cold 10\% TCA for ten min. Filters were washed three times in cold 10\% TCA and a final wash in cold absolute ethanol, all washes were $10 \mathrm{~min}$. Filters were then dried and placed in Ecoscint XR scintillation solution (National Diagnostics) and radioactivity was measured using a liquid scintillation counter.

\section{RT-PCR of HIV-1 genomic template}

One hundred ng of HIV-1 genomic transcript was reverse transcribed using 1 unit of HIV-1 RT (Ambion), $20 \mathrm{mM}$ dNTPs (Invitrogen) in a buffer containing $50 \mathrm{mM}$ Tris$\mathrm{HCl}$ (pH 8.3), $75 \mathrm{mM} \mathrm{KCl}, 3 \mathrm{mM} \mathrm{MgCl}$ and $5 \mathrm{mM}$ DTT. Reaction was carried out using either $100 \mathrm{ng}$ of an 18 nucleotide DNA primer matching the HIV-1 PBS or a $3 \mu \mathrm{g}$ mixture of purified calf liver tRNA containing the natural primer tRNA ${ }^{\text {Lys3 }}$ to test the HIV-1 genomic construct. RT PCR parameters were $45{ }^{\circ} \mathrm{C}$ for $30 \mathrm{~min}$. Then DNA product was then amplified using PCR by adding 2.5 U of PFU Turbo DNA polymerase 
(Stratagene), $20 \mathrm{mM}$ fresh dNTPs, $100 \mathrm{ng}$ of each primer U3 (5'

CTGGTTAGACCAGATCTGAGC) and the PBS (5'GTCCCTGTTCGGGCGCCA). PCR parameters were $95^{\circ} \mathrm{C}$ for 2 min then 25 cycles $\left(95^{\circ} \mathrm{C}\right.$ for $30 \mathrm{sec}, 57^{\circ} \mathrm{C}$ for $30 \mathrm{sec}$, $72{ }^{\circ} \mathrm{C}$ for $1 \mathrm{~min}$ ). The expected 192 base pair product was electrophoresed at 90 volts in a $0.8 \%$ agarose gel containing ethidium bromide.

\section{Cell lysate}

On ice, $1 \times 10^{6}$ cells were incubated with cold NP-40 lysis buffer (1\% NP-40, 50 $\mathrm{mM}$ Tris [pH 8.8], $150 \mathrm{mM} \mathrm{NaCl}$ ) containing protease inhibitor cocktail (1:25; Sigma P8340) for 20 minutes. Cells were scraped off the dish and centrifuged (Eppendorf 5415C centrifuge) for $10 \mathrm{~min}, 4^{\circ} \mathrm{C}$, at $14,000 \mathrm{rpm}$ to remove nuclei and cell. Lysates were treated with $10 \% \operatorname{SDS}(0.1 \%$ [final] $)$ and stored at $-80{ }^{\circ} \mathrm{C}$ prior to SDS-PAGE separation.

\section{Western blot analysis of HINT1 and hPth2}

Fifteen $\mu 1$ of $200 \mathrm{X}$ recombinant HIV-1 virus pellet (gift from John Gray, St Jude Children's Research Hospital), seven $\mu$ l of 293 cell lysate, and seven $\mu 1$ of crude sythetase preperation $(12 \mathrm{mg} / \mathrm{ml})$ were mixed 1:1 with $2 x$ loading buffer [104], boiled for $10 \mathrm{~min}$, chilled on ice, then electrophoresed through a $10-20 \%$ SDS polyacrylamide gel (Invitrogen) and transferred to a nitrocelluose membrane (Protran, Schleicher and Schuell). The membrane was cut in half at the $15 \mathrm{kDa}$ molecular mass marker, blocked for $2 \mathrm{hrs}$ in $6 \%$ dry milk, and $2 \%$ Tween 20 , then the top half was incubated for the histidine triad nucleotide binding protein 1 (HINT1) using mouse anti-HINT1 (1:1000, Genway), The bottom was probed for human peptidyl tRNA hydrolase 2 (hPth2) with chicken Affi-anti CGI-147 IgY (1:500 Abnova) over-night. Primary antibody HINT1 was detected by incubation with goat anti-mouse antibody conjugated to horseradish peroxidase $(1: 10,000)$ for 45 min followed by incubation with Super Signal West Pico Chemiluminescent Substrate (Pierce). Primary antibody, Affi-anti CGI-147 IgY was detected by incubation with anti-chicken antibody conjugated to horseradish peroxidase $(1: 50,000)$ for 45 min followed by incubation with ECL Chemiluminescent Substrate (Amersham).

\section{Results}

\section{Putative active site}

To identify possible hydrolase sites on the RT enzyme the typical catalytic triad found in hydrolases (nucleophile [serine], an acid [aspartic acid], and a basic [histidine] residue [105]) served as a guide for what types of residues to identify. To better understand the size and orientation of a hydrolase active site, the crystal structure of human Pth2 was analyzed [106]. AMV RT would have been the ideal protein to 
investigate, given it is a RT that displays hydrolase activity, however the crystal structure has not been solved. By examining the crystal structure of HIV-1 RT [107] in MBT [108], a practical hydrolase active site was located (Figure 3-1A). The site contains the necessary catalytic residues (Serine, Aspartate, and Lysine) to form a possible active site. The residues are in the correct formation and distance apart (Figure 3-1B) when compared to the active site in hPth2. A protein sequence alignment of HIV-1 RT (1HYS_A)and AMV RT [109] performed using Expasy illustrated that these same residues in HIV-1 RT were conserved in AMV RT (Figure 3-2). Using the protein sequence alignment of the two enzymes a theoretical structure of AMV-RT was created using Swiss-Model and the same active site located (Figure 3-3). Based on the computergenerated model, the same three residues occur in a similar location to that of the HIV-1 RT.

\section{Sub cloning and in vitro transcription of HIV-1 genomic segment}

Polymerase chain reaction (PCR) was used to amplify nucleotides 1-652 of the HIV-1 genome from pLL3.7 a lentiviral expression plasmid. This genomic template (Figure 3-4A) contains all of the known interactions between the tRNA ${ }^{\text {Lys3 }}$ and the HIV-1 genome. Utilizing EcoR I and Xma I restriction sites contained in the primers, a fragment containing the HIV-1 genomic segment was cloned into the E.coli expression vector pUC18 and its identity confirmed by sequencing. The SP6 RNA polymerase promoter site was also included in the primer design which resulted in the first nucleotide transcribed being nucleotide 1 of the HIV-1 genome. Plasmid DNA was linearized using Xma 1 and the linear DNA was in vitro transcribed using the SP6 enzyme. The RNA product 652 nucleotides long (Figure 3-4B) was verified by gel electrophoresis. Due to the different properties between RNA and DNA, the transcript migrates slightly faster than expected when compared to the DNA size ladder. To determine if the transcripts were indeed functional, they were tested in RT reactions using either a short DNA primer or tRNA primer matching the PBS (Figure 3-4C).

\section{Optimization of the heat-annealing method of primer tRNA association with a genomic template}

Both the PBS contained within the U5 region of the HIV-1 genome and the tRNA possess large amounts of secondary structure [110,111]. In order for priming to take place both the tRNA and the genomic template must undergo partial unfolding. There are two established methods used to accomplish this unfolding. The first is the use of the viral nucleocapsid [112], which is thought to cause continuous melting and reannealing so that nucleic acids are able to undertake different conformations allowing them to find the most stable state [113]. The second mechanism for annealing tRNA to viral different conformations as they cool. Maximum annealing is important due to the poor level of priming observed by tRNA when compared to short 18 bp DNA or RNA primers in vitro [114]. In order to increase the efficiency of future experiments it was important to optimize the annealing procedure. Three different annealing protocols were tried 
Figure 3-1. Potential hydrolase site in HIV-1 RT. A) Crystal structure viewed in MBT Protein Workshop [115] of HIV-1 RT in complex with polypurine tract DNA:RNA template [107]. Potential hydrolase site residues are space filled and labeled. B) Closer view of the HIV-1 RT, active site residues are red and space filled. Catalytic triad of potential active site residues are purple, space filled, and distance between them measured in angstroms. 
A.

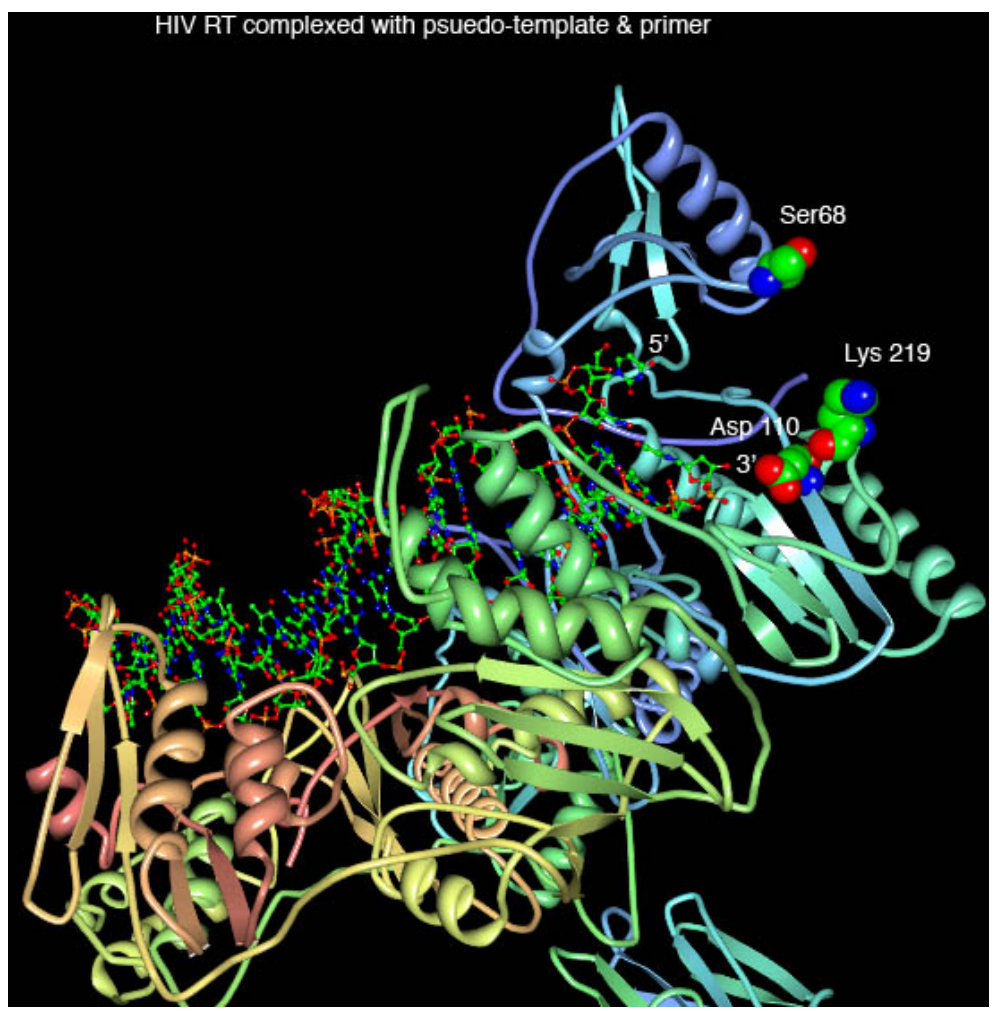

B.

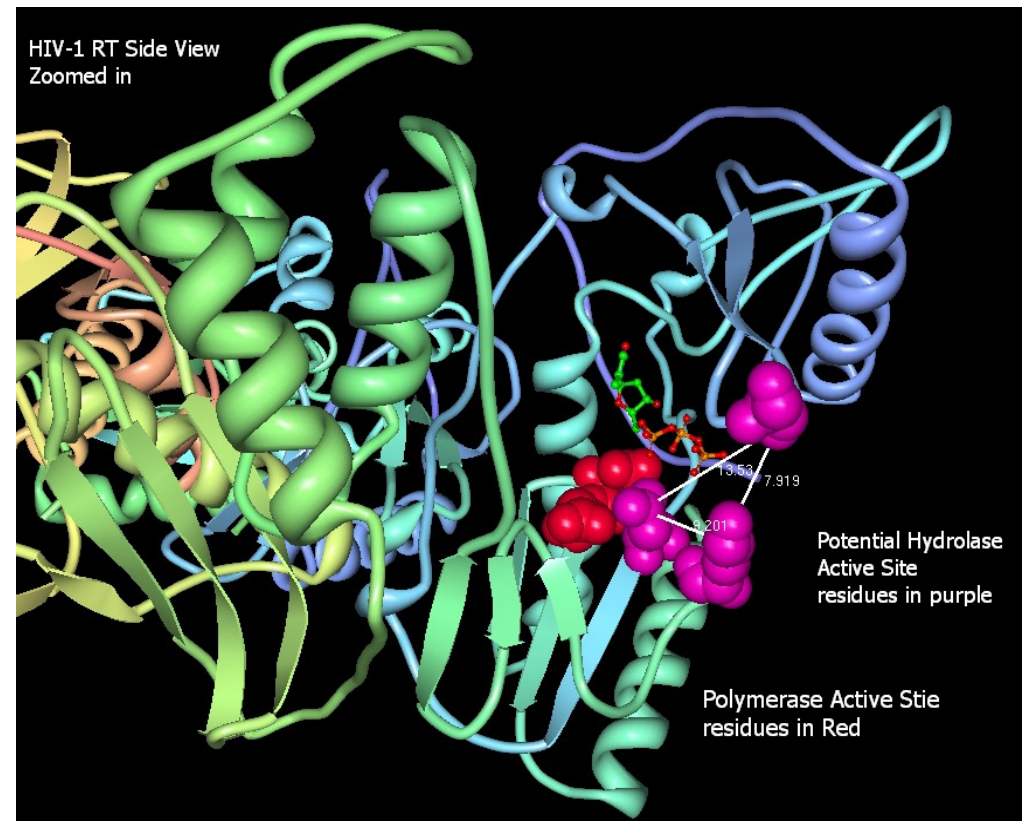




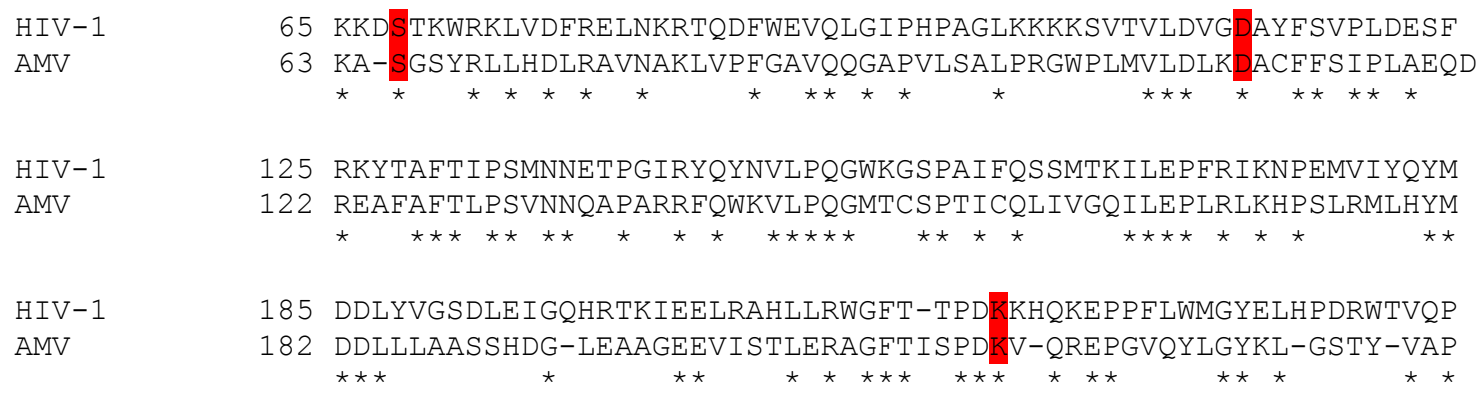

Figure 3-2. Sequence alignment of HIV-1 RT and AMV RT. Protein sequence alignment of HIV-1 RT and AMV RT using EXpasy pairwise alignment program. Potential active site residues are indicated in red. 


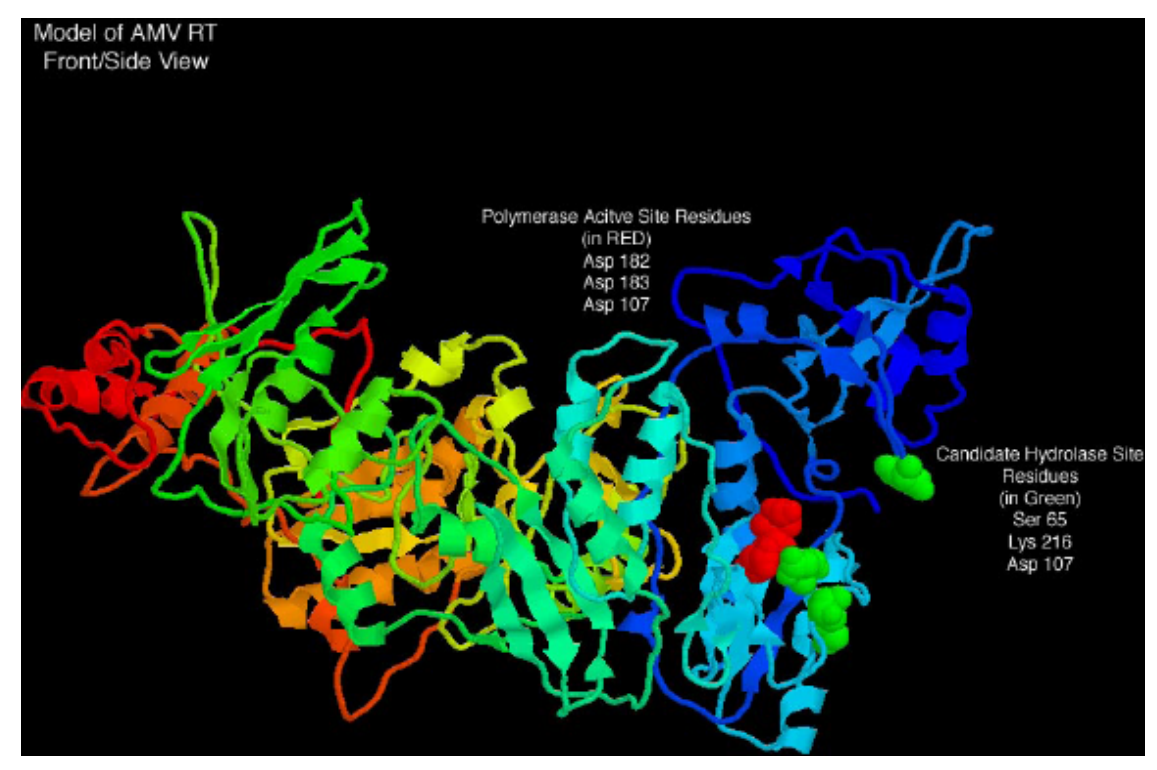

Figure 3-3. Potential hydrolase site within model of AMV-RT. Computer generated model of AMV RT created by Swiss Model and viewed in RasMac. Polymerase active site residues are spaced filled and red, potential hydrolase active site residues are space filled and represented in green. 
A.

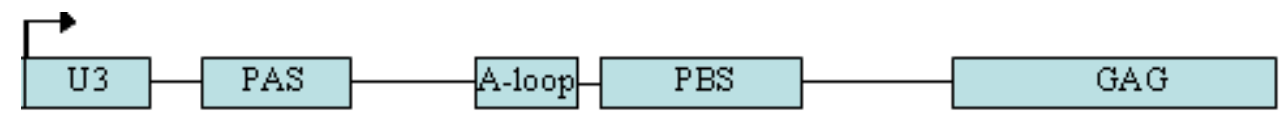

B.

HIV RNA template

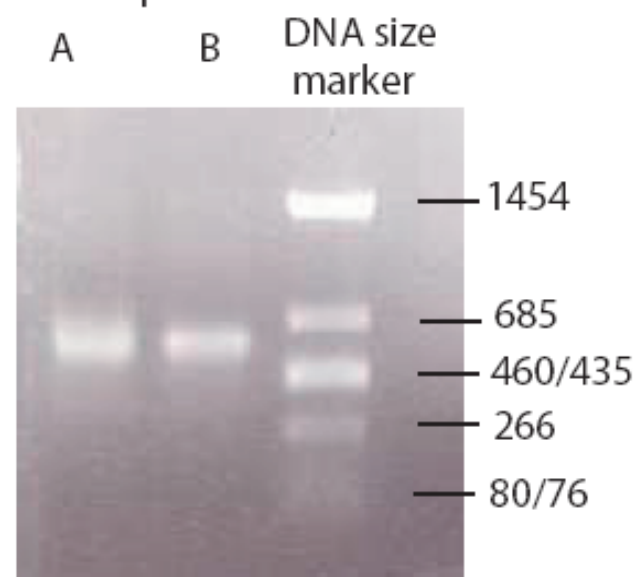

C.

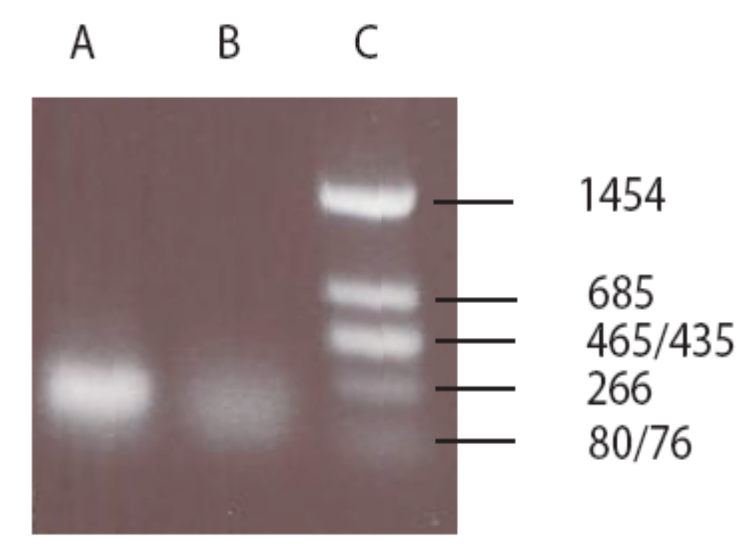

Figure 3-4. 652 nucleotide RNA transcript of HIV-1 genomic template. A) Schematic of the RNA transcript produced by the SP6 enzyme. It consists of nucleotides 1-652 of the HIV-1 genome (NC-001802) and contains the unique 3' sequence (U3), the primer activation site (PAS), the A rich sequence (A-loop), the primer binding site (PBS) and approximately 330 nucleotides of the Gag polyprotein. B) Gel electrophoresis of RNA prouduced from in vitro transcription reactions. Lanes A and B are $5 \mu 1$ from $20 \mu 1$ in vitro transcription reactions, lane $\mathrm{C}$ is $1 \mu \mathrm{g}$ of DNA ladder. Aliquots $\mathrm{A}$ and $\mathrm{B}$ were heated to $95^{\circ} \mathrm{C}$ for 2 minutes then loaded onto a $0.8 \%$ agarose gel containing ethidium bromide. Samples were electrophoresed at 90 volts in a formaldehyde based running buffer. C) RT-PCR of the in vitro transcription product. $100 \mathrm{ng}$ of HIV-1 genomic transcript were reverse transcribed by HIV-1 RT using either a 18 nucleotide DNA primer matching the PBS (lane A) or tRNA ${ }^{\text {Lys3 }}$ (lane B). DNA products were amplified by PCR using DNA primers matching the sequence in the U3 and the PBS. The expected 192 base pair product was electrophoresed at 90 volts in a $0.8 \%$ agarose gel containing ethidium bromide beside a 1 ug DNA ladder (lane C). 
(Table 3.1A). They were tested by measuring the amount radioactivity detected in ${ }^{32} \mathrm{P}-$ labeled dCTP single nucleotide extensions by HIV-1 RT (Table 3-1B).

\section{Crude purification of synthetases and aminoacylation of tRNA}

There are 20 different Aminoacyl-tRNA synthetases (aaRS). Each aaRS is capable of charging all of its cognate tRNAs and can discriminate from all other tRNAs with great efficiency [116]. In order to perform key deaminoacylation experiments with RT, tRNA ${ }^{\text {Lys3 }}$ needed to be charged with ${ }^{14} \mathrm{C}$ Lysine using the lysyl-tRNA synthetase (LysRS). Synthetase proteins were partially purified from the livers of 14 week old B6 mice. Homogenate from the livers was ultracentrifuged and the supernatant was further purified based on charge using a DEAE cellulose column. The column fractions were analyzed by spectrophotometry and fractions containing over $5 \mathrm{mg} / \mathrm{ml}$ were pooled (Figure 3-5). To insure the crude synthetase preperation still maintained activity after the purification process it was tested by charging tRNA with ${ }^{14} \mathrm{C}$ Lysine (Figure 3-6). The reaction which contained the synthetase preperation yielded high levels of charged tRNA when compared to the same reaction which did not contain the synthetase preperation.

\section{Deaminoacylation of lys-tRNA ${ }^{\text {Lys }}$ by HIV-1 RT and AMV RT}

Based on the structural data it appeared that HIV-1 RT had a possible hydrolase site in the expected region. The hypothesis that HIV-1 RT had hydrolase activity was tested. When ${ }^{14} \mathrm{C}$ Lys-tRNA ${ }^{\text {Lys }}$ that was heat annealed to the HIV-1 genomic template is incubated with HIV-1 RT, the loss of radioactivity observed is roughly equal to that of the heat inactivated control (Figure 3-7). The decrease in radioactivity signifies the population which becomes deaminoacylated. The control sample, which contains heatinactivated HIV-1 RT, represents the in vitro rate of the spontaneous deaminoacylation of ${ }^{14}$ C Lys-tRNA ${ }^{\text {Lys }}$. The presence of HIV-1 RT does not increase the deaminoacylation rate and therefore does not appear to have hydrolase activity. However, the limitations of this assay permit any definitive conclusions. The rate of spontaneous deaminoacylation of tRNA ${ }^{\text {Lys }}$ in vitro observed in the control (Figure 3-7 and Figure 3-8) is very high. It therefore possible that HIV-1 RT does have a low level of hydrolase activity but is being masked by the high level of spontaneous deaminoacylation.

AMV RT on the other hand has been shown to contain hydrolase activity when incubated with its own genomic RNA annealed to ${ }^{14} \mathrm{C}$ Trp-tRNA ${ }^{\text {Trp }}$. Is this hydrolase activity specific to its own primer tRNA or is it capable of hydrolyzing Lys-tRNA ${ }^{\text {Lys3 }}$ as well? To analyze this question, AMV RT was incubated with Lys-tRNA ${ }^{\text {Lys }}$ that was heat annealed to the HIV-1 genomic template (Figure 3-8). AMV RT, unlike many other RTs, is capable of initiating reverse transcriptase on an HIV-1 genome using tRNA ${ }^{\text {Lys }}$ as a primer [117]. However, based on the results of this experiment, it does not appear that AMV RT is capable of deaminoacylating Lys-tRNA ${ }^{\text {Lys }}$. The rate of spontaneous deaminoacylation is high but is not increased with the addition of AMV RT. 


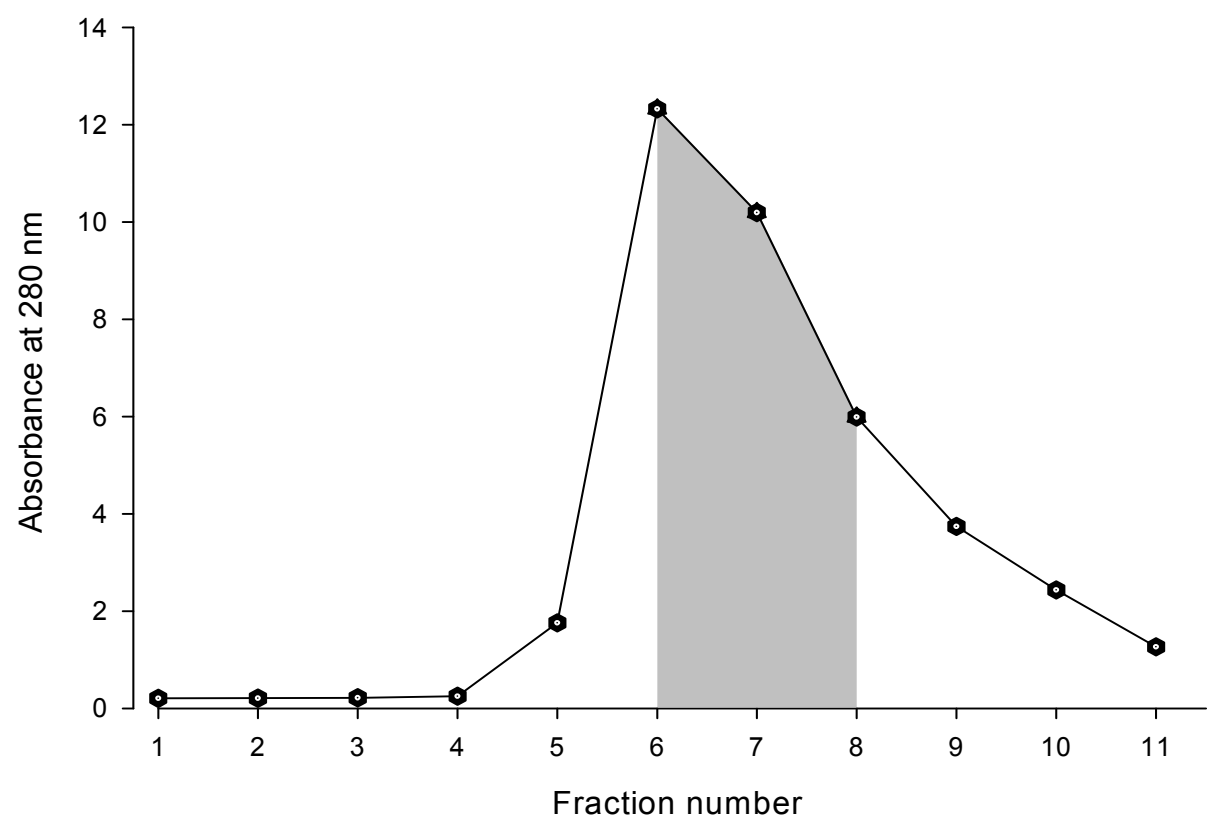

Figure 3-5. Collection of crude murine aminoacyl-tRNA synthetase. $20 \mathrm{ml}$ of murine liver homogenate was ultra centrifuged at $100,000 \times g$ for $90 \mathrm{~min}$. Supernatant was loaded onto a DEAE cellulose column. Four $\mathrm{ml}$ fractions were collected and their absorbance at $280 \mathrm{~nm}$ was measured. Fractions with high $280 \mathrm{~nm}$ absorbance, indicated by grey shaded region, were pooled together for aminoacylation reactions. 


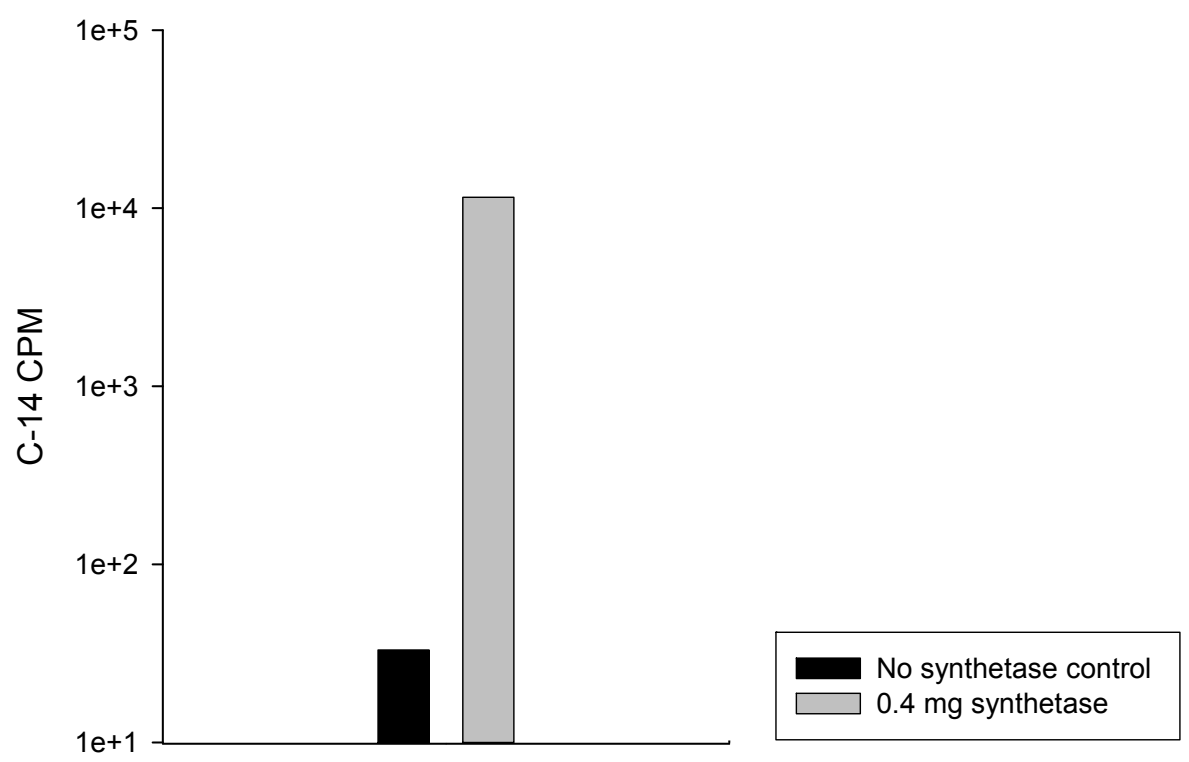

Figure 3-6. Aminoacylation of rabbit tRNA lysine by crude murine aminoacyltRNA synthetase. Crude murine aminoacyl-tRNA synthetase preperation was tested for aminoacylation activity. Two $400 \mathrm{ml}$ reactions both containing $3 \mu \mathrm{Ci}$ of $\mathrm{C}-14$ labeled lysine, and $1 \mathrm{mg}$ of rabbit tRNA were set up. The first reaction, indicated by the black bar, did not contain the aminoacyl-tRNA synthetase. The second reaction, indicated by the grey bar, contained $0.4 \mathrm{mg}$ of the aminoacyl-tRNA synthetase. Both reactions were incubated at $30{ }^{\circ} \mathrm{C}$ for one hour. $2 \mu$ from each reaction was spotted on whatman $\mathrm{GF} / \mathrm{C}$ filter paper and soaked in cold 10\% TCA (trichloroacetic acid). Filters were washed in $10 \%$ TCA and radioactivity counted using a liquid scintillation counter. 


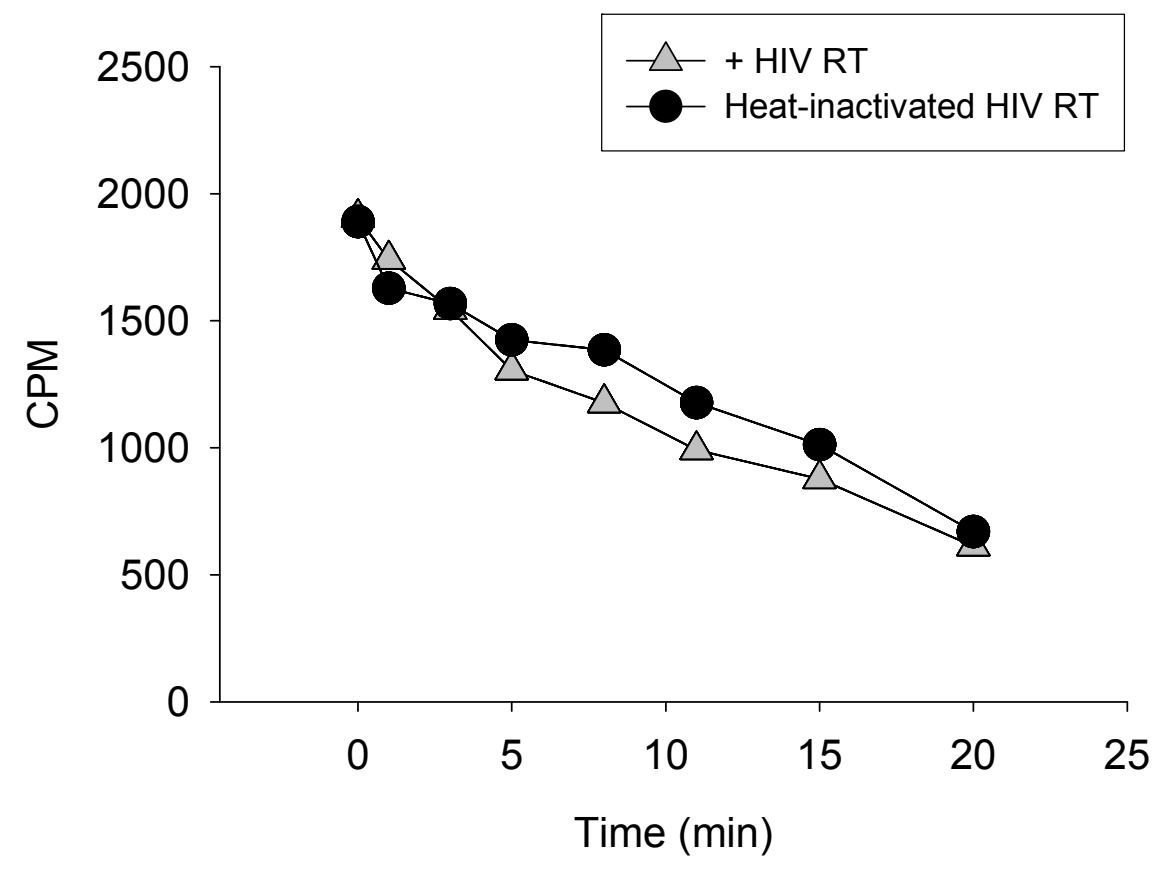

Figure 3-7. Deacylation of ${ }^{14} \mathrm{C}$-labeled Lys-tRNA ${ }^{\text {Lys }}$ by $\mathrm{HIV}-1$ reverse transcriptase. $50 \mu 1$ reactions containing $50 \mathrm{mM}$ Tris- $\mathrm{HCl}\left(\mathrm{pH} 8.3\right.$ ), $75 \mathrm{mM} \mathrm{KCl}, 3 \mathrm{mM} \mathrm{MgCl}_{2}, 5 \mathrm{mM}$ DTT and 250 ng of HIV-1 genomic RNA template annealed with ${ }^{14} \mathrm{C}$ Lys-tRNA ${ }^{\text {Lys }}$. Reactions either contained $25 \mathrm{U}$ of HIV-1 RT or $25 \mathrm{U}$ of heat inactivated HIV-1 RT. Reactions were incubated at $37{ }^{\circ} \mathrm{C}$ and stopped at various time points by the addition of cold $10 \%$ TCA. Aliquots were spotted onto nitrocellulose membranes, washed, and counted via liquid scintillation counter. 


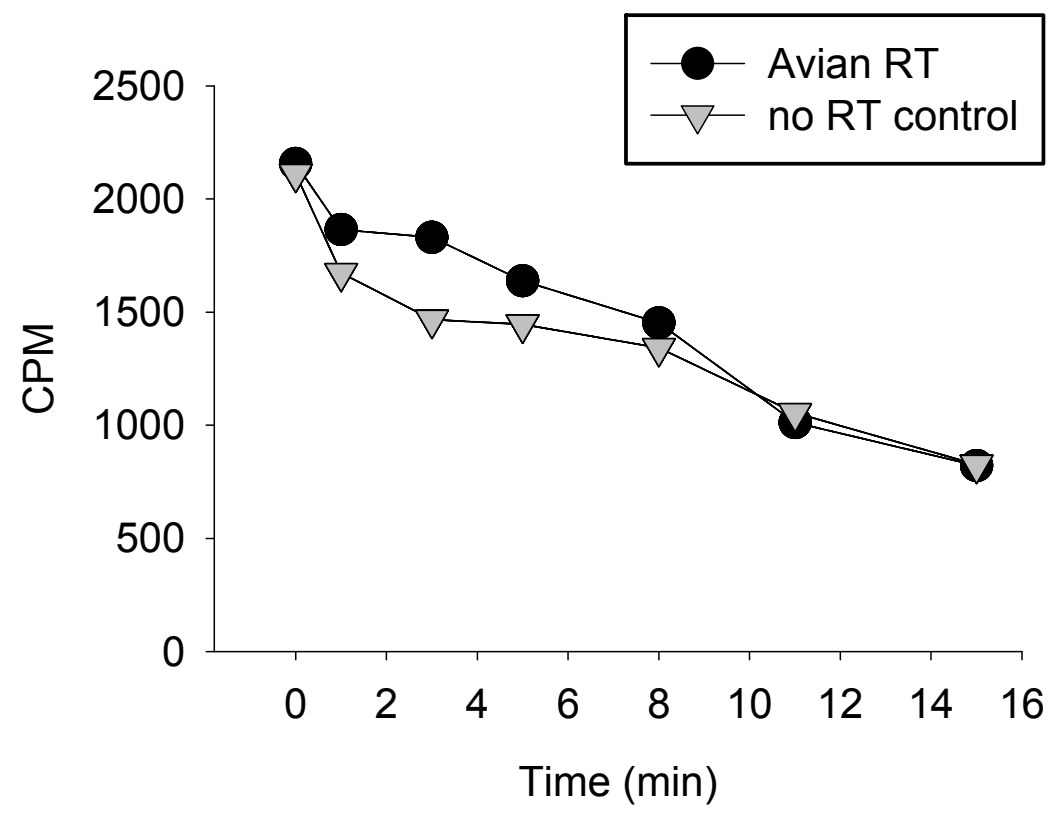

Figure 3-8. Deacylation of ${ }^{14} \mathrm{C}$-labeled Lys-tRNA ${ }^{\text {Lys }}$ by $\mathrm{AMV}$ reverse transcriptase. $50 \mu 1$ reactions containing $50 \mathrm{mM}$ Tris- $\mathrm{HCl}\left(\mathrm{pH} 8.3\right.$ ), $75 \mathrm{mM} \mathrm{KCl}, 3 \mathrm{mM} \mathrm{MgCl}_{2}, 5 \mathrm{mM}$ DTT and 250 ng of HIV-1 genomic RNA template annealed with ${ }^{14}{ }^{14}$ Lys-tRNA ${ }^{\text {Lys }}$. Reactions were carried out either $+/-25$ U of AMV RT. Reactions were incubated at 37 ${ }^{\circ} \mathrm{C}$ and stopped at various time points by the addition of cold $10 \%$ TCA. Aliquots were spotted onto nitrocellulose membranes, washed, and counted via liquid scintillation counter. 


\section{Detection of cellular proteins within recombinant HIV-1}

An alternative possibility for deaminoacylation of the HIV-1 primer tRNA could cellular proteins. I examined the possibility that a cellular protein may be recruited into the virion to carry out this function. Based on the literature, HINT1 and hPth2 were two candidate of cellular proteins that may have roles in the aminoacylation and deaminoacylation process. HINT1 is a cellular protein which has an array of functions including interaction with LysRS to form charged Lys-tRNA ${ }^{\text {Lys }}$ [118]. Its role is to hydrolyze the AMP that is linked to lysine during the first step of the charging reaction. To determine the presence of HINT1 in recombinant HIV-1 (gift from John Gray), the virus was lysed and incubated using antibodies specific for HINT 1 (Figure 3-9). The result was that the $13.9 \mathrm{kDa}$ HINT1 was not present in the HIV-1 recombinant pellet but was present in the positive controls, which were lysate from a 293 cell line and protein from the crude murine synthetase preperation.

hPth2, also called Bcl-2 inhibitor of transcription 1 (Bit1), displays excellent hydrolase activity against Lys-tRNALys [106]. It plays a critical role in cellular protein synthesis by freeing up tRNA that is bound to proteins which have not been fully translated [119]. Given this proteins ability to hydrolyze the bond between a tRNA and its amino acid chain, it was an excellent candidate for deaminoacylation of the primer tRNA within HIV-1. Its presence was confirmed by performing western blot analysis on the recombinant HIV-1 pellet with antibodies specific to hPth2 (Figure 3-10).

\section{Discussion}

\section{Retroviruses evolved different mechanisms to obtain deaminoacylated primer tRNAs}

Given the intense interaction between HIV-1 RT with tRNA ${ }^{\text {Lys }}$ during recruitment [84-87] and the evidence that AMV RT deaminoacylates its primer tRNA [100], HIV-1 RT seemed a very likely candidate to carry out the deaminoacylation step. Examination of its crystal structure led to the identification of a possible hydrolase site. When the catalytic activity of this site was tested, the evidence showed that HIV-1 RT did not increase the rate of deaminoacylation over that of the rate of spontaneous deaminoacylation. I interpret this result to indicate that HIV-1 RT was not capable of deaminoacylating its primer tRNA at a rate that exceeds spontaneous loss of the amino acid. AMV RT is able to deaminoacylate $50 \%$ of trp-tRNA ${ }^{\text {Trp }}$ within 10 min [100]. If HIV-1 RT were able to deaminoacylate its primer tRNA at a rate similar to AMV RT we would expect to observe a decrease in the total amount of radioactivity that exceeded the spontaneous loss. A decrease would be most apparent at the later time points when compared to the control. However, the total amount of acid-precipitable radioactivity is the same as the control after 15 minutes (Figure 3.7). I interpret this as evidence that HIV-1 probably uses an alternative mechanism to deaminoacylate tRNA ${ }^{\text {Lys } 3}$. The use of another mechanism by HIV-1 would indicate that retroviruses have evolved different 


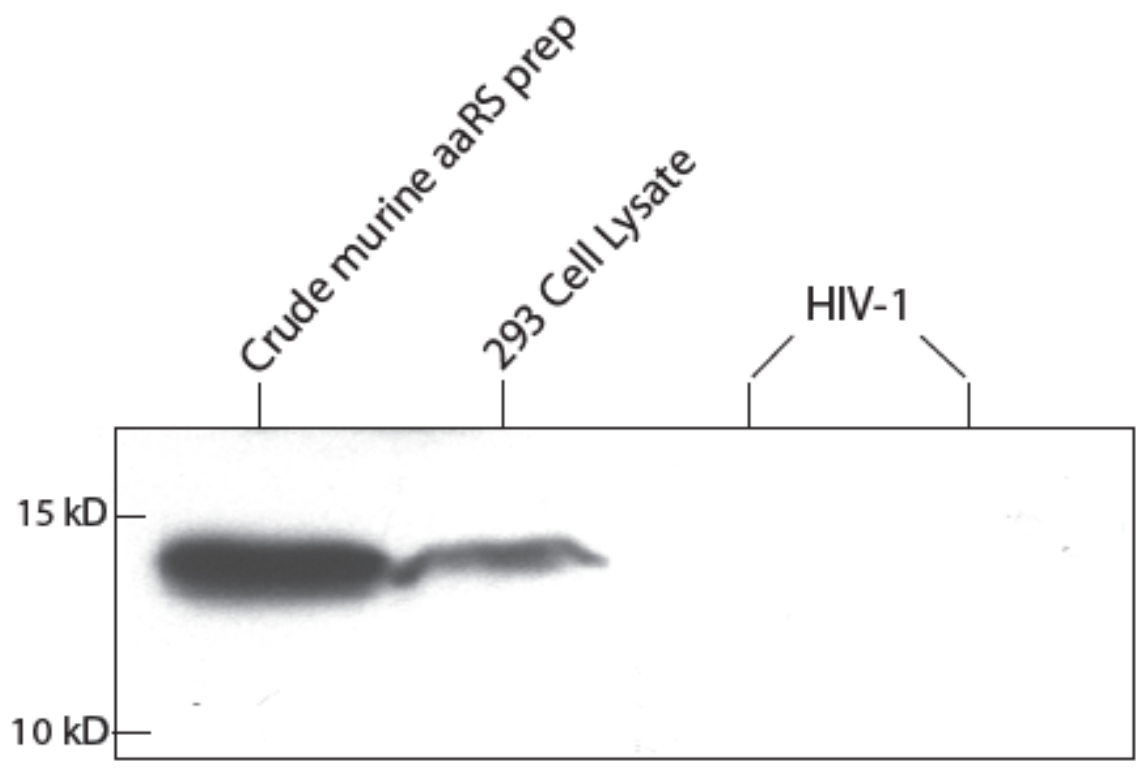

Figure 3-9. Absence of HINT1 from recombinant HIV-1. Samples were separated via $10-20 \%$ SDS-PAGE and transferred to a nitrocellulose a membrane. Membrane was incubated with HINT1 polyclonal antibody. 


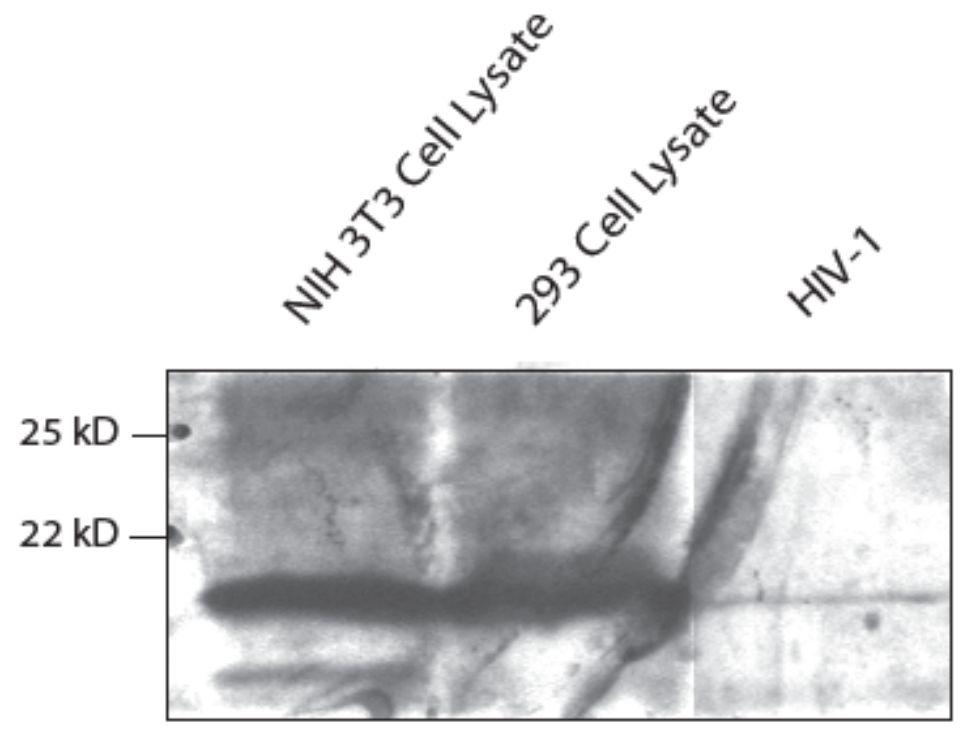

Figure 3-10. hPTH2 in recombinant HIV-1 virions. Samples were separated via 10$20 \%$ SDS-PAGE and transferred to a nitrocellulose a membrane. Membrane was incubated with Affi-anti CGI-147 IgY antibody. 
ways to accomplish this common goal of primer deaminoacylation. These results, however, do not rule out the possibility that HIV-1 RT has a low level of hydrolase activity towards tRNA ${ }^{\text {Lys3 }}$. To better understand the process of primer deaminoacylation by retroviruses further experiments should be carried out. The sensitivity of the assay needs to be improved, specifically by achieving a lower level of spontaneous deaminoacylation of lys-tRNA ${ }^{\text {Lys }}$. This could be accomplished by lowering the $\mathrm{pH}$ of the reaction. Multiple reactions could be set up, each one having a slightly lower $\mathrm{pH}$ then the other. It should be noted that going below a certain $\mathrm{pH}$ will inactivate the HIV-1 polymerase activity and might similarly inhibit the hydrolase activity.

Currently, the mechanism for deaminoacylation of tRNA ${ }^{\text {Pro }}$ by MoMLV is unknown. Since deaminoacyation by the AMV RT enzyme is the only established mechanism, it remains the most likely candidate in other retroviruses as well. Similar experiments could be carried out using the RT of MoMLV. MoMLV genomic RNA could be harvested from virus productions. Purified tRNA, ${ }^{14} \mathrm{C}$-labeled proline, and purified MoMLV RT are commercially available. Using protocols described in this chapter MoMLV RT could be tested to determine its ability to deaminoacylate its primer tRNA. Other aa-tRNAs have shown lower in vitro rates of spontaneous deaminoacylation then Lys-tRNA ${ }^{\text {Lys }}$ displayed. Therefore, this assay may be more sensitive when using different aa-tRNAs.

\section{AMV-RT shows specificity towards tRNA ${ }^{\text {Trp }}$}

Specific conformations and interactions occur between tRNA ${ }^{\text {Lys3 }}$, the HIV-1 genome, RT, and nucleocapsid, which allow priming and initiation of reverse transcription to take place $[117,120-122]$. It has been shown that AMV RT, unlike many other retroviral RTs (including FIV, EIAV and MLV), is capable of initiating reverse transcription of the HIV-1 genome using its cognate primer tRNA ${ }^{\text {Lys3 }}$. However, AMV RT was not able to increase the rate of deaminoacylation over the background levels of spontaneous deaminoacylation of noncognate $t R N A^{\text {Lys }}$. The rate of deaminoacylation of the cognate $\mathrm{RRNA}^{\mathrm{Trp}}$ by AMV RT is about $50 \%$ in $15 \mathrm{~min}$ [100]. Given this high rate, if AMV RT were capable of recognizing tRNA ${ }^{\text {Lys }}$ as efficiently as its cognate tRNA, a higher level of deaminoacylation would be observed in the presence of RT. From the data, it appears thus far that the hydrolase activity demonstrated by AMV RT is specific to tRNA ${ }^{\text {Trp }}$. This study was limited in that it only tested AMV RT's ability to prime one other retroviral genome. AMV can only deaminoacylate its own primer tRNA when the tRNA is bound to the genome. Due to the specific conformations formed when a tRNA interacts with a retroviral genome it would be interesting to determine if AMV RT could deaminoacylate its cognate tRNA when it is bound to a foreign genome. To test this, the genomes of other avian viruses including Rous sarcoma virus would be used; it utilizes the same primer as AMV. ${ }^{14} \mathrm{C}$-Trp-tRNA ${ }^{\text {Trp }}$ would be heat annealed to this genome and incubated with AMV RT. The rate of deaminoacylation would be compared to the same reaction containing heat inactivated AMV-RT. The data gained from this experiment would provide information about the influence of interactions between $\mathrm{tRNA}^{\mathrm{Trp}}$ and a different genome on deaminoacylation. If the interactions sites between the genome and 
tRNA $^{\text {Trp }}$ are similar, the orientation of AMV RT should also be similar and therefore be able to deaminoacylate the primer. However, if there are alternate interaction sites between the genome and primer, this could change the conformation of the entire RT:genome:tRNA complex and therefore AMV RT would most likely not be able to deaminoacylate tRNA ${ }^{\text {Trp }}$.

\section{The presence and absence of cellular proteins from recombinant HIV-1}

The absence of HINT1 from HIV-1 lentiviral vectors suggests that it does not play a role in the deaminoacylation process within the virion. Its absence however does provide other clues to the recruitment of LysRS into the HIV-1 virion. Many labs have shown recruitment of LysRS to the HIV-1 virion but the origin and type of LysRS remains a heated debate. There are two forms of LysRS, a mitochondrial and a cytoplasmic, that result from an alternative splice of the same gene [158]. The two forms which share 576 identical amino acid residues differ only at their amino terminus [124, 159]. The LysRS present in virions does not seem to originate from any of the identified steady-state cellular compartments, which include the cytoplasmic high molecular weight aaRS complex, nuclei, and cell membrane $[83,123]$. Some investigators believe the source to be the mitochondrial form [124] while others believe newly synthesized LysRS [123] is the source. Recently HINT1 has been isolated from complexes containing LysRS and appears to function in part to regulate the catalytic activity of LysRS [118]. Given their close interaction, both physically and chemically, it is likely that many forms of the LysRS would be found in association with HINT1. The absence of HINT1 from HIV-1 virions may provide clues as to which source of LysRS the virus recruits. By isolating and testing the different sources of LysRS it would be possible to determine which sources are associated with HINT1. The sources of LysRS that do not contain HINT1 will probably not be recruited by HIV-1.

The presence of hPth2 with the recombinant HIV-1 virion is very exciting. The role of this protein within HIV-1 is currently unknown. Due to its cellular function, it instantly becomes a candidate in the role of deaminoacylation of the primer tRNA ${ }^{\text {Lys3 }}$. Given the nature of retroviruses, it is possible that this protein is not specifically recruited but simply taken up by the virus as it buds from the cell and may have absolutely no role in viral replication. The low levels detected within the virion seem to suggest this may indeed be the case. To examine if hPth2 has any role in HIV-1 replication, HIV-1 should be produced from cells containing reduced amounts of hPth2. To accomplish this siRNAs directed against hPth 2 could be used. Western blot analysis of these cells would be needed to determine if the siRNA effectively downregulated hPth2. HIV-1 could be produced from these cells and its infectivity compared to that of HIV-1 produced from hPth2 positive cells. 


\section{Chapter 4. Increasing MoMLV Envelope Gene Expression}

\section{Introduction}

One method of producing recombinant replication deficient MoMLV is the threeplasmid system. The gag and pol genes are expressed from the pcDNA-MoMLV Gag/Pol plasmid and env gene is expressed from the pcDNA-MoMLV Env plasmid. These plasmids are provided exogenously through transient transfection. The third plasmid, which acts as the viral genome, is provided from within the cell. The producer cell line, termed H1-BAG, is a human embryonic kidney 293 cell line that contains an integrated copy of the pBAG plasmid [125]. This plasmid contains the LacZ gene under the control of the viral 5' LTR and contains the psi sequence. The presence of $p s i$ marks the transcript for viral packaging and allows the transcript to act as a viral genome. This system produces recombinant MoMLV that is capable of a single round of infection only.

In MoMLV, as well as all other retroviruses, alternative splicing of the genomic mRNA produces the Env transcript. This subgenomic mRNA codes for Env but does not contain the coding sequences for Gag, Pro, or Pol. The ratio between full length genomic mRNA and the spliced Env mRNA is approximately 2:1, respectively [126]. One outcome of using the three plasmid system was that the ratio of pcDNA MoMLV Gag/Pol to pcDNA-MoMLV Env was not 2:1 as expected. Much greater amounts of the pcDNA-MoMLV Env were needed for transfection than was predicted. To address this problem the nucleotide sequence of pcDNA-MoMLV Env was analyzed. The sequence contained the viral splice donor (SD), splice acceptor (SA), and three short open reading frames (ORFs). The presence of the SD, SA, and ORFs suggested two hypotheses. The first was the short ORFs were somehow distracting or stalling the ribosomes during scanning so that many ribosomes released the mRNA prematurely, resulting in reduced Env expression. The second was that the Env mRNA was not being spliced efficiently, thereby trapping the mRNA in the nucleus and leading to reduced Env expression.

The AUG codon marks the beginning of an ORF and serves as the start codon to initiate translation. Translation efficiency of a gene depends upon the context of the AUG start codon. In eukaryotic cells, selection of the appropriate AUG codon is facilitated by the presence of a Kozak sequence: 5' RNNAUGR 3', where R denotes a purine and $\mathrm{N}$ denotes any nucleotide. Of the three upstream ORFs found in pcDNAMoMLV Env, ORF 1 and 2 (designated by their position relative to the 5' end), are not in a Kozak consensus sequence and are not in the same reading frame. The $3^{\text {rd }}$ ORF is in the correct reading frame and contained an optimal Kozak sequence. It was reasoned that the first two upstream ORFs may be distracting ribosomes by attracting them to the incorrect translation initiation site or stalling the ribosomes leading to a decrease in the amount of protein produced from these transcripts. This hypothesis is supported by the finding, that elimination of upstream AUG sites, not in Kozak consensus, increased gene expression in retroviral vectors [127]. It is possible the $3^{\text {rd }}$ ORF is being translated but it is unknown if the protein produced from this site is stable or goes in virions. Therefore, the presence of the $3^{\text {rd }}$ ORF could also be inhibiting the optimal expression of pcDNA- 
MoMLV Env. To evaluate this hypothesis, mutations in pcDNA-MoMLV Env were made which eliminated the three upstream ORFs. Env expression and viral infectivity were examined in recombinant MoMLV produced using these mutants.

An alternative hypothesis is that a reduced amount of message in the cytoplasm available for translation is due to inefficient splicing and nuclear export of Env mRNA. Splicing of pre-mRNA is tied to nuclear export [128]. Many of the proteins responsible for splicing are also involved in nuclear export pathways [129-132]. The presence of a SD and SA in pcDNA-MoMLV Env should therefore increase the amount of mRNA in the cytoplasm and increase the amount of Env expression. However, the natural SD and SA sequence present in MoMLV, and therefore pcDNA-MoMLV Env, do not match the consensus sequence necessary for efficient splicing. Early studies in avian retroviruses proved that this was a strategy employed by these viruses as a way to regulate alternative splicing and maintain the proper balance between genomic and subgenomic mRNAs [133]. Mutations to SA that improved splicing efficiency, resulted in reduced viral replication due to the lack of full length transcripts [126]. Given that splicing is important for nuclear export, it was reasoned that many of the pcDNA-MoMLV Env transcripts were not being exported from the nucleus and therefore not being translated. To examine this possibility the SD and SA sequences were mutated to improve or inhibit the splicing. The effects of the mutations on envelope protein expression and viral infectivity in recombinant MoMLV were examined in the following experiments.

\section{Materials and methods}

\section{Cell lines}

Human 293 embryonic kidney cells and mouse NIH 3 T3 fibroblasts were maintained in DMEM containing 8\% donor calf serum. The packaging cell line H1-BAG (293 cells stably expressing recombinant MoMLV BAG genome encodes the betagalactosidase gene) [125] was maintained in DMEM containing $8 \%$ fetal bovine serum (FBS) and $250 \mu \mathrm{g}$ of G418/ml.

\section{Plasmid construction}

Plasmid pcDNA-MoMLV Env containing only the envelope [134] was used as the backbone to create variations in the 5' untranslated region. Specific point mutations were made using oligonucleotide-directed mutagenesis with the primers listed in Table 41. Primer pairs that contained a 5' phosphate group were used in conjunction with the ExSite kit (Stratagene) according to the manufacturer's protocol with the exception of the PCR parameters which are described in this section. All other mutations were performed using the QuikChange kit (Stratagene) according to the manufacturer's protocol. 
Table 4-1. Oligonucleotides used for mutagenesis.

\begin{tabular}{|c|c|}
\hline Oligonucleotide & Nucleotide sequence \\
\hline ORF 1-fwd & 5'-GGAGGTAAGCTGGGCTATCGGATCTTATATGGGGCACCC-3' \\
\hline ORF1-rev & 5'-GGGTGCCCCATATAAGATCCGATAGCCCAGCTTACCTCC -3' \\
\hline ORF1+2-fwd & $\begin{array}{l}\text { 5'-CACCACCGGGAGGTAAGCTGGGCTATCCGATCTTATACAGGGCACCCCCGCCCC } \\
\text { TTGTAAACTTCCCTGAC-3' }\end{array}$ \\
\hline ORF1+2-rev & $\begin{array}{l}\text { 5'-GTCAGGGAAGTTTACAAGGGGCGGGGGTGCCCTGTATAAGATCGGATAGCCCAG } \\
\text { CTTACCTCCCGGTGGTG-3' }\end{array}$ \\
\hline ORF3-fwd & 5'-СCTTGTAAACTTCCCTGACCCTGACTGTACAAGAGTTACTAACAGCCCCTCTC-3' \\
\hline ORF3-rev & 5'-GAGAGGGGCTGTTAGTAACTCTTGTACAGTCAGGGTCAGGGAAGTTTACAAGG-3' \\
\hline $\begin{array}{l}\text { p-Splice Donor- } \\
\text { fwd }\end{array}$ & 5'-GACCACCGACCCACCACCTGCAGGTAAGCTGGGCTATGAG-3' \\
\hline $\begin{array}{l}\text { p-Splice Donor- } \\
\text { rev }\end{array}$ & 5'-CTCATAGCCCAGCTTACCTGCAGGTGGTGGGTCGGTGGTC-3' \\
\hline $\begin{array}{l}\text { p-Splice acceptor- } \\
\text { fwd }\end{array}$ & 5'-Phosphate-тCTCTCCTCTCTGCAGGTCACTTACAGGCTCTCTACTTAGTCC-3' \\
\hline $\begin{array}{l}\text { p-Splice acceptor- } \\
\text { rev }\end{array}$ & 5'-Phosphate-GTTAGTAACTCTTGTCATGTCAGGG-3' \\
\hline SA fix-fwd & 5'-Phosphate-GACATGACAAGAGTTACTAACTTCTTCCCCTCTCTGCAGGTCAC-3' \\
\hline SA fix-rev & 5'-Phosphate-GTGACCTGCAGAGAGGGGAAGAAGTTAGTAACTCTTGTCATGTC-3' \\
\hline fused-fwd & $\begin{array}{l}\text { 5'GAGACCCCTGCCCAGGGACCACCGACCCACCACCGGGAGCTCACTTACAGGCTCTCTACTT } \\
\text { AGTCCAGCACGAAGTCTG-3' }\end{array}$ \\
\hline fused-rev & $\begin{array}{l}\text { 5'CAGACTTCGTGCTGGACTAAGTAGAGAGCCTGTAAGTGAGCTCCCGGTGGTGGGTCGGTG } \\
\text { G TCCCTGGGCAGGGGTCTC-3' }\end{array}$ \\
\hline pCMV-Env-fwd & 5'-phosphate-GACATGGCGCGTTCAACGCTCTC-3' \\
\hline pCMV-Env-rev & 5'-Phosphate-AAGCTTGGGTCTCCCTATAGTGAGTC-3' \\
\hline SA fix fwd & 5'-GACATGACAAGAGTTACTAACTTCTTCCCСTCTCTGCAGGTCAC-3' \\
\hline SA fix rev & 5'-GTGACCTGCAGAGAGGGGAAGAAGTTAGTAACTCTTGTCATGTC-3' \\
\hline
\end{tabular}


The ORF 1, ORF 1+2, ORF 3, pEnv pft Splice donor, pEnv Fused and pCMVEnv variants were constructed using pcDNA-MoMLV Env as the template. The ORF $1+2+3$ variant was constructed using the ORF $1+2$ variant as the template using the ORF 3 primer pair. pEnv Fused was constructed by using pcDNA-MoMLV Env as the template with the Fused primer pair. The pEnv pft Splice acceptor variant was initially made using pcDNA-MoMLV Env with the p-Splice acceptor primer pair, which resulted in a variant containing the sequence 5'-agccctctctgcaggctcacttaca-3'. This variant was subsequently used as a template with the SA fix primer pair to obtain the $\mathrm{pEnv} p \mathrm{pt}$ Splice acceptor. The pEnv pft SD $+\mathrm{SA}$ variant was constructed using the $\mathrm{pEnv}$ pft Splice acceptor as a template in conjunction with the p-Splice Donor primer pair. For construction of the $p E n v$ Actin Intron variant, the pCAGGS vector was digested with Eco R1, Hinf 1, and Pst 1. The 1056 bp DNA fragment containing the intron from a chicken $\beta$ actin gene (Accession number X00182) including its splice donor and splice acceptor sequences was isolated, its ends blunted using the Klenow fragment of the E.coli DNA Polymerase and then ligated into thePml 1 site of the pEnv Fused variant.

The PCR parameters to create p-Splice acceptor were as follows; anneal at $60{ }^{\circ} \mathrm{C}$, extend at $68{ }^{\circ} \mathrm{C}$ for 5 cycles, then to push reaction towards desired product, the anneal temperature was raised to $65^{\circ} \mathrm{C}$ and extend at $68^{\circ} \mathrm{C}$ for 20 cycles. This did not result in desired product, instead sequence read $5^{\prime}$-agccctctctgcaggctcacttaca-3' This plasmid was termed transitional Splice acceptor and used as a template to create $p E n v$ Splice acceptor using the same PCR parameters as above with the SA fix fwd and SA fix rev primers. pCMV-AUG was constructed using pcDNA-MoMLV Env as the template. The PCR parameters were as follows; anneal at $50{ }^{\circ} \mathrm{C}$, extend at $68^{\circ} \mathrm{C}$ for 5 cycles then switch annealing temperature to $55^{\circ} \mathrm{C}$ and extend at $68^{\circ} \mathrm{C}$ for $20 \mathrm{~min}$.

\section{Virus production, titration, and western blot analysis}

H1-BAG cells were seeded at approximately $25 \%$ confluence in $100-\mathrm{mm}$ dishes and two days later fresh medium was added. When cells reached $85 \%$ confluency, 2, 5, or $15 \mu \mathrm{g}$ of a pcDNA-MoMLV Env construct and $25 \mu \mathrm{g}$ of pcDNA MoMLV gag/pol construct were transfected into them using calcium phosphate co-precipitation. After 24 $\mathrm{hr}$ the medium was replaced with $10 \mathrm{ml}$ fresh DMEM containing 8\% FBS. Twenty-four hr later the virus supernatant was collected and filtered through a $0.45 \mu \mathrm{m}$ filter. A $2 \mathrm{ml}$ aliquot was used to quantify infection by end point dilution on NIH 3 T3 cells seeded at $10 \%$ confluency in 24 -well plates. Cells were exposed overnight to 10 -fold serial dilutions of virus containing $20 \mu \mathrm{g}$ of polybrene $/ \mathrm{ml}$. Forty-eight hr later cells were fixed and stained with 5-bromo-4-chloro-3-indolyl $\beta$-D-galactopyranoside. The virus titer was calculated as the Tissue Culture Infectious Dose 50 (TCID 50) from the end point dilution. The remaining $8 \mathrm{ml}$ of virus supernatant was pelleted by ultracentrifugation using a Beckman SW40 rotor at 30,000 rpm for $90 \mathrm{~min}$ at $4^{\circ} \mathrm{C}$. Virus pellets were resuspended in $40 \mu \mathrm{l}$ of ice cold PBS. Ten $\mu$ l of virus pellet was mixed 1:1 with $2 \mathrm{x}$ loading buffer [104], boiled for ten min, chilled on ice, then electrophoresed through an $8 \%$ SDS-PAGE and transferred to a nitrocelluose membrane (Protran,Schleicher and Schuell). The membrane was cut in half at the $50 \mathrm{kDa}$ molecular mass marker, blocked 
for $2 \mathrm{hrs}$ in $6 \%$ dry milk, and $2 \%$ Tween 20 . The top half was probed for the surface protein (SU) using goat anti-gp70 antiserum (Quality Biotech no. 80S000018; 1:100), and the bottom was probed for capsid protein (CA) with goat anti-p30 antiserum (Quality Biotech no. 80S000018; 1:100) for one hr. The primary antibody was detected by incubation with mouse anti-goat antibody conjugated to horseradish peroxidase $(1: 5,000)$ for 45 min followed by incubation with SuperSignal West Pico Chemiluminescent Substrate (Pierce).

\section{Results}

\section{Increasing pcDNA-MoMLV Env positively affects Env expression and recombinant MoMLV infectivity}

Recombinant MoMLV was produced by transfecting the pcDNA-MoMLV Env and pcDNA MoLV Gag/Pol into H1-BAG cells [125]. The level of MoMLV envelope transfected was either 2, 5, or $15 \mu \mathrm{g}$. As the amount of plasmid increased so did the amount of envelope protein present in the virus production as detected by western blot analysis (Figure 4-1A). The MoMLV CA, which represents the physical particles produced, was used as a loading control and is observed to be at a similar level throughout all three samples. This shows that the increase in Env is not due to the presence of more virus particles.

Each of these virus productions was tested for the ability to infect NIH $3 \mathrm{~T} 3$ cells. Infection was determined by expression of the marker LacZ gene in an end point dilution assay. The level of infection corresponded with the amount of envelope protein expressed (Figure 4-1B). Almost a twenty-fold increase in infectivity was observed when fifteen vs. two $\mu \mathrm{g}$ of envelope plasmid was used. Increasing the amount pcDNAMoMLV Env leads to increased Env expression and increased recombinant MoMLV infectivity.

\section{Mutations of the short open reading frames in the 5' untranslated region of the MoMLV envelope gene}

In pcDNA-MoMLV Env, there are three ORFs that are directly upstream of the natural ribosomal initiation site (Figure 4-2). The role of these upstream ORFs was investigated by performing site-directed mutagenesis The nucleotide sequences, but not the amino acid sequences of pcDNA-MoMLV Env were altered to eliminate the ORFs . Each one is designated either ORF 1, ORF 2, or ORF 3 based on its orientation from the 5 ' terminus of the plasmid. Four constructs were made: the first eliminated ORF 1, the second eliminated ORF1 and ORF 2, the third eliminated ORF 3, and the fourth eliminated all three ORFs. 

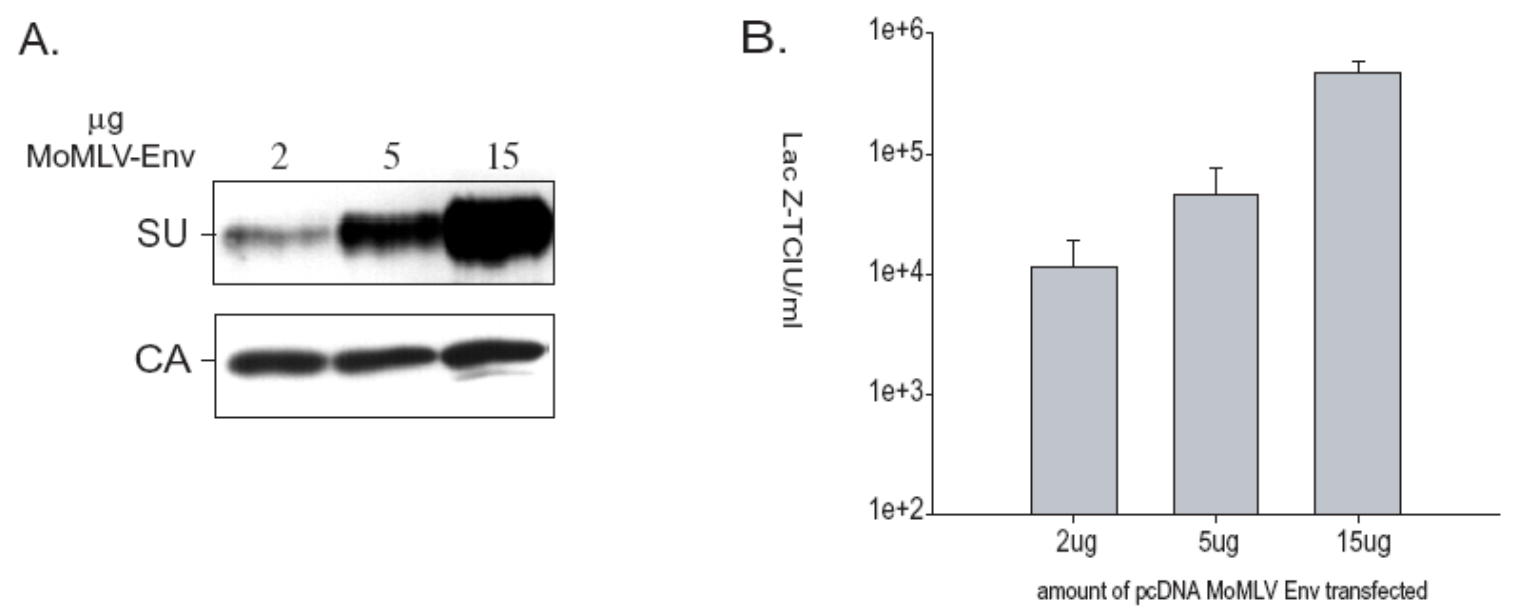

Figure 4-1. Western blot and titer analysis of virus produced with pcDNA-MoMLV Env. Recombinant MoMLV virus was produced by transfecting two, five, or fifteen $\mu \mathrm{g}$ of pcDNA-MoMLV Env and twenty-five $\mu \mathrm{g}$ of a pcDNA MoMLV Gag/Pol plasmid into H1-BAG cells. A) Western blot analysis of envelope production. Virus particles were purified by ultracentrifugation and separated via $8 \%$ SDS-PAGE. Proteins were transferred to nitrocellulose and the membranes were cut in half at the $50 \mathrm{kDa}$ marker band. The top half of the membrane was incubated with anti-SU antiserum to detect the $70 \mathrm{kDa}$ surface unit (SU) protein of the viral envelope. The bottom half of the membrane was incubated with anti-capsid antiserum to detect the viral capsid (CA) which acts as a loading control. B) Infection level on NIH 3 T3 cells using increasing amounts of pcDNA-MoMLV Env. NIH 3 T3 cells were exposed to viral supernatant and infection was quantified by end point dilution of cells expression the Lac $Z$ gene. Values are shown as a $\log$ scale representation of the mean \pm standard deciation of three independent experiments. 


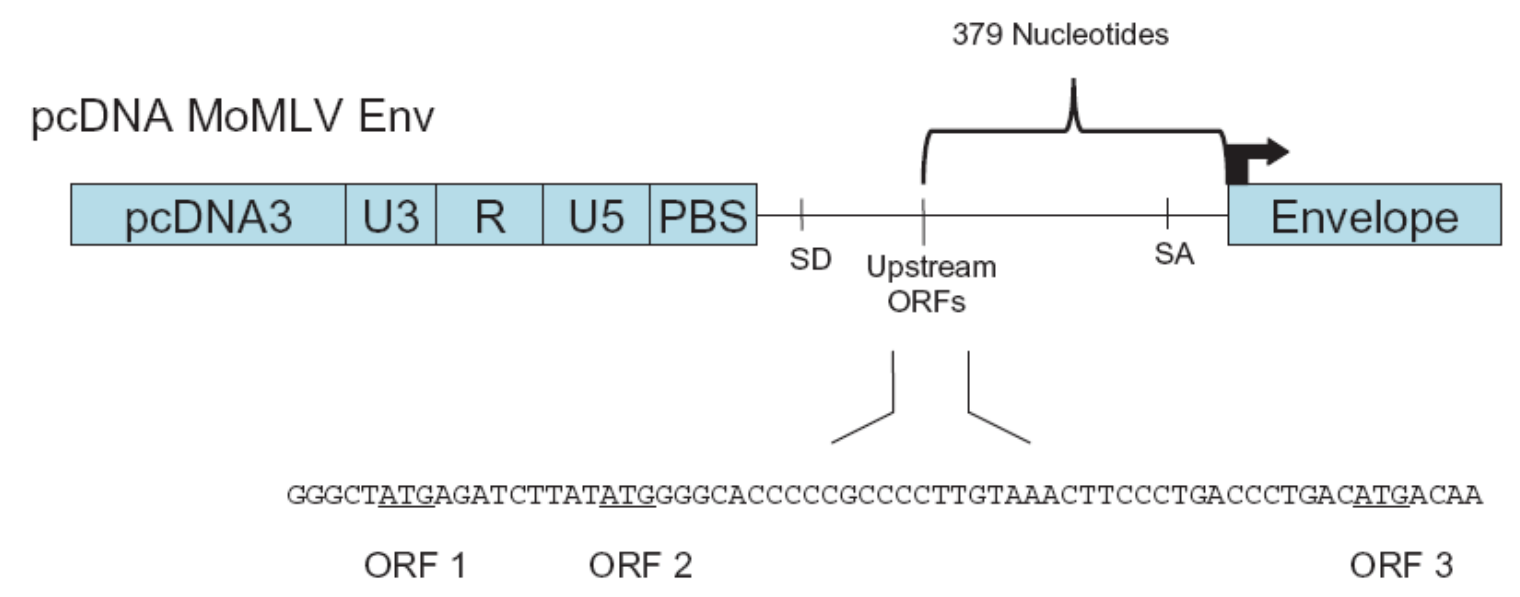

Figure 4-2. Schematic diagram of upstream ORFs found in pcDNA-MoMLV Env.

The black arrow indicates the translation initiation site of the envelope protein. The three upstream ORFs are depicted in the context of their sequence. ORF 1 and ORF 2 are not in the same reading frame and are not in an optimal Kozak sequence. ORF 3 is in the correct reading frame surrounded by an optimal Kozak sequence. There are 379 nucleotides between ORF 1 and the true translation initiation site. Also depicted are the unique 3' (U3), repeat (R), unique 5' (U5), primer binding site (PBS), splice donor (SD), and splice acceptor (SA) sequences. 
Recombinant MoMLV was produced by transfection using the same amount (2 $\mu \mathrm{g}$ ) of either pcDNA-MoMLV Env or the mutant constructs. Western blot analysis of the virus productions illustrated that mutation of the three upstream ORFs did not lead to a change in the amount of Env (Figure 4-3A). The level of Env expressed from pcDNAMoMLV Env is nearly identical to that of each mutant ORF construct. This observation disproved the first hypothesis that the upstream ORFs were limiting or stalling ribosomes from actively translating Env mRNA from the natural AUG site. To ensure Env produced from the ORF mutants was not affected in some other manner, each mutant was tested for its ability to infect NIH 3 T3 cells (Figure 4-3B). When compared to pcDNAMoMLV Env the level of infection by the mutants was not statistically significant based on a $P$ value of 0.3 . The ORF $1+2+3$ construct did show a slight reduction in titer. Based on the titer of the ORF $1+2$ and ORF 3 mutants I believe this lower titer observed by ORF $1+2+3$ is due to the quality of the DNA preperation used for transfection.

\section{Mutational analysis of the splice donor and splice acceptor region of the MoMLV envelope gene}

To address the hypothesis that poor splicing was responsible for low envelope expression an array of constructs were generated by oligonucleotide directed mutagenesis using pcDNA-MoMLV Env as the template (Figure 4-4). pEnv perfect (pft) Splice acceptor, $\mathrm{pEnv} \mathrm{pft}$ Splice donor, and $\mathrm{pEnv} \mathrm{pft} \mathrm{SD}+\mathrm{SA}$ all contained mutations making the SD or SA sequence match the consensus sequence for optimal splicing. The pCMVAUG construct was created by deleting the entire sequence between the CMV promoter and the true AUG start codon. This eliminated the SD, SA, and the 5' untranslated region and should not allow any splicing to take place. pEnv Fused was designed so that the intronic sequence between the SD and SA was eliminated as if splicing had already take place. Using this construct as a template, the pEnv Actin Intron construct was designed to rescue the protein expression of Env by introducing a foreign SD and SA with a good consensus sequence.

In agreement with the hypothesis, western blot analysis demonstrated that mutations which should have improved splicing yielded higher levels of Env expression. Likewise mutations that should have inhibited splicing resulted in either reduced or undetectable Env expression (Figure 4-5A). There was a direct correlation between the number of nucleotides needed to make the splice site match the consensus sequence and the level of Env expression. The SD only needed a few mutations to match the perfect consensus sequence and therefore only improved the protein expression by a small margin. The SA required many more mutations to match the perfect consensus sequence and showed a greater level of protein expression when these mutations were made. The construct $\mathrm{pEnv} \mathrm{pft} \mathrm{SD}+\mathrm{SA}$, which had both a perfect SD and SA sequence, produced the highest amount of protein expression. The pEnv Fused and pCMV-AUG construct, which should not permit splicing to take place, did not produce any detectable amounts of Env. The rescue of the pEnv Fused construct by the addition of the actin intron further supports the hypothesis that improved splicing is the cause of increased Env expression. Each recombinant MoMLV production was tested for the ability to infect NIH 3T3 cells 
Figure 4-3. Western blot and titer analysis of virus produced using ORF envelope constructs. Recombinant MoMLV virus was produced by by transfecting two $\mu \mathrm{g}$ of envelope construct along with twenty-five $\mu \mathrm{g}$ of a MoMLV Gag/Pol plasmid into H1BAG cells. A) Western blot analysis of envelope production for the different envelope constructs. Virus particles were purified by ultracentrifugation and separated via $8 \%$ SDS-PAGE. Proteins were transferred to nitrocellulose and the membranes were cut in half at the $50 \mathrm{kDa}$ marker band. The top half of the membrane was incubated with anti-SU antiserum to detect the $70 \mathrm{kDa}$ surface unit (SU) protein of the viral envelope. The bottom half of the membrane was incubated with anti-capsid antiserum to detect the viral capsid (CA) which acts as a loading control. B) Infection level on NIH 3 T3 cells of virus produced with each of the different envelope constructs. NIH 3 T3 cells were exposed to viral supernatant and infection was quantified by end point dilution of cells expression the Lac $Z$ gene. Values are shown as a log scale representation of the mean \pm standard deviation of three independent experiments. (TCIU) Statistical difference was calculated by performing a student $t$-test. P values were $0.68,0.43,0.84$, and 0.32 for ORF 1 , ORF $1+2$, ORF 3 , and ORF $1+2+3$ respectively. 

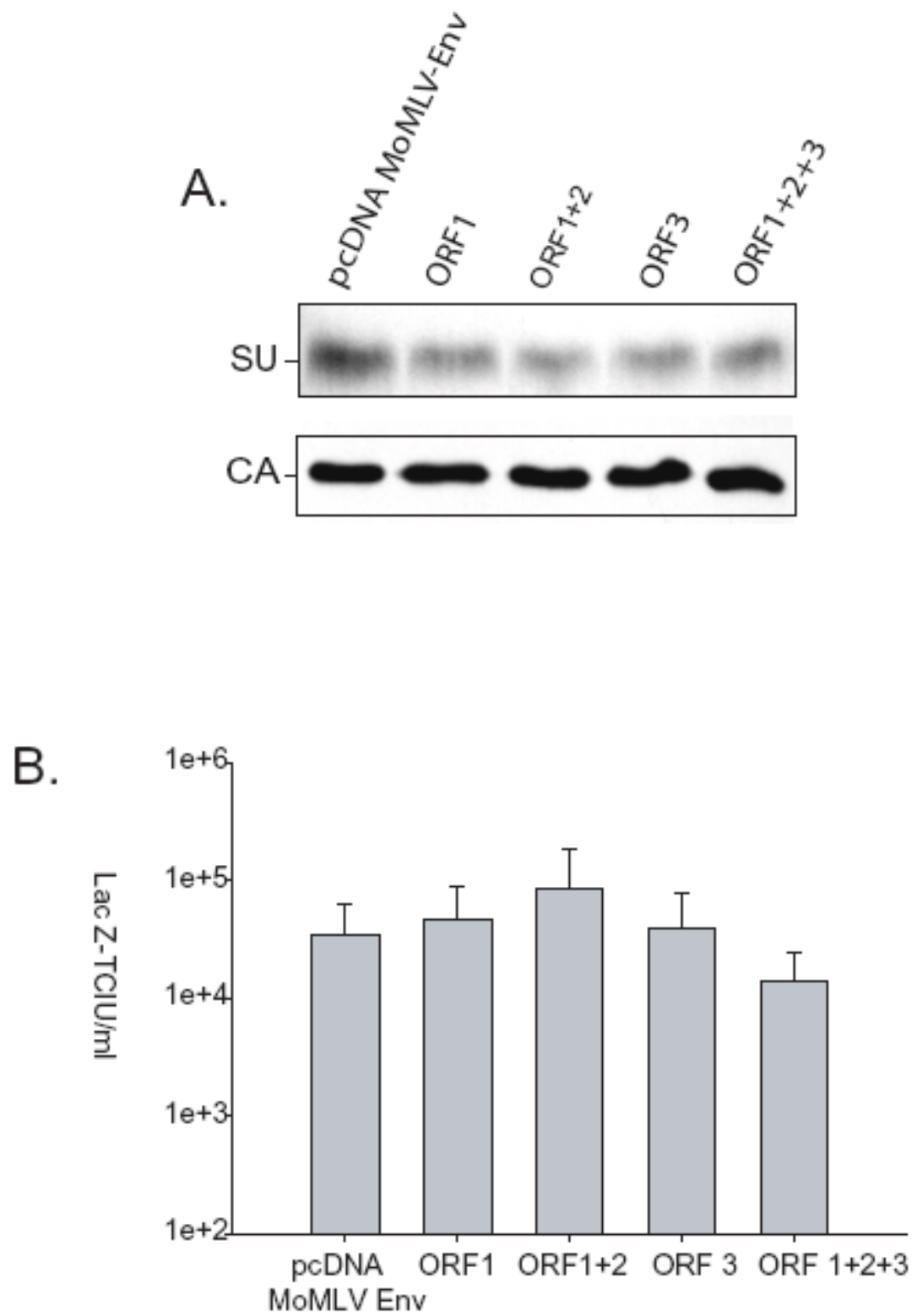

ORF Env-mutants 


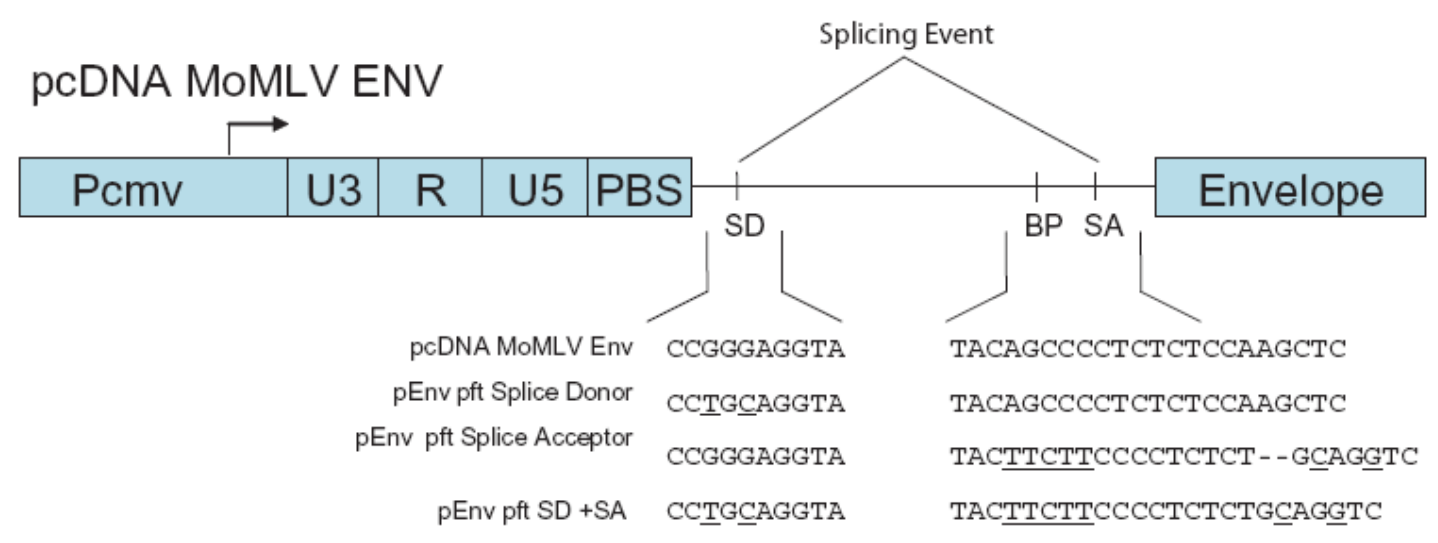

pEnv Fused

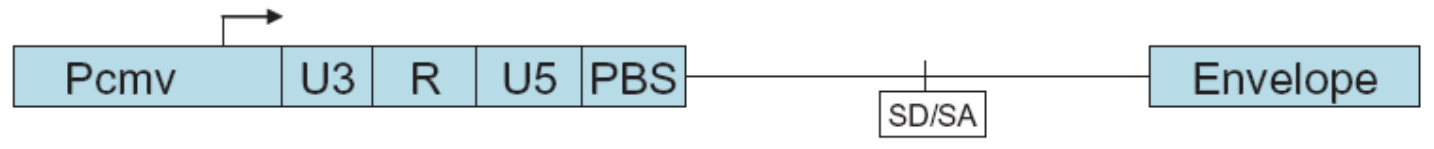

pEnv Actin Intron
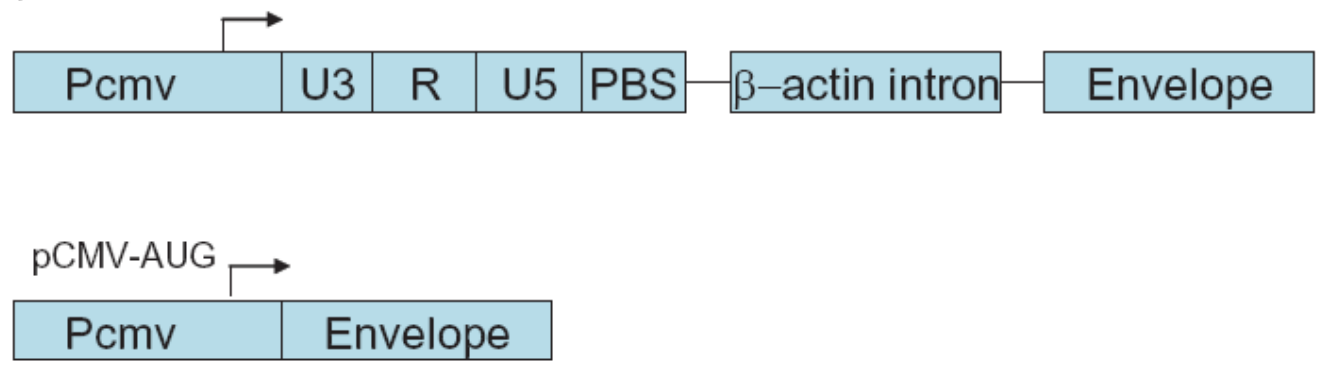

Figure 4-4. pcDNA-MoMLV Env and derived splicing mutants. Mutations made to the key regions, including the splice donor (SD), splice acceptor (SA) and branch point (BP) are shown. Mutations generated in these regions are underlined and deletions are marked by (-). The pEnv Fused plasmid was deleted for the entire sequence between the $\mathrm{SD}$ and SA. pEnv Actin Intron was generated by inserting an intron from the chicken $\beta$ actin gene (Accession number X00182) into the pEnv Fused plasmid. pCMV-AUG was deleted for the 5' untranslated region, which brought the AUG ribosomal start site immediately downstream of the pCMV promoter. Arrow indicates initiation of transcription. Also depicted are the unique 3' (U3), repeat (R), unique 5' (U5), and primer binding site (PBS). 
Figure 4-5. Western blot and titer analysis of virus produced using splicing envelope constructs. Recombinant MoMLV virus was produced by by transfecting two $\mu \mathrm{g}$ of pcDNA MoMVL Env or mutant construct along with twenty-five $\mu \mathrm{g}$ of a MoMLV Gag/Pol plasmid into H1-BAG cells. A) Western blot analysis of envelope production for the different envelope constructs. Virus particles were purified by ultracentrifugation and separated via $8 \%$ SDS-PAGE. Proteins were transferred to nitrocellulose and the membranes were cut in half at the $50 \mathrm{kDa}$ marker band. The top half of the membrane was incubated with anti-SU antiserum to detect the $70 \mathrm{kDa}$ surface unit (SU) protein of the viral envelope. The bottom half of the membrane was incubated with anti-capsid antiserum to detect the viral capsid (CA) which acts as a loading control. B) Infection level on NIH 3 T3 cells by virus produced using each of the different envelope constructs. NIH 3T3 cells were exposed to viral supernatant and infection was quantified by end point dilution of cells expression the Lac Z gene. Values are shown as a $\log$ scale representation of the mean \pm standard deviation of three independent experiments. 

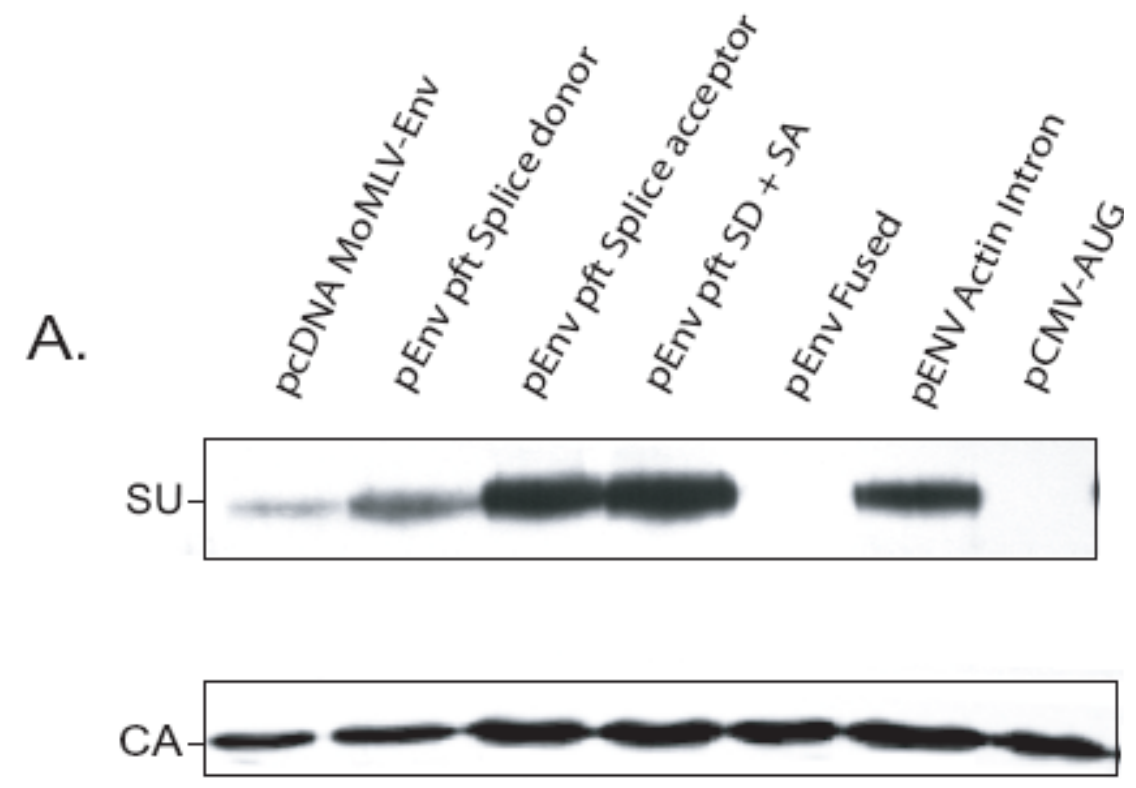

B.

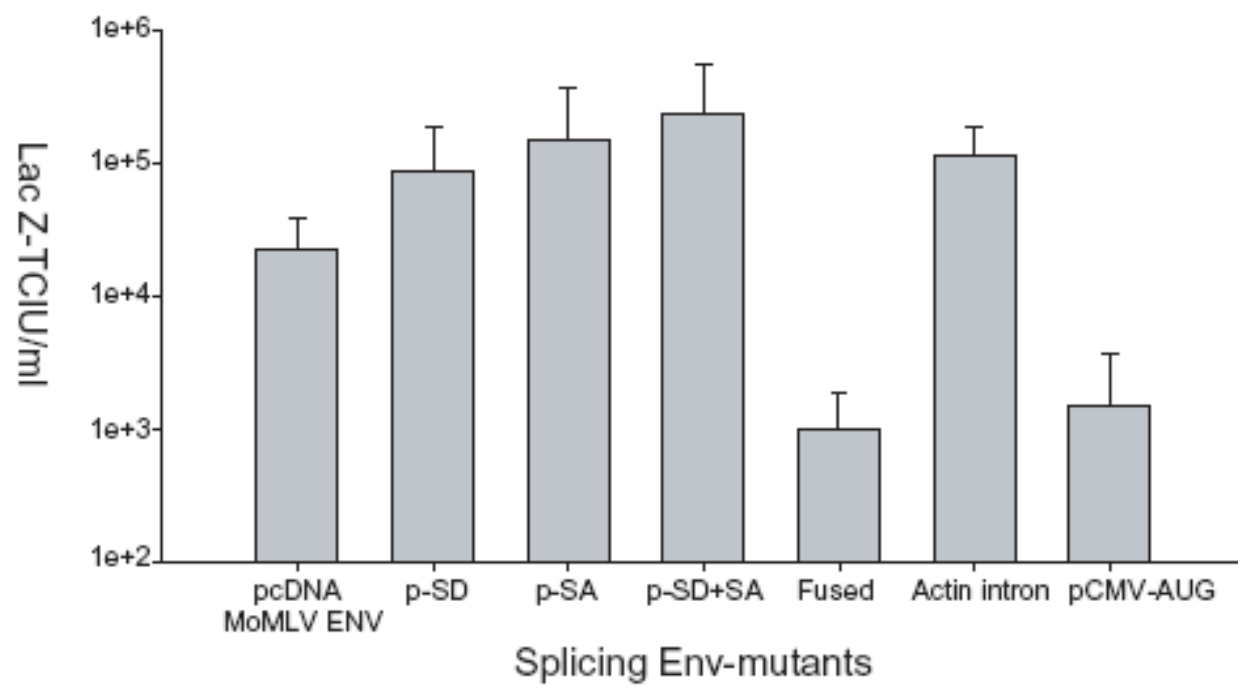


(Figure 4-5B). The level of infection, based on an end point dilution assay of each virus, directly correlated with the level of Env expression. Virus produced from constructs that contained improved SD or SA sequences lead to and increase in titer when compared to pcDNA-MoMLV Env. Virus produced with pEnv Fused or pCMV-Aug constructs displayed approximately a ten fold decrease in titer despite the having a similar level of physical particles. The $\mathrm{pEnv}$ Actin Intron construct was able to restore the viral titer to levels close to that of the $\mathrm{pSD}+\mathrm{SA}$ construct.

\section{Discussion}

\section{Cis-elements are important in retroviral vectors}

Retroviral vectors like MLV have been extremely important tools in molecular biology as well as gene therapy $[135,136]$. The retroviral genome is small but is extremely efficient. It contains many known cis acting sequences that allow a single genomic transcript to code for multiple proteins as well as interact with many cellular and viral proteins that provide assistance through different stages of the retroviral lifecycle. Through natural selection, the full length genome of the virus has become optimized for interaction with its host cell through the use of these cis-elements. One goal in creating retroviral vectors is to eliminate as much of the viral sequence as possible to prevent the occurrence of replication competent retroviruses caused by homologous recombination [137]. In doing so, many of the cis-elements are excluded or misused. When used in the proper context these elements can be exploited to boost titer and gene expression from retroviral vectors. Some examples include the central polypurine tract (cPPT) that enhances nuclear translocation of the preintegration complexes in HIV-1, SIV, and EIAV [138] or the woodchuck hepatitis virus posttranscriptional regulatory element (WPRE) that helps to stabilize the mRNA therefore increasing protein expression [139-141]. The results from this study demonstrate the pitfalls using cis-elements out of the context of the entire genome. The SA sequence found within the MoMLV genome works in concert with many other cis-elements to regulate splicing so that optimal MoMLV replication is obtained. However, this same SA sequence used in the context of pcDNA-MoMLV Env plasmid inhibited maximal expression.

In this case, the upstream ORFs did not interfere with the expression of the MoMLV envelope protein or infection of virus produced with these ORF mutants. Hildinger et. al. [127] reported that deletion of aberrant ORFs improved gene expression slightly in the 5' LTR of retroviral vectors, pointing out concern for toxicity and immunogenicity of proteins possible expressed from these ORFs. The conflicting results can probably be explained by the small increase in protein expression observed and the greater sensitivity of the assay used by Hildinger and colleagues [127]. In the context of gene therapy the deletion of deviant upstream ORFs may prove to be at worst a neutral modification. 


\section{Splicing in MLV is regulated by multiple cis-elements including the splice acceptor}

Regulation of alternative splicing in retroviruses occurs due to interactions between viral cis-acting sequences and cellular splicing factors including the spliceosome $[142,143]$. In eukaryotic cells splicing is catalyzed by the spliceosome. The spliceosome complex is an RNA-Protein aggregate which has been estimated to contain several hundred different proteins in addition to five spliceosomal snRNAs [144-147]. Alternative splicing of HIV-1, a complex retrovirus and ASV, a simple retrovirus are very well studied. Both of the viruses use a sub-optimal 3' SA to regulate splicing [133, 148, 149]. By having a sub-optimal SA the host cell splicing machinery cannot efficiently splice the viral transcript, which provides the correct ratio of spliced and unspliced message for optimal viral replication. MLVs also contain a sub-optimal 3' splice acceptor [150] and until recently were thought to regulate splicing by this same mechanism. However it was shown the MLV splice acceptor can be replaced with one containing the optimal consensus sequence and unspliced transcripts are still produced [151]. This suggested an alternate mechanism for regulation. It was then shown that contrary to HIV-1 and ASV, MLV regulates splicing through the 5' splice donor [152]. The splice donor of MLV matches the consensus sequence almost perfectly but is regulated by upstream cis-elements which form an inhibitory stem-loop around the SD [152].

The evidence in this study suggests that it is very likely that the MLV SA does in fact play a role in the regulation of spliced message. Mutating the SD and SA of pcDNAMoMLV Env to match the consensus sequence resulted in an increase of envelope expression. The mechanism is most likely do to an increase in splicing efficiency leading to better nuclear export of the transcript. This hypothesis was further supported by the pEnv Actin Intron construct, which showed the observed effect is directly due to the splicing sequence. However, the apparent role of the sub-optimal SA in pcDNAMoMLV Env may not be the same when placed in the context of the virus genome. Many other cis-elements exist in retroviruses that regulate splicing both positively and negatively: exonic splicing enhancer (ESE), intronic splicing silencer (ISS), negative regulator of splicing (NRS), exonic splicing suppressor (ESS) [10, 153]. In fact many retroviruses including ASV use a variety of cis-elements to regulate splicing [153], resulting in a highly complex and poorly understood process. Due to the large number of signals involved it comes as no surprise that the ratio of transcripts produced by alternative splicing can vary depending on the environment $[3,10]$.

In conclusion, the results of this study suggest that the sub-optimal SD and SA in pcDNA-MoMLV Env regulate splicing. It also suggests that the SA in MoMLV, like all other retroviruses, plays a role in the regulation of splicing. To confirm the role the SA in MoMLV more experiments need to be carried out. The SA of MoMLV should be mutated using site directed mutagenesis to match the consensus sequence. These mutant clones should be transfected into NIH 3 T3 cells along with wild type MoMLV clones as a control. The cytoplasmic mRNA from these cells should be harvested and subjected to real time RT PCR. The primers used should be able to detect either full length MoMLV mRNA or spliced MoMLV mRNA. This will allow for quantification of the two forms. 
The ratio of these forms can be compared to that of the ratio of the control sample. This should establish if there is a difference in the level of splicing taking place. If the SA in MoMLV regulates splicing then changing the sequence to a perfect SA would change the natural ratio of full length vs. spliced mRNA. An increase in the amount of spliced Env mRNA and a decrease in full length genomic mRNA would occur. This would result in a decrease in progeny virus production by lowering the amount of full length transcript available for translation and viral genome. However, the progeny virus would likely be more infectious do to an increase in the amount of envelope protein incorporated. This could be investigated by transfecting NIH 3T3 cells with either a wild type molecular clone or a clone containing the perfect SA and examining their growth kinetics. Wild type virus would be expected to produce higher levels of progeny virus and therefore spread faster than virus produced from the SA clone. Over time, the virus produced from the SA clone should accumulate mutations including ones that revert the perfect SA back to an imperfect sequence that restores the balance of mRNA. The progeny acquiring these mutations should emerge as the dominant variant. 


\section{Chapter 5. Discussion}

There are many steps in the life cycle of a retrovirus. Some are well defined while others remain essentially a mystery. This study brings to light new information about retrovirus entry, primer tRNA deaminoacylation, and splicing. To begin an infection the virus must gain entry to the host cell cytoplasm. After receptor binding retroviruses undergo a membrane fusion step that occurs via rearrangements of the viral glycoprotein which allow the fusion peptide to become exposed. Low $\mathrm{pH}$, receptor engagement, and protease cleavage are mechanisms used by enveloped viruses to trigger these rearrangements. Currently, MoMLV membrane fusion is thought to be $\mathrm{pH}$ triggered. However, the $\mathrm{pH}$ dependence observed for MoMLV may actually reflect a requirement for the activity of host cell cathepsins, instead of a $\mathrm{pH}$ trigger for membrane fusion. MoMLV enters through the endocytic pathway where it would likely encounter members of the cathepsins family. Many of the different cathepsins examined were able to cleave MoMLV SU and therefore may be implemented during the membrane fusion step. Similar observations have been made outside the field of retrovirology in both the Paramyxoviridae and Filoviridae families; cathepsins are either known or implemented to trigger the membrane fusion step.

Retroviruses begin reverse transcription of their genome shortly after budding and complete it after gaining entry to the host cell cytoplasm. The RT of all retroviruses use host cell tRNAs to prime reverse transcription. In order for RT to initiate synthesis, the tRNA must first be deaminoacylated. The only known mechanism for primer deaminoacylation in retroviruses is that of AMV. AMV appears to accomplish this via the hydrolase activity found within its RT. HIV-1 RT on the other hand does not appear to have similar levels of hydrolase activity towards its cognate primer. This suggests that HIV-1 and perhaps other retroviruses use a different strategy to achieve this task. Unlike AMV , HIV-1 is a complex retrovirus and encodes several other accessory proteins. The proteins as well as cellular proteins recruited by HIV-1 could play a role in deaminoacylation.

Once the RNA genome is completely reverse transcribed into double stranded DNA it becomes integrated into the host cell chromosomal DNA. The provirus is transcribed, modified, and spliced by the host cell machinery. The ratio between full length and spliced mRNA is critical for optimal viral infectivity and must be tightly regulated. This regulation occurs through a variety of different mechanisms. This study implicates the use of a sub-optimal 3' SA by MoMLV. This mechanism was first discovered in the avian retroviruses and seems to be common to most simple retroviruses. By evolving sub-optimal SA retroviruses reduced the efficiency with which their mRNAs are spliced as a form regulation. Other forms of regulation include a variety of splicing enhancer and suppressor sequences, which can be further regulated by secondary structure within the mRNA transcript itself. 


\section{List of References}

1. Lodish, H.B., A. Baltimore, David., Molecular Cell Biology. 4th ed. 2000: W.H Feeman and Company. 120-6.

2. David M. Knipe, P.M.H., Fields Virology. 5th ed, ed. D.M. Knipe. 2007, Philadelphia: Lippincott Williams and Wilkins. 2000-51.

3. Coffin, J.M., S. H. Hughes, and H. E. Varmus, Retroviruses. 1997, Cold Springs Harbor, NY: Cold Springs Harbor Laboratory. 121-60.

4. Fields Virology. 5th ed, ed. D.M. Knipe. 2007, Philadelphia: Lippincott Williams and Wilkins. 2000-51.

5. $\quad$ Furuichi,Y., A.J.S., Stavnezer, E., and Bishop J.M., Blocked, methylated 5' terminal sequence in avian sarcoma virus RNA. Nature, 1975 (257) 618-20.

6. $\quad$ Duesberg, M.M.C.L.a.P.H., Adenylic acid-rich sequence in RNAs of Rous sarcoma virus and Rauscher mouse leukaemia virus. Nature, 1972. 235: p. 38386.

7. Keith, K.L.B.a.J., Localizaton of N6-methyladenosine in the Rous sarcoma virus genome. J. Mol. Biol., 1977. 113: p. 165-79.

8. Lobel, L.I., and S.P. Goff, Reverse transcription of retroviral genome: mutations in the terminal repeat sequences. J. Virology, 1985. 74: p. 295-305.

9. Cobrinik, D., L. Sskey, and J. Leis., A retroviral RNA secondary structure required for efficient initiation of reverse transcription. J. Virology, 1998. 62: p. 3622-30.

10. Flint, S.J., L. W. Enquist, R. M. Krug, V. R. Racaniello, and A. M. Skalka, Principles of Virology. 2000.

11. Erikson, E. and R.L. Erikson, Association of $4 S$ ribonucleic acid with oncornavirus ribonucleic acids. J Virol, 1971. 8(2): p. 254-6.

12. Sawyer, R.C., F. Harada, and J.E. Dahlberg, Virion-associated RNA primer for Rous sarcoma virus DNA synthesis: isolation from uninfected cells. J Virol, 1974. 13(6): p. 1302-11.

13. Fisher, A.G., et al., The sor gene of HIV-1 is required for efficient virus transmission in vitro. Science, 1987. 237(4817): p. 888-93.

14. Eisenman, V.M.V.a.R., Identification of a large polypeptide precursor of avian oncornavirus proteins. Proc. Natl. Acad. Sci, 1973. 70: p. 1734-8.

15. Rein, A., et al., Myristylation site in Pr65gag is essential for virus particle formation by Moloney murine leukemia virus. Proc Natl Acad Sci U S A, 1986. 83(19): p. 7246-50.

16. Rhee, S.S. and E. Hunter, Myristylation is required for intracellular transport but not for assembly of D-type retrovirus capsids. J Virol, 1987. 61(4): p. 1045-53.

17. Craven, R.C., et al., Genetic analysis of the major homology region of the Rous sarcoma virus Gag protein. J Virol, 1995. 69(7): p. 4213-27.

18. Mammano, F., et al., Role of the major homology region of human immunodeficiency virus type 1 in virion morphogenesis. J Virol, 1994. 68(8): p. 4927-36. 
19. Davis, N.L. and R.R. Rueckert, Properties of a ribonucleoprotein particle isolated from Nonidet P-40-treated Rous sarcoma virus. J Virol, 1972. 10(5): p. 1010-20.

20. Bonnet-Mathoniere, B., et al., Nucleocapsid protein 10 activates dimerization of the RNA of Moloney murine leukaemia virus in vitro. Eur J Biochem, 1996. 238(1): p. 129-35.

21. Katz, R.A. and A.M. Skalka, The retroviral enzymes. Annu Rev Biochem, 1994. 63: p. 133-73.

22. Battula, N. and L.A. Loeb, On the fidelity of DNA replication. Lack of exodeoxyribonuclease activity and error-correcting function in avian myeloblastosis virus DNA polymerase. J Biol Chem, 1976. 251(4): p. 982-6.

23. Katz, R.A. and A.M. Skalka, Generation of diversity in retroviruses. Annu Rev Genet, 1990. 24: p. 409-45.

24. Kohlstaedt, L.A., et al., Crystal structure at 3.5 A resolution of $H I V-1$ reverse transcriptase complexed with an inhibitor. Science, 1992. 256(5065): p. 1783-90.

25. Molling, K., et al., Association of viral reverse transcriptase with an enzyme degrading the RNA moiety of RNA-DNA hybrids. Nat New Biol, 1971. 234(51): p. 240-3.

26. Von der Helm, K., Cleavage of Rous sarcoma viral polypeptide precursor into internal structural proteins in vitro involves viral protein p15. Proc Natl Acad Sci U S A, 1977. 74(3): p. 911-5.

27. Crawford, S. and S.P. Goff, A deletion mutation in the 5' part of the pol gene of Moloney murine leukemia virus blocks proteolytic processing of the gag and pol polyproteins. J Virol, 1985. 53(3): p. 899-907.

28. Doms, R.W., et al., Folding and assembly of viral membrane proteins. Virology, 1993. 193(2): p. 545-62.

29. Dong, J.Y., et al., Mutations within the proteolytic cleavage site of the Rous sarcoma virus glycoprotein define a requirement for dibasic residues for intracellular cleavage. J Virol, 1992. 66(2): p. 865-74.

30. Freed, E.O., D.J. Myers, and R. Risser, Mutational analysis of the cleavage sequence of the human immunodeficiency virus type 1 envelope glycoprotein precursor gp160. J Virol, 1989. 63(11): p. 4670-5.

31. Gallaher, W.R., Detection of a fusion peptide sequence in the transmembrane protein of human immunodeficiency virus. Cell, 1987. 50(3): p. 327-8.

32. Bowerman, B., et al., A nucleoprotein complex mediates the integration of retroviral DNA. Genes Dev, 1989. 3(4): p. 469-78.

33. Lewis, P.F. and M. Emerman, Passage through mitosis is required for oncoretroviruses but not for the human immunodeficiency virus. J Virol, 1994. 68(1): p. 510-6.

34. Miller, D.G., M.A. Adam, and A.D. Miller, Gene transfer by retrovirus vectors occurs only in cells that are actively replicating at the time of infection. Mol Cell Biol, 1990. 10(8): p. 4239-42.

35. Bukrinsky, M.I., et al., Active nuclear import of human immunodeficiency virus type 1 preintegration complexes. Proc Natl Acad Sci U S A, 1992. 89(14): p. 6580-4. 
36. Hunter, E. and R. Swanstrom, Retrovirus envelope glycoproteins. Curr Top Microbiol Immunol, 1990. 157: p. 187-253.

37. White, J., M. Kielian, and A. Helenius, Membrane fusion proteins of enveloped animal viruses. Q Rev Biophys, 1983. 16(2): p. 151-95.

38. Marsh, M. and A. Helenius, Virus entry into animal cells. Adv Virus Res, 1989. 36: p. 107-51.

39. Redmond, S., G. Peters, and C. Dickson, Mouse mammary tumor virus can mediate cell fusion at reduced $p H$. Virology, 1984. 133(2): p. 393-402.

40. Marsh, M. and A. Helenius, Virus entry: open sesame. Cell, 2006. 124(4): p. 72940.

41. Stein, B.S., et al., pH-independent HIV entry into CD4-positive T cells via virus envelope fusion to the plasma membrane. Cell, 1987. 49(5): p. 659-68.

42. McClure, M.O., et al., The $p H$ independence of mammalian retrovirus infection. $\mathrm{J}$ Gen Virol, 1990. 71 ( Pt 4): p. 767-73.

43. Andersen, K.B. and B.A. Nexo, Entry of murine retrovirus into mouse fibroblasts. Virology, 1983. 125(1): p. 85-98.

44. Andersen, K.B. and H. Skov, Retrovirus-induced cell fusion is enhanced by protease treatment. J Gen Virol, 1989. 70 ( Pt 7): p. 1921-7.

45. Simkovic, D., N. Valentova, and V. Thurzo, An in vitro system for the detection of the Rous sarcoma virus in the cells of the rat tumour XC. Neoplasma, 1962. 9: p. 104-6.

46. Stetina, R., J. Svoboda, and O. Mach, Long-term preservation of transfecting activity of DNA isolated from rat virogenic XC cells transformed by Prague strain of Rous sarcoma virus. Folia Biol (Praha), 1975. 21(5): p. 334-9.

47. Svoboda, J., et al., Demonstration of the absence of infectious Rous virus in rat tumor XC, whose structurally intact cells produce Rous sarcoma when transferred to chicks. Folia Biol (Praha), 1963. 9: p. 77-81.

48. Ishidoh, K., S. Taniguchi, and E. Kominami, Egr family member proteins are involved in the activation of the cathepsin L gene in v-src-transformed cells. Biochem Biophys Res Commun, 1997. 238(2): p. 665-9.

49. Stearns, N.A., et al., Comparison of cathepsin L synthesized by normal and transformed cells at the gene, message, protein, and oligosaccharide levels. Arch Biochem Biophys, 1990. 283(2): p. 447-57.

50. Rawlings, N.D., et al., MEROPS: the peptidase database. Nucleic Acids Res, 2008. 36(Database issue): p. D320-5.

51. Koblinski, J.E., M. Ahram, and B.F. Sloane, Unraveling the role of proteases in cancer. Clin Chim Acta, 2000. 291(2): p. 113-35.

52. Jaattela, M., Multiple cell death pathways as regulators of tumour initiation and progression. Oncogene, 2004. 23(16): p. 2746-56.

53. Kumar, P., et al., Host cell cathepsins potentiate Moloney murine leukemia virus infection. J Virol, 2007. 81(19): p. 10506-14.

54. Diederich, S., et al., The nipah virus fusion protein is cleaved within the endosomal compartment. J Biol Chem, 2005. 280(33): p. 29899-903.

55. Pager, C.T. and R.E. Dutch, Cathepsin L is involved in proteolytic processing of the Hendra virus fusion protein. J Virol, 2005. 79(20): p. 12714-20. 
56. Pager, C.T., et al., A mature and fusogenic form of the Nipah virus fusion protein requires proteolytic processing by cathepsin L. Virology, 2006. 346(2): p. 251-7.

57. Chandran, K., et al., Endosomal proteolysis of the Ebola virus glycoprotein is necessary for infection. Science, 2005. 308(5728): p. 1643-5.

58. Kaletsky, R.L., G. Simmons, and P. Bates, Proteolysis of the Ebola virus glycoproteins enhances virus binding and infectivity. J Virol, 2007. 81(24): p. 13378-84.

59. Simmons, G., et al., Inhibitors of cathepsin L prevent severe acute respiratory syndrome coronavirus entry. Proc Natl Acad Sci U S A, 2005. 102(33): p. 1187681.

60. Bosch, B.J., W. Bartelink, and P.J. Rottier, Cathepsin L functionally cleaves the severe acute respiratory syndrome coronavirus class I fusion protein upstream of rather than adjacent to the fusion peptide. J Virol, 2008. 82(17): p. 8887-90.

61. Regan, A.D., et al., Differential role for low $\mathrm{pH}$ and cathepsin-mediated cleavage of the viral spike protein during entry of serotype II feline coronaviruses. Vet Microbiol, 2008 Dec 10;132(3-4):235-48.

62. White, J.M., et al., Structures and mechanisms of viral membrane fusion proteins: multiple variations on a common theme. Crit Rev Biochem Mol Biol, 2008. 43(3): p. 189-219.

63. Qiu, Z., et al., Endosomal proteolysis by cathepsins is necessary for murine coronavirus mouse hepatitis virus type 2 spike-mediated entry. J Virol, 2006. 80(12): p. 5768-76.

64. McGrath, M.E., The lysosomal cysteine proteases. Annu Rev Biophys Biomol Struct, 1999. 28: p. 181-204.

65. Tezuka, K., et al., Molecular cloning of a possible cysteine proteinase predominantly expressed in osteoclasts. J Biol Chem, 1994. 269(2): p. 1106-9.

66. Kirschke, H., et al., Cathepsin S from bovine spleen. Purification, distribution, intracellular localization and action on proteins. Biochem J, 1989. 264(2): p. 467-73.

67. Garnero, P., et al., The collagenolytic activity of cathepsin $K$ is unique among mammalian proteinases. J Biol Chem, 1998. 273(48): p. 32347-52.

68. Telesnitsky, A., and Goff, S. P., Retroviruses. 1997, Cold Springs Harbor, NY: Cold Springs Harbor Laboratory. 121-60.

69. Baltimore, D., RNA-dependent DNA polymerase in virions of RNA tumour viruses. Nature, 1970. 226(5252): p. 1209-11.

70. Peters, G. and C. Glover, $t R N A$ 's and priming of RNA-directed DNA synthesis in mouse mammary tumor virus. J Virol, 1980. 35(1): p. 31-40.

71. Harada, F., R.C. Sawyer, and J.E. Dahlberg, A primer ribonucleic acid for initiation of in vitro Rous sarcarcoma virus deoxyribonucleic acid synthesis. $\mathrm{J}$ Biol Chem, 1975. 250(9): p. 3487-97.

72. Mak, J. and L. Kleiman, Primer tRNAs for reverse transcription. J Virol, 1997. 71(11): p. 8087-95.

73. Peters, G., et al., Low-molecular-weight RNAs of Moloney murine leukemia virus: identification of the primer for RNA-directed DNA synthesis. J Virol, 1977. 21(3): p. 1031-41. 
74. Peters, G.G. and J. Hu, Reverse transcriptase as the major determinant for selective packaging of tRNA's into Avian sarcoma virus particles. J Virol, 1980. 36(3): p. 692-700.

75. Sonigo, P., et al., Nucleotide sequence of the visna lentivirus: relationship to the AIDS virus. Cell, 1985. 42(1): p. 369-82.

76. Jiang, M., et al., Identification of tRNAs incorporated into wild-type and mutant human immunodeficiency virus type 1. J Virol, 1993. 67(6): p. 3246-53.

77. Waters, L.C., et al., tRNA's associated with the 70S RNA of avian myeloblastosis virus. J Virol, 1975. 16(6): p. 1608-14.

78. Waters, L.C. and B.C. Mullin, Transfer RNA into RNA tumor viruses. Prog Nucleic Acid Res Mol Biol, 1977. 20: p. 131-60.

79. Dahlberg, J.E., et al., Transcription of DNA from the 70S RNA of Rous sarcoma virus. I. Identification of a specific 4S RNA which serves as primer. J Virol, 1974. 13(5): p. 1126-33.

80. Waters, L.C., Lysine tRNA is the predominant tRNA in murine mammary tumor virus. Biochem Biophys Res Commun, 1978. 81(3): p. 822-7.

81. Levin, J.G. and J.G. Seidman, Selective packaging of host tRNA's by murine leukemia virus particles does not require genomic RNA. J Virol, 1979. 29(1): $\mathrm{p}$. 328-35.

82. Cen, S., et al., Retrovirus-specific packaging of aminoacyl-tRNA synthetases with cognate primer tRNAs. J Virol, 2002. 76(24): p. 13111-5.

83. Guo, F., et al., Specific inhibition of the synthesis of human lysyl-tRNA synthetase results in decreases in $t R N A(L y s)$ incorporation, $t R N A(3)$ (Lys) annealing to viral $R N A$, and viral infectivity in human immunodeficiency virus type 1. J Virol, 2003. 77(18): p. 9817-22.

84. Barat, C., S.F. Le Grice, and J.L. Darlix, Interaction of HIV-1 reverse transcriptase with a synthetic form of its replication primer, $t R N A(L y s, 3)$. Nucleic Acids Res, 1991. 19(4): p. 751-7.

85. Barat, C., et al., HIV-1 reverse transcriptase specifically interacts with the anticodon domain of its cognate primer tRNA. Embo J, 1989. 8(11): p. 3279-85.

86. Sarih-Cottin, L., et al., Preferential interaction of human immunodeficiency virus reverse transcriptase with two regions of primer $t R N A(L y s)$ as evidenced by footprinting studies and inhibition with synthetic oligoribonucleotides. J Mol Biol, 1992. 226(1): p. 1-6.

87. Wohrl, B.M., et al., Nuclease footprinting of human immunodeficiency virus reverse transcriptase/tRNA(Lys-3) complexes. J Biol Chem, 1993. 268(18): p. 13617-24.

88. Cen, S., et al., Incorporation of lysyl-tRNA synthetase into human immunodeficiency virus type 1. J Virol, 2001. 75(11): p. 5043-8.

89. Sawyer, R.C. and H. Hanafusa, Comparison of the small RNAs of polymerasedeficient and polymerase-positive Rous sarcoma virus and another species of avian retrovirus. J Virol, 1979. 29(3): p. 863-71.

90. Mak, J., et al., Role of Pr160gag-pol in mediating the selective incorporation of tRNA(Lys) into human immunodeficiency virus type 1 particles. J Virol, 1994. 68(4): p. 2065-72. 
91. Levin, J.G. and J.G. Seidman, Effect of polymerase mutations on packaging of primer tRNAPro during murine leukemia virus assembly. J Virol, 1981. 38(1): p. 403-8.

92. Marquet, R., et al., tRNAs as primer of reverse transcriptases. Biochimie, 1995. 77(1-2): p. 113-24.

93. Rhim, H., J. Park, and C.D. Morrow, Deletions in the tRNA(Lys) primer-binding site of human immunodeficiency virus type 1 identify essential regions for reverse transcription. J Virol, 1991. 65(9): p. 4555-64.

94. Aiyar, A., et al., Interaction between retroviral U5 RNA and the T psi C loop of the $t R N A(T r p)$ primer is required for efficient initiation of reverse transcription. $\mathrm{J}$ Virol, 1992. 66(4): p. 2464-72.

95. Beerens, N., F. Groot, and B. Berkhout, Initiation of HIV-1 reverse transcription is regulated by a primer activation signal. J Biol Chem, 2001. 276(33): p. 3124756.

96. Liang, C., et al., The importance of the A-rich loop in human immunodeficiency virus type 1 reverse transcription and infectivity. J Virol, 1997. 71(8): p. 5750-7.

97. Beerens, N. and B. Berkhout, Switching the in vitro tRNA usage of HIV-1 by simultaneous adaptation of the PBS and PAS. Rna, 2002. 8(3): p. 357-69.

98. Ogilvie, A., U. Huschka, and W. Kersten, Control of protein synthesis in mammalian cells by aminoacylation of transfer ribonucleic acid. Biochim Biophys Acta, 1979. 565(2): p. 293-304.

99. Javanbakht, H., et al., Correlation between tRNALys3 aminoacylation and its incorporation into HIV-1. J Biol Chem, 2002. 277(20): p. 17389-96.

100. Sarih, L., et al., Avian myeloblastosis reverse transcriptase deacylates tryptophanyl-tRNA. Nucleic Acids Res, 1982. 10(22): p. 7387-93.

101. Haseltine, W.A., et al., Interaction of tryptophan $t R N A$ and avian myeloblastosis virus reverse transcriptase: further characterization of the binding reaction. Biochemistry, 1977. 16(16): p. 3625-32.

102. Hu, J.C. and J.E. Dahlberg, Structural features required for the binding of tRNATrp to avian myeloblastosis virus reverse transcriptase. Nucleic Acids Res, 1983. 11(14): p. 4823-33.

103. Rigourd, M., et al., Effects of tRNA 3 Lys aminoacylation on the initiation of HIV1 reverse transcription. Biochimie, 2003. 85(5): p. 521-5.

104. Sambrook, J.F., E F.; Maniatis, T. , Molecular cloning: a laboratory manual. 2nd ed., ed. C.S.H.L. Press. 1989, Cold Springs Harbor, N.Y: Cold Springs Harbor Laboratory Press p.7.5-7.6

105. Sanishvili, R., et al., Integrating structure, bioinformatics, and enzymology to discover function: BioH, a new carboxylesterase from Escherichia coli. J Biol Chem, 2003. 278(28): p. 26039-45.

106. De Pereda, J.M., et al., Crystal structure of a human peptidyl-tRNA hydrolase reveals a new fold and suggests basis for a bifunctional activity. J Biol Chem, 2004. 279(9): p. 8111-5.

107. Sarafianos, S.G., et al., Crystal structure of HIV-1 reverse transcriptase in complex with a polypurine tract RNA:DNA. Embo J, 2001. 20(6): p. 1449-61. 
108. Moreland, J.L., et al., The Molecular Biology Toolkit (MBT): a modular platform for developing molecular visualization applications. BMC Bioinformatics, 2005. 6: p. 21.

109. Harald Sobeck, R.M., Manfred Schimidt, Bruno Frey and Markus Pajastsch, Method for producing an active heterodimeric AMV-RT in prokaryotic cells, in http://www.patentstorm.us/patents/6902920-fulltext.html. Accessed July 27, 2007. U.S. Patent, Editor. 2005, Roche Diagnostics Operations, INC: US.

110. Baudin, F., et al., Functional sites in the 5' region of human immunodeficiency virus type 1 RNA form defined structural domains. J Mol Biol, 1993. 229(2): p. 382-97.

111. Beerens, N., B. Klaver, and B. Berkhout, A structured RNA motif is involved in correct placement of the $t R N A(3)$ (Lys) primer onto the human immunodeficiency virus genome. J Virol, 2000. 74(5): p. 2227-38.

112. Darlix, J.L., et al., First glimpses at structure-function relationships of the nucleocapsid protein of retroviruses. J Mol Biol, 1995. 254(4): p. 523-37.

113. Williams, M.C., et al., Mechanism for nucleic acid chaperone activity of HIV-1 nucleocapsid protein revealed by single molecule stretching. Proc Natl Acad Sci U S A, 2001. 98(11): p. 6121-6.

114. Iwatani, Y., et al., Efficient initiation of $H I V-1$ reverse transcription in vitro. Requirement for RNA sequences downstream of the primer binding site abrogated by nucleocapsid protein-dependent primer-template interactions. J Biol Chem, 2003. 278(16): p. 14185-95.

115. Bourne, J.L.M.a.P.E., The Molecular Biology Toolkit (MBT) : a modular platform for devloping molecular visualization applications BMC Bioinformatics, 2005. 6(21).

116. Schulman, L.H., Recognition of $t R N A$ s by aminoacyl-tRNA synthetases. Prog Nucleic Acid Res Mol Biol, 1991. 41: p. 23-87.

117. Arts, E.J., et al., Initiation of (-) strand DNA synthesis from $t R N A(3 L y s)$ on lentiviral RNAs: implications of specific HIV-1 RNA-tRNA(3Lys) interactions inhibiting primer utilization by retroviral reverse transcriptases. Proc Natl Acad Sci U S A, 1996. 93(19): p. 10063-8.

118. Chou, T.F. and C.R. Wagner, Lysyl-tRNA synthetase-generated lysyl-adenylate is a substrate for histidine triad nucleotide binding proteins. J Biol Chem, 2007. 282(7): p. 4719-27.

119. Menninger, J.R., Peptidyl transfer RNA dissociates during protein synthesis from ribosomes of Escherichia coli. J Biol Chem, 1976. 251(11): p. 3392-8.

120. Brule, F., et al., Structural and functional properties of the HIV-1 RNAtRNA(Lys) 3 primer complex annealed by the nucleocapsid protein: comparison with the heat-annealed complex. Rna, 2002. 8(1): p. 8-15.

121. Isel, C., et al., Initiation of reverse transcription of HIV-1: secondary structure of the HIV-1 RNA/tRNA(3Lys) (template/primer). J Mol Biol, 1995. 247(2): p. 23650.

122. Isel, C., et al., Structural basis for the specificity of the initiation of HIV-1 reverse transcription. Embo J, 1999. 18(4): p. 1038-48. 
123. Halwani, R., et al., Cellular distribution of Lysyl-tRNA synthetase and its interaction with Gag during human immunodeficiency virus type 1 assembly. $\mathrm{J}$ Virol, 2004. 78(14): p. 7553-64.

124. Kaminska, M., et al., Viral hijacking of mitochondrial lysyl-tRNA synthetase. $\mathrm{J}$ Virol, 2007. 81(1): p. 68-73.

125. Zavorotinskaya, T. and L.M. Albritton, Suppression of a fusion defect by second site mutations in the ecotropic murine leukemia virus surface protein. J Virol, 1999. 73(6): p. 5034-42.

126. Katz, R.A., M. Kotler, and A.M. Skalka, cis-acting intron mutations that affect the efficiency of avian retroviral RNA splicing: implication for mechanisms of control. J Virol, 1988. 62(8): p. 2686-95.

127. Hildinger, M., et al., Design of 5' untranslated sequences in retroviral vectors developed for medical use. J Virol, 1999. 73(5): p. 4083-9.

128. Luo, M.J. and R. Reed, Splicing is required for rapid and efficient mRNA export in metazoans. Proc Natl Acad Sci U S A, 1999. 96(26): p. 14937-42.

129. Strasser, K. and E. Hurt, Splicing factor Sub2p is required for nuclear $m R N A$ export through its interaction with Yralp. Nature, 2001. 413(6856): p. 648-52.

130. Wiegand, H.L., S. Lu, and B.R. Cullen, Exon junction complexes mediate the enhancing effect of splicing on mRNA expression. Proc Natl Acad Sci U S A, 2003. 100(20): p. 11327-32.

131. Dimaano, C. and K.S. Ullman, Nucleocytoplasmic transport: integrating $m R N A$ production and turnover with export through the nuclear pore. Mol Cell Biol, 2004. 24(8): p. 3069-76.

132. Reed, R. and E. Hurt, A conserved $m R N A$ export machinery coupled to pre- $m R N A$ splicing. Cell, 2002. 108(4): p. 523-31.

133. Katz, R.A. and A.M. Skalka, Control of retroviral RNA splicing through maintenance of suboptimal processing signals. Mol Cell Biol, 1990. 10(2): p. 696-704.

134. Zavorotinskaya, T. and L.M. Albritton, Two point mutations increase targeted transduction and stabilize vector association of a modified retroviral envelope protein. Mol Ther, 2001. 3(3): p. 323-8.

135. Miller, A.D., et al., Use of retroviral vectors for gene transfer and expression. Methods Enzymol, 1993. 217: p. 581-99.

136. Mulligan, R.C., The basic science of gene therapy. Science, 1993. 260(5110): p. 926-32.

137. Delenda, C., Lentiviral vectors: optimization of packaging, transduction and gene expression. J Gene Med, 2004. 6 Suppl 1: p. S125-38.

138. Logan, A.C., et al., Factors influencing the titer and infectivity of lentiviral vectors. Hum Gene Ther, 2004. 15(10): p. 976-88.

139. Zufferey, R., et al., Woodchuck hepatitis virus posttranscriptional regulatory element enhances expression of transgenes delivered by retroviral vectors. $\mathrm{J}$ Virol, 1999. 73(4): p. 2886-92.

140. Donello, J.E., J.E. Loeb, and T.J. Hope, Woodchuck hepatitis virus contains a tripartite posttranscriptional regulatory element. J Virol, 1998. 72(6): p. 5085-92. 
141. Sinn, P.L., S.L. Sauter, and P.B. McCray, Jr., Gene therapy progress and prospects: development of improved lentiviral and retroviral vectors--design, biosafety, and production. Gene Ther, 2005. 12(14): p. 1089-98.

142. Marchand, V., et al., A Janus splicing regulatory element modulates HIV-1 tat and rev $m R N A$ production by coordination of hnRNP Al cooperative binding. $\mathrm{J}$ Mol Biol, 2002. 323(4): p. 629-52.

143. Cook, C.R. and M.T. McNally, Interaction between the negative regulator of splicing element and a 3' splice site: requirement for U1 small nuclear ribonucleoprotein and the $3^{\prime}$ splice site branch point/pyrimidine tract. J Virol, 1999. 73(3): p. 2394-400.

144. Adams, M.D., D.Z. Rudner, and D.C. Rio, Biochemistry and regulation of pre$m R N A$ splicing. Curr Opin Cell Biol, 1996. 8(3): p. 331-9.

145. Jurica, M.S. and M.J. Moore, Pre-mRNA splicing: awash in a sea of proteins. Mol Cell, 2003. 12(1): p. 5-14.

146. Lamond, A.I., The spliceosome. Bioessays, 1993. 15(9): p. 595-603.

147. Nilsen, T.W., The spliceosome: the most complex macromolecular machine in the cell? Bioessays, 2003. 25(12): p. 1147-9.

148. Domsic, J.K., et al., Human immunodeficiency virus type 1 hnRNP A/B-dependent exonic splicing silencer ESSV antagonizes binding of U2AF65 to viral polypyrimidine tracts. Mol Cell Biol, 2003. 23(23): p. 8762-72.

149. Purcell, D.F. and M.A. Martin, Alternative splicing of human immunodeficiency virus type $1 \mathrm{mRNA}$ modulates viral protein expression, replication, and infectivity. J Virol, 1993. 67(11): p. 6365-78.

150. Lazo, P.A., V. Prasad, and P.N. Tsichlis, Splice acceptor site for the env message of Moloney murine leukemia virus. J Virol, 1987. 61(6): p. 2038-41.

151. Kraunus, J., et al., Self-inactivating retroviral vectors with improved RNA processing. Gene Ther, 2004. 11(21): p. 1568-78.

152. Kraunus, J., et al., Murine leukemia virus regulates alternative splicing through sequences upstream of the 5' splice site. J Biol Chem, 2006. 281(49): p. 37381-90.

153. Cochrane, A.W., M.T. McNally, and A.J. Mouland, The retrovirus RNA trafficking granule: from birth to maturity. Retrovirology, 2006. 3: p. 18.

154. Schimmel, P., Aminoacyl tRNA synthetases: general scheme of structure-function relationships in the polypeptides and recognition of transfer RNAs. Annu Rev Biochem, 1987. 56: p. 125-58.

155. Soll, D., The accuracy of aminoacylation--ensuring the fidelity of the genetic code. Experientia, 1990. 46(11-12): p. 1089-96.

156. Mirande, M., D. Le Corre, and J.P. Waller, A complex from cultured Chinese hamster ovary cells containing nine aminoacyl-tRNA synthetases. Thermolabile leucyl-tRNA synthetase from the tsH1 mutant cell line is an integral component of this complex. Eur J Biochem, 1985. 147(2): p. 281-9.

157. Schimmel, P.R. and D. Soll, Aminoacyl-tRNA synthetases: general features and recognition of transfer RNAs. Annu Rev Biochem, 1979. 48: p. 601-48.

158. Chow, C.M. and U.L. Rajbhandary, Regulation of the nuclear genes encoding the cytoplasmic and mitochondrial leucyl-tRNA synthetases of Neurospora crassa. Mol Cell Biol, 1989. 9(11): p. 4645-52. 
159. Tolkunova, E., et al., The human lysyl-tRNA synthetase gene encodes both the cytoplasmic and mitochondrial enzymes by means of an unusual alternative splicing of the primary transcript. J Biol Chem, 2000. 275(45): p. 35063-9.

160. Shackleford, G.M. and H.E. Varmus, Construction of a clonable, infectious, and tumorigenic mouse mammary tumor virus provirus and a derivative genetic vector. Proc Natl Acad Sci U S A, 1988. 85(24): p. 9655-9.

161. Mirande, M., B. Cirakoglu, and J.P. Waller, Macromolecular complexes from sheep and rabbit containing seven aminoacyl-tRNA synthetases. III. Assignment of aminoacyl-tRNA synthetase activities to the polypeptide components of the complexes. J Biol Chem, 1982. 257(18): p. 11056-63.

162. Purdy, A., et al., Unique resistance of I/LnJ mice to a retrovirus is due to sustained interferon gamma-dependent production of virus-neutralizing antibodies. J Exp Med, 2003. 197(2): p. 233-43.

163. Ross, S.R., et al., Mouse transferrin receptor 1 is the cell entry receptor for mouse mammary tumor virus. Proc Natl Acad Sci U S A, 2002. 99(19): p. 12386-90. 


\title{
Appendix
}

\section{Introduction}

\begin{abstract}
Aminoacyl-tRNA synthetases
There are 20 different Aminoacyl-tRNA synthetases (aaRS). Each aaRS is capable of charging all of its cognate tRNAs and can discriminate from all other tRNAs with great efficiency [116]. In an ATP dependent reaction called aminoacylation, the synthetase links an amino acid to the free 2' or 3' hydroxyl group of the adenosine located at the 3' terminus of the tRNA via an ester bond $[1,154,155]$. aaRSs fall into two main classes based on structural motifs. These structural motifs define how they interact with and charge their cognate tRNA; class I charges the 2'-OH while class II charges the 3'-OH. Located in the cytoplasm of higher eukaryotic cells is a multienzyme complex containing glutamyl-, prolyl-, isoleucyl-, leucyl-, methionyl-, glutaminyl-, lysyl-, arginyl-, and aspartyl-tRNA synthetases called the MARS complex (Multi-Aminoacyl-tRNA Synthetase) [156]. Interestingly, there are exactly ten class I and ten class II aaRS and the MARS complex is a hodge-podge of both classes.
\end{abstract}

\section{Two forms of LysRS}

In eukaryotic cells the majority of the twenty aaRSs are found in two forms; either a mitochondrial or cytoplasmic form. Despite mitochondria having their own genome the mitochondrial aaRSs are nuclear encoded proteins, synthesized in the cytosol then imported into the mitochondria [157]. The two forms of the protein result from separate genes or from an alternative splice of the same gene [158]. LysRS, a class II enzyme in eukaryotic cells is found both in the mitochondria and in the cytoplasm where it is associated with the MARS complex. The two forms which share 576 identical amino acid residues arise from an alternative splicing event and differ only at their amino terminus $[124,159]$. As discussed in chapter three HIV-1 specifically recruits its primer,

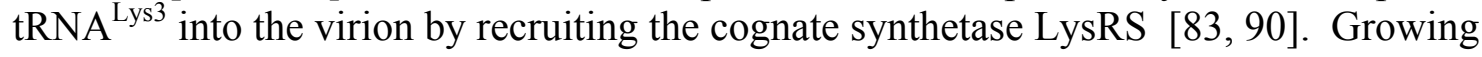
evidence indicates that it is the mitochondrial form of the aaRS that is recruited into the HIV-1 virion. The first clue was that other members of the MARS complex could not be detected in HIV-1 virions [88]. The previous work done to identify LysRS in HIV-1 was performed using polyclonal antibodies that could not differentiate between the two forms [82]. Recently Marc Mirande and co-workers generated antibodies to synthetic peptides matching residues 1-19 of human cytoplasmic LysRS and residues 25-42 of human mitochondrial LysRS [124]. Using these antibodies they showed that the LysRS in HIV1 reacted with the mitochondrial specific antibody and not the cytoplasmic [124]. MMTV, like HIV-1, uses tRNA ${ }^{\text {Lys3 }}$ as its primer for replication and specifically recruits tRNA $^{\text {Lys }}$ isoacceptors into the virion during the assembly process [70]. However, the mechanism for this specific recruitment is currently unknown. The goal of these 
experiments was to determine if LysRS is packaged by MMTV and if so, determine which form is of LysRS is present.

\section{Materials and methods}

\section{Previously described protocols}

The methods used to propagate cells and prepare cell lysates and crude purification of murine synthetase are described in chapters two and three.

\section{MMTV production and western blot analysis}

The pHP plasmid encoding an infectious molecular clone of MMTV was introduced into NIH 3 T3 cells by calcium phosphate transfection [160]. Cells were then grown in DMEM containing $8 \%$ fetal bovine serum (FBS) and G418 $(250 \mu \mathrm{g} / \mathrm{ml})$ to select for cells containing the plasmid. Virus containing supernatant was collected $48 \mathrm{hrs}$ after cells reached $100 \%$ confluence and filtered through a $0.45 \mu \mathrm{m}$ filter. The filtrate was subjected to ultracentrifugation using a Beckman SW40 rotor at 30,000 rpm for 90 min at $4^{\circ} \mathrm{C}$. Virus pellets were resuspended in $40 \mu \mathrm{l}$ of ice cold PBS. Ten $\mu 1$ of virus pellet was mixed 1:1 with $2 x$ loading buffer [104], boiled for ten min, chilled on ice, then electrophoresed through an 10-20\% SDS polyacrylamide gel and transferred to a nitrocelluose membrane (Protran, Schleicher and Schuell). The membrane was cut in half at the $37 \mathrm{kDa}$ molecular mass marker, blocked for $2 \mathrm{hrs}$ in $6 \%$ dry milk, $2 \%$ Tween 20 , then the top half was probed for LysRS using rabbit anti-KRS (1:1000) [161], and the bottom half was probed for the MMTV capsid protein ( $\mathrm{p} 27)$ by incubation with undiluted mouse monoclonal anti p-27 antibodies [162] for two hrs. The primary antibodies were detected by incubation with goat anti-mouse antibody conjugated to horseradish peroxidase $(1: 10,000)$ for 45 min followed by incubation with SuperSignal West Pico Chemiluminescent Substrate (Pierce).

After exposure membranes were stripped by incubation with Restore Western Blot Stripping Buffer (Pierce) according to the manufacturer's protocol, with two exceptions. First, the incubation temperature was increased to $37^{\circ} \mathrm{C}$. Second, the time of incubation was increased to $25 \mathrm{~min}$ and including an additional $10 \mathrm{~min}$ at room temperature with constant rocking. The membrane was cut in to pieces at the $37 \mathrm{kDa}$ mark. Each half was incubated with either rabbit anti-cytoplasmic KRS (anti-cKRS) or anti-mitochondrial KRS (anti-mKRS) antibodies (1:10,000) (gift from Marc Mirande) overnight in blocking solution. The primary antibodies were detected by incubation with goat anti-rabbit antibody conjugated to horseradish peroxidase $(1: 5,000)$ for $45 \mathrm{~min}$ followed by incubation with SuperSignal West Pico Chemiluminescent Substrate (Pierce). 


\section{Results}

MMTV was produced by transfection of the pHP plasmid into NIH 3 T3 cells [160]. Virus was pelleted by ultracentrifugation of the cell culture supernatant, the viral proteins were separated by SDS-PAGE, transferred to a nitrocellulose membrane, and subjected to western blot analysis. The top half of the membrane was probed with a polyclonal antibody against LysRS and the bottom half was probed with a monoclonal antibody for p27 the capsid protein of MMTV (Figure A-1). Three main observations were made in this analysis. First, the MMTV samples contained LysRS but it was slightly smaller in size when compared to the positive controls (NIH 3T3 cell lysate and crude murine synthetase preparation). Second, unexpectedly the supernatant of NIH 3T3 cells that were not transfected with pHP plasmid contained LysRS and contained some form of anti-p27 reactive protein as well. Unfortunately, without a true negative control it cannot be concluded that the LysRS present was incorporated in MMTV. Lastly, upon a longer exposure of the western blot, p27 was present in all of the samples.

Next, the top section of the membrane was stripped and cut in half. Each half contained identical samples. The left side was probed with anti-mLysRS (mitochondrial LysRS) and the right side was probed with anti-cKRS (cytoplasmic LysRS) (Figure A-2). Anti-mLysRS did not show specificity and reacted with several other proteins, thus it cannot be determined if mLysRS is actually present in any of the samples. cLysRS was detected in the MMTV sample however it was also detected in what should have been the negative control. Since this antibody was generated to a synthetic peptide matching the human form of LysRS it may be not as sensitive against mouse cLysRS. cLysRS can easily be detected in human 293 cell lysates but not in mouse NIH 3T3 cell lysates (data not shown). Therefore, it is interesting that the amount of cLysRS present in the supernatant and synthetase preparation is detectable.

\section{Discussion}

The unexpected presence of MMTV capsid in all of the samples was disappointing and precluded determining if LysRS is truly present within MMTV virions or merely in the NIH 3T3 supernatant. However this work does invoke some interesting discussion.

Why do the negative control NIH 3T3 cells contain p27? One explanation is contamination with MMTV. The pHP plasmid produces fully infectious MMTV capable of infecting and replicating in other cells. Both cell lines were handled in the same area of the lab and therefore contamination would be possible. However, p27 is also detected in the crude murine synthetase preparation. As described in the materials and methods of chapter 3 this preparation is made by column purification of the liver homogenate from B6 mice. This suggests that the presence of p27 in both samples is the result of active endogenous MMTV. To eliminate this problem the experiment could be carried out in 

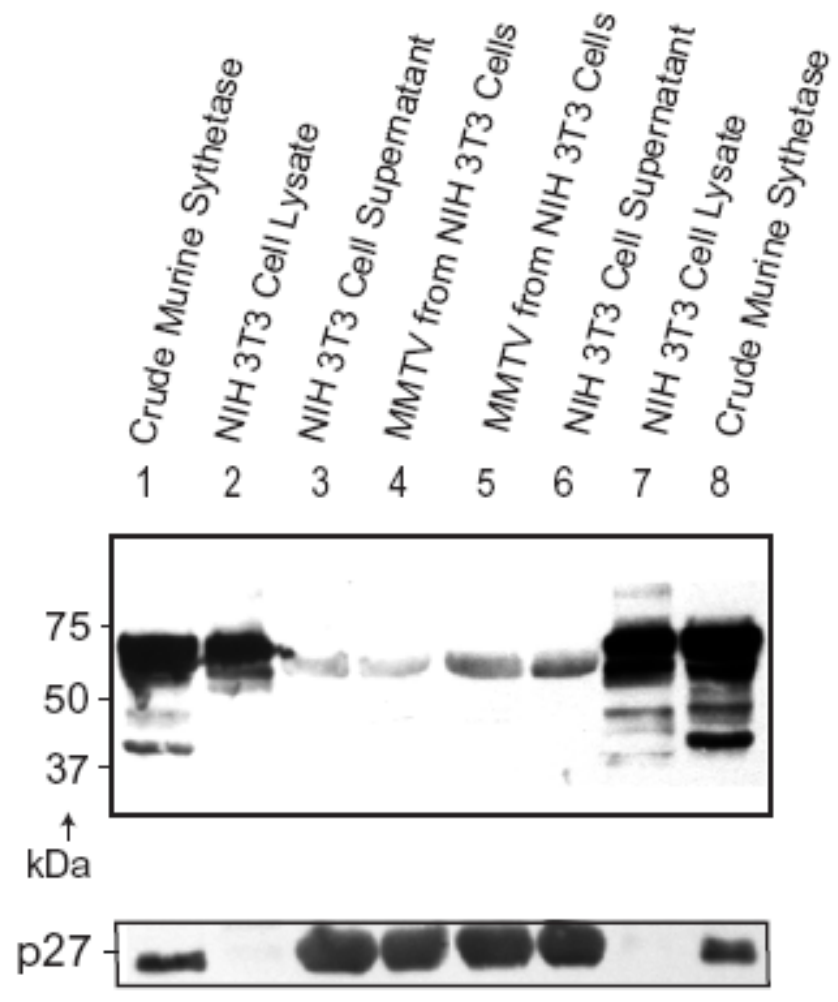

Figure A-1. Detection of lysine synthetase in MMTV. Samples were separated on a 10-20\% SDS-PAGE gradient gel. The proteins were transferred to nitrocellulose and the membrane was cut in half just below the $37 \mathrm{kDa}$ molecular mass maker. The top portion of the membrane was incubated with polyclonal anti-KRS antibody to detect lysine synthetase, while the bottom half was incubated with monoclonal anti-p27 antibody to detect MMTV capsid protein. 


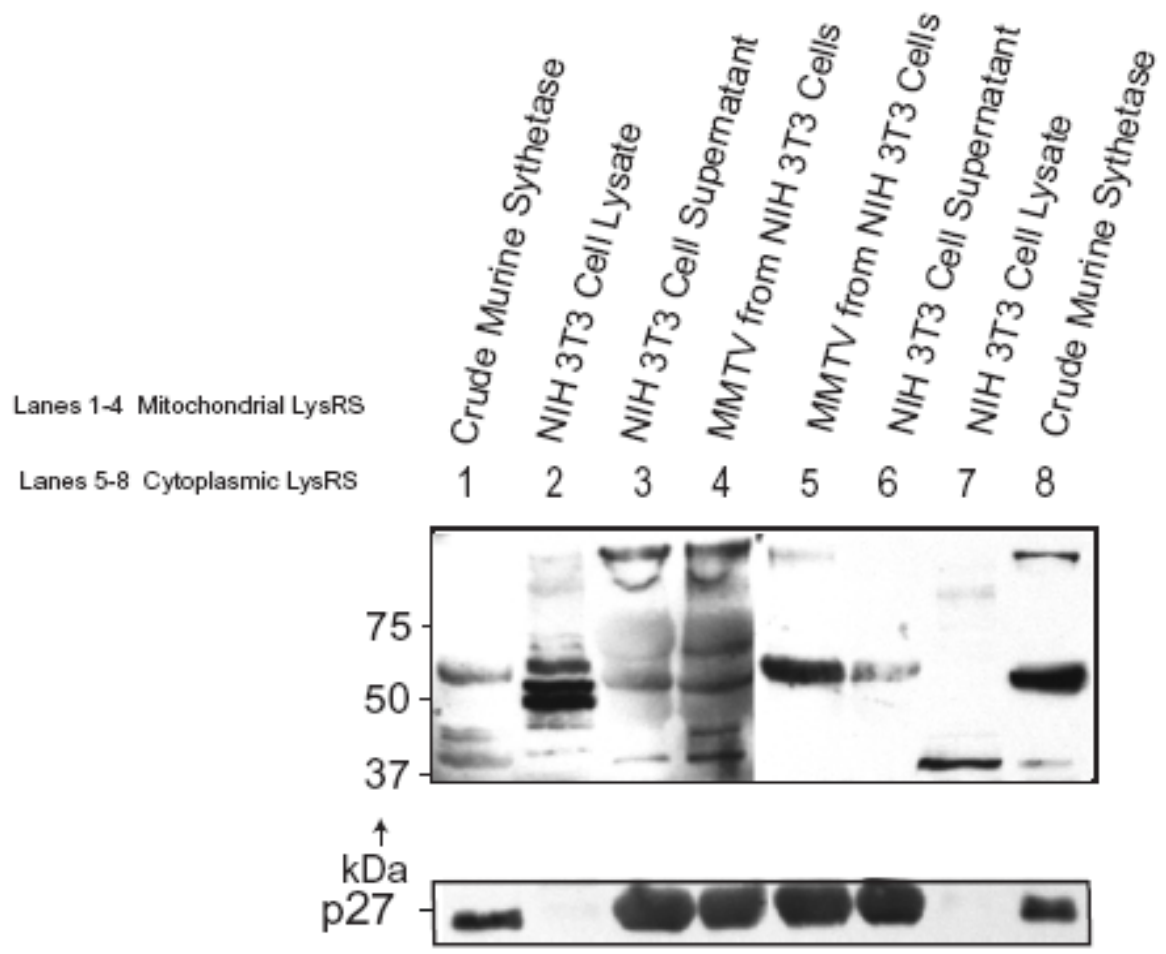

Figure A-2. Detection of the cytoplasmic and mitochondrial forms of lysyl synthetase in MMTV. The top half of the membrane from Figure A-1 was cut in half vertically then stripped and re-probed. Lanes 1-4 were incubated with anti- cKRS and lanes 5-8 were incubated with anti-mKRS. 
human 293 cells transfected with mouse transferrin receptor 1, the MMTV receptor [163]. It should be noted though that it is possible that MMTV could recruit mouse LysRS but not human.

What could the small size difference observed between LysRS detected in the supernatant samples versus that detected in the NIH 3T3 lysate and synthetase preparation (Figure A-1) be? Assuming MMTV recruits the LysRS one explanation that could account for this is cleavage by the viral protease. LysRS may contain a sequence or motif that is recognized by the viral protease. Figure A-2 shows that the cytoplasmic form of LysRS is present and this form is normally associated with the MARS complex. Cleavage of LysRS could free it from the MARS complex and allow its specific recruitment into the virion. This hypothesis could also explain the difference in the relative abundance of LysRS seen in each sample. Using the polyclonal LysRS antibody, a much greater amount of LysRS protein was detected in the cell lysate than in the supernatant samples (Figure A-1). However, when the same samples were probed with cKRS the inverse was true (Figure A-2). The truncated version of LysRS could be missing key epitopes for the polyclonal antibody resulting in underestimation of the amount of protein observed in the supernatant samples. 


\section{Vita}

Timothy Sullivan was born in Galax, Virginia, on August 27, 1981. In 2000 he graduated from Central High School and attended the University of South Florida. In 2004 he received a degree of Bachelor of Science, majoring in biology and was accepted into the University of Tennessee College of Graduate Health Sciences Integrated Program in Biomedical Sciences the same year. Timothy defended his thesis and received a Master of Science degree in December 2008. 